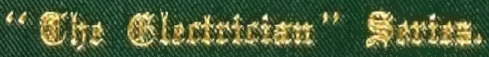

BLECTRIOITY IN AGRIOULTURE AND

HORTICULTURE.

BV PROA: S. LEMSTRÖM. 


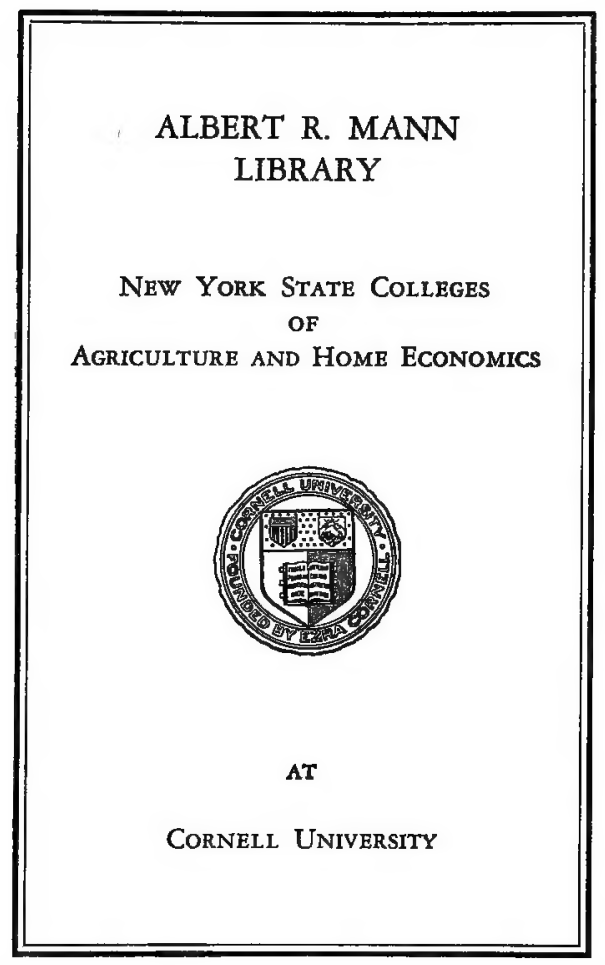




\section{Cornell University Library}

\section{SB 139.L56}

Electricity in agriculture and horticult Electricity in agriculture and hor

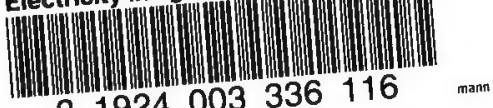

31924003336116 


\section{Cornell University Library}

The original of this book is in the Cornell University Library.

There are no known copyright restrictions in the United States on the use of the text.

http://www.archive.org/details/cu31924003336116 






\title{
ELECTRICITY IN AGRICULTURE
}

\author{
AND \\ HORTICULTURE.
}

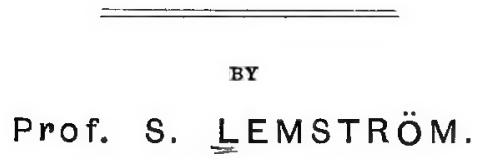

WITH ILLUSTRATIONS.

COPYRIGHT.

ENGLAND:

“THE ELEC CRICIAN" PRINTING \& PUBLISHING COMPANY, LTD., SAlisbury Court, Flemt StreEt, London.

United States: The D. Van Nostrand Co., 23, Murray Street, New York. Japan: Z. P. MARUYA \& Co., 14, Nihonbashi Tori Sancbome, Tokyo. 


\section{$S B$ \\ 139 \\ $\angle 56$ \\ 308959}

LONDON :

PRINTED BT GEORGE TUCEER, SALISBURY COURT, FLEET STREIT. 


\section{PREFACE.}

"THE Electrician" Printing and Publishing Company

1 has had the kindness to undertake the publishing of "Electricity in Agriculture and Horticulture," which, I venture to hope, will be received favourably by the English-speaking public who read it. It contains the results of a long study and numerous experiments, which had their origin in the Polar regions, were continued in more southern latitudes, and have led not only to an increase of the harvest of every kind of plant which has come under treatment, but also to a favourable change of their chemical compounds, e.g., an increase of the digestible nitrogenous matter in seeds, of the sugar in sugar-beets, proved by chemical analyses, and of the sweetness in berries, \&c. The earlier ripening of some berries and fruits is also a proved result. There have been many difficulties to overcome, including the English language; but here the Publisher, Mr. Geo. Tucker, has kindly given me assistance by reading the manuscript for the press, for which I am very thankful. The like gratitude I would express to $\mathrm{Mr}$. R. B. Greig, for much good counsel and many corrections.

A great difficulty has been to estimate the cost of the apparatus and the quantities of some of the articles necessary for the electrical installation to enable me to apply the electric air current to growing crops, especially the cost of wood-posts, of labour, of inspection, \&c., which are of 
iv.

varying value in different countries; but as these quantities form in the total cost only a small part, this does not affect the calculations in a serious way.

THE AUTHOR.

\section{PUBLISHER'S NOTE.}

The Publisher is desirous of placing Prof. Lemström's interesting work before the public, with the view of hastening the time when the utilisation of the electric current in agricultural and horticultural work will become a recognised development of the science and industry of up-to date cultivation of the land for market crops. That this development will be advanced by Prof. Lemström's valuable experiments there can, the Publisher considers, be no question.

As the greater part of the Author's scientific determinations regarding temperatures are made in Centigrade degrees, and for other measurements in the metric system, the Publisher, in accord with the Author's wishes; and desirous of facilitating the reading of this book, has printed on the last pages tables containing a Figure showing the relations between the different thermometers, and a Table showing the metric measures (with their signs) in English measures. The Table is attached in such a manner that it can be readily consulted by the reader during his reading of the book. 


\section{ELECTRICITY IN AGRICULTURE AND HORTICULTURE.}

By Prof. S. LEMSTRÖM.

INTRODUCTORY.

\$1. It is well known that the question which is the subject of this book has been a favourite field of investigation for a century past. As the subject is connected with no less than three sciences-viz., physics, botany and agricultural physics-it is in itself not particularly attractive. The causes which induced me to begin an investigation of this matter were manifold, and I venture to hope that a short exposition of them will not be without interest.

During several voyages in the Polar regions (I868 to Spitzbergen and the north of Norway, and I87 I, I882, I884 to Finnish Lapland), I had occasion to observe with my own eyes a peculiarity in the vegetable kingdom which also has attracted the attention of other explorers. When the plants in these regions have resisted the frequently destructive night frosts they show a degree of development which greatly surpasses that of plants in more southern regions, where the climatic conditions are more advantageous. This rich development appears principally in the fresh and clear colours of the flowers, in their strong perfume, in the rapid development of the leaves on the trees, and their scent, but particularly in the rich harvest which different seeds-such as rye, oats and barley-will produce when, as before stated, they are not destroyed by the frosts. From a bushel of rye sown they will often produce 
40 bushels, and from barley 20 bushels, and so forth. It is the same with grass. These results are attained although the people cultivate their soil very imperfectly, using only ploughs and harrows of wood.

Vegetables require, for a rich development, a fertile soil and a sufficient quantity of heat, light and humidity; but one of these principal conditions, that of heat, is to be found only in a slight degree in the Polar regions. To be convinced of this it is only necessary to glance at a map and follow the yearly isothermes, and especially the summer isothermes. The isotherm corresponding to a mean temperature of $-7^{\circ} \mathrm{C}$. to $-8^{\circ} \mathrm{C}$. crosses Spitzbergen, and that of $0^{\circ} \mathrm{C}$. goes through the north of Finnish Lapland. The mean temperature for the month of July is there $10^{\circ} \mathrm{C}$., and at Spitzbergen $5^{\circ} \mathrm{C}$.*

The cause of the astonishing development of vegetation under such conditions has hitherto been held to lie in the long day, which lasts from two to three months in these regions during their short summer. It is further sometimes supposed that this circumstance will provide the crops with more light and heat, the principal factors of vegetation. This is, however, not true, for calculation shows that the quantity, notwithstanding this long day, is less than it is, for instance, in $60 \mathrm{deg}$. of latitude. In consequence of the low height of the sun over the horizon, the rays meet the earth in such an oblique direction that their illuminating and heating power is greatly lessened, and this power is also lessened by the great absorption in the atmosphere. Since the quantities of light and heat received are relatively smaller than in more southern regions, the cause of the rich development of the vegetables cannot lie in the long day, and must be sought elsewhere.

For several reasons I was induced to search for the cause in electrical currents, the effect of which appears in the Polar light, and which are going from the atmosphere

\footnotetext{
* See Thermometer Table at end of book.
} 
to the earth or vice versa. The existence of these currents has been proved beyond all doubt through the experiments of the Finnish International Polar Expedition of I882-84.

§ 2. My reasons will be shown in the following order :-

(a) The physiology of plants gives a satisfactory explanation of the functions which most of their organs have to perform, and good reasons for their existence and their varying forms. This is, however, not the case with the needle-like shape of the leaves in fir trees, and the beard on the ears of most cereals. Since nothing exists without a purpose in all the infinite number of objects in Nature, then the needle-shaped leaves and the beard must have their determined ends. In fact, they are very well fitted to be the means through which the electricity goes from the atmosphere into the earth, or vice versa; that is to say, they act in the same fashion as metallic points. To pretend that they really serve as a means of transmitting electricity only because their form shows them capable of it would be to go too far. The presence of electricity in the air around them shows that they are, in fact, in a position to perform this function of transmission. Through experiments made during the above-named expedition, it was, at least by analogy, proved that they really serve that end, for it was not only shown that such electrical currents exist, but these currents were even measured by means of a specially constructed apparatus provided with metallic points.

We are thus induced to concede that an electrical current is going on through the needle-formed leaves of the pine, and the beard on the ears of cereals, not to particularise other plants. Though this is the case, it is not, however, shown that this electrical current exercises any influence whatever in the process of vegetation, or, in other words, has any definite effect on the plant life itself. That must be proved by experiments, and a description of them, with an exposition of their results, is the principal object of this volume. 
(b) In studying and observing sections of fir trees from different latitudes ( $60 \mathrm{deg}$. to $67 \mathrm{deg}$.) we have found a peculiarity in their yearly growth in thickness or year rings. They show in general a great difference in growth during different ages, but when due regard is paid to this fact, so that these differences may be eliminated, there remains another difference, which clearly must depend on the more or less advantageous nature of the atmospheric conditions of the year.

These latter variations, taking into account principally the thickness of the year rings, show a periodicity in full agreement with the periods of the sun spots and the aurorasnamely, a period of from Io to I I years. By a comparison between sections of large pine trees from the Polar regions of lat. $67 \mathrm{deg}$. and from more southern latitudes (about $60 \mathrm{deg}$.), it will be seen that this periodic variation is much more pronounced the more nearly we approach the Polar regions. The circumstance that this periodicity agrees with that of the auroras will conduce to an investigation of a possible connection betweeen the electrical current producing auroras and the year rings of these trees. As this peculiarity is more strongly developed in those regions of the earth where the electrical currents in question are of greater frequency and higher intensity, it indicates a connection between cause and effect which demands an investigation.*

(c) In a short Paper entitled, "On the Periodic Variations in some Meteorological Phenomena, their Connection with the Changes of the Solar Surface and their Probable Influence on the Vegetation," $†$ I have suggested, with a high degree of probability, that the harvest results in Finland show a periodicity which agrees with periodical variations in the sun spots and in the number of Polar lights. The greater the yearly number of sun spots and auroras, the more abundant is the harvest of seeds, roots, and grass. +

* This investigation is not yet published.

+ Finsk tidflkrift, 1878, in Swedish.

$\ddagger$ These harvest results also give evidence of the longer cycle period of about 58 years. 
In the Paper'in which I treated these phenomena I have found the explanation of this periodicity in the different state of the heat radiating from the sun, either without spots or supplied with them. In the former case the greater part of the heat rays are light, and of shorter wave length ; in the latter case the greater number are dark, and of greater wave length. The rays must pass through the atmosphere, and the darker heat rays will be absorbed during this passage rather than the lighter ones, and hence there will be more heat stored up in the atmosphere in the case when spots appear on the sun. This heat, generally contained in watery vapours, is transported through the air currents or winds into higher latitudes, and will there exercise its beneficent effect. Though I continue to regard this explanation as highly probable, I must introduce some modification, in order to ascribe a large influence to the Polar light, or rather its cause, the electric current from the atmosphere.

In consequence of this modification of my ideas, I must give it an important place in order to explain the periodicity of the harvests.

§ 3. Everyone who has given attention to the question of the causes of the electrical conditions of the atmosphere, knows that several theories on this matter have been brought forward. The most widely known suppositions are the following :-

(a) Unipolar induction, caused by the earth, as a magnet, rotating around its axis, produces a force component, which carries the positive electricity up in the atmosphere.

(b) Evaporation, which, according to the opinion of several physicists, produces electricity, the vapours being positive.

(c) Unipolar induction working together with the evaporation in making every particle, great or little, carried from the earth, positively electric. 
(d) The vegetation process on the earth; the friction of the small solid or liquid particles suspended in the atmosphere with the air, or between each other, the air's friction against the surface of the earth.

(e) The direct effect of the sun rays on the different layers of the atmosphere.

A discussion of these very different views cannot be entered upon here. I will, therefore, only say that the majority of the physicists, as it seems to me, are at present inclined to give a certain precedence to the opinion which searches for the cause of the atmospheric electricity in the evaporation which is going on all over the earth (perhaps in connection with the unipolar induction). For my part I have no doubt that this conception is right-viz., that the watery vapours act as transmitters of the atmospheric electricity and carry it to the upper layers of the air, because it seems to me that this theory is very well founded and in full harmony with other closely allied phenomena.

According to this opinion, therefore, the evaporation must be subjected to the same periodicity as the sun spots and also the electrical phenomena in the atmosphere. My opinion upon the manner in which Nature is fulfilling all this process is shortly as follows:-**

The quantities of electricity which are carried up by the water vapours to the higher parts of the atmosphere reach there an air stratum with a low pressure. As this rarefied air is provided with a relatively high conducting power, it will form with the surface of the earth a nearly spherical condenser. The rarefied air space-lies, principally in consequence of the lower temperature, nearer to the earth surface around the poles. Through this circumstance a greater quantity of electricity will accumulate in these regions, and there discharge in auroral displays or in a current from the atmosphere.

* See also "L'Aurore Boreale," by S. Lemström. Paris : Gauthier Villars, I886, p. $x_{3}$ and following. 
It has already been announced that the Finnish International Polar Expedition produced, by experiments made on mountain tops, auroral beams and light phenomena of the same nature as the auroras, and hence contributed to the confirmation of the opinion that auroras are caused by electric currents in the atmosphere. The E.M.F. (electromotive force), or the force which produces this current, was measured. It was absolutely very little, but always existing, though with varying intensity. It is only in exceptional cases that it will produce light phenomena-viz., when the conditions of the atmosphere are favourable and the current is of high intensity. The most important result here is the proof of the existence of such a current, which is always passing either downwards or upwards.

The experiments which have been carried out in Finnish Lapland, do not, strictly speaking, apply to other regions of the earth. Considering, however, that the laws of atmospheric electricity are nearly the same for all latitudes, the existence of such a current in the whole atmosphere seems not to be in doubt.

This electric atmospheric current has hitherto been very little investigated; it is only the atmospheric electricity which has been measured. The method has been to measure the potential in a point of the air (or the electrical tension of it). These results cannot be used for conclusions regarding electrical current from the atmosphere, and, in consequence, not for the laws it follows. These observations of atmospheric electricity can, however, contribute to some general propositions. When it has been found, for instance, that the air near the earth's surface is positive electrically (and seldom negative), and that the potential increases with the height, a general conclusion can be drawn that an electric current, an equalising of the difference of potential, is going on between the whole atmosphere and the earth.

As has been said above, this current produces luminous phenomena or Polar light only when in a state of high 
intensity. When these manifestations appear, principally in the Polar regions, it must be admitted that the current there possesses the highest intensity. The effect of it must, therefore, be more remarkable there than elsewhere.

Once convinced not only of the necessity for finding a cause for the above-mentioned phenomena of the vegetable kingdom in the Polar regions, but also for the existence of the electric current from the atmosphere, I was strongly induced to connect the two phenomena, and to regard the electric current as the cause of the peculiar phenomena in the vegetation, and all that has been said about these peculiarities will find its explanation in this:-(I) The rich harvests and their periodicity; (2) the periodical increase in the year rings of the fir woods; and (3) the needleformed leaves and the beards of the ears will, from this point of view, only be the means by which the electricity is conducted from the atmosphere to the earth. As the intensity of the current is highest in the Polar regions, its effect must also there be the greatest.

It must not be overlooked that electricity has hitherto been regarded as of little or no importance in the complex life of a plant, and a great effect from its application was not anticipated. From a further consideration of the subject it will, however, be clear that this conception must be changed, and that electricity must be numbered among the principal factors in plant life.

\section{THE EXPERIMENTS.}

$\S 4$. Since the year I 746, when the Scotchman, Maimbray, made his experiments on the influence of electricity on two myrtles, a great number of researches have been performed to examine this influence. The most striking feature of these experiments is that they are always contradictory. Hardly has one explorer obtained favourable results before another presents himself with directly oppo- 
site ones. A closer scrutiny shows that a favourable result is obtained every time the experiments are executed with artificial electricity-namely, with a machine. Exception shows only one case in which negative electricity was employed. The experiments have never been executed on a large scale, because the method was not convenient. In the case when the method was intended to spread the electricity over a larger field its application seemed to present much difficulty.

The cause of the contradictory results has been searched for under conditions of only occasional occurrence-for instance, difference in soil, different illumination, \&c. Without denying that such circumstances can exercise a very great influence, my more recent experience has shown that these contradictions can be explained without reference to chance. Consideration of all the evidence I have obtained shows so decidedly that electricity exercised a favourable influence on the growing plants that I found a new examination of the question necessary.

My first experiments, the aim of which was to test the usefulness of the method, were carried out in the physical laboratory of the University of Helsingfors. Omitting a number of experiments, the results of which only encouraged me to continue further, I will enumerate the first definite experiments made, from the beginning of May to June 24,1885 :-

(I) Before a window looking to the south three small compartments of cardboard were constructed, and on a table within were placed two flower-pots in each compartment. In these pots were sown barley, wheat and ryefour grains of each sort. The grains of every kind were of the same weight and appearance. Over the pots was hung a net of wires provided with points, separated from each other and insulated. The soil in the pots was connected with the earth by tinfoil in such manner that, when we call the compartments I., II., III., the electric current from 
the positive pole of a Holtz electric influence machine was going in

I. From the points in the air to the soil.

I.I. From the soil in the pot to the points.

III. Without wires.

The negative pole of the machine was conducted to earth.

The pots were watered with water of the same temperature and of the same quantity in every pot. After certain intervals the plants were measured as to their height, and the leaves both as to breadth and length.

A week passed. We could already see a remarkable difference. The plants in the compartments I. and II. developed much more strongly and more rapidly than in III. The electrical machine was kept working five hours daily. The experiments were continued to June 24th, when the increase of vegetation in I. and II. under the influence of the electric current was estimated to be 40 per cent. beyond the result in III. As the soil in the six pots was exactly alike, the cause of the greater development must be sought in the electric current.

The difference between I. and II. was barely perceptible, though the current in I. was + and in II. - . ${ }^{*}$ No difference between $+\mathrm{E}$ and $-\mathrm{E}$ is shown in these experiments. (See also p. Ir on this point).

(2) In the summer of 1885 , the first experiments were performed on a field. This was a small barley field on the farm of Mr. W. Lemström, in the parish of Vichtis, in the south of Finland.

Though the external circumstances were unfavourable, dryness being prevalent, $\uparrow$ the results were very satisfactory, the part of the field under the electric current giving an increase of about $35^{\circ} \mathrm{I}$ per cent.

(3) In the summer of 1886 , the experiments were executed on a garden field belonging to the Garden Society

* + stands for positive current, - for negative current.

+ That dryness would be unfavourable was not known at this time, but this will be seen later on. 
in Helsingfors. The plants came under treatment in such a way that half a garden bed of about 7 metres ( 23 feet) in length was under the current, the other half serving as "control." The following are the results in percentages:-

\begin{tabular}{|c|c|c|c|}
\hline - & $\begin{array}{l}\text { Per cent. } \\
\text { increase. }\end{array}$ & - & $\begin{array}{l}\text { Per cent. } \\
\text { inc. or dec. }\end{array}$ \\
\hline $\begin{array}{l}\text { White beets } \\
\text { Potatoes }\end{array}$ & $\begin{array}{l}+10722 \\
+\quad 76.2\end{array}$ & Garden strawberries in & * \\
\hline Red beets... & $\begin{array}{l}+76^{2} \\
+\quad 65.29\end{array}$ & Carrots .................. & $-5 \cdot 12$ \\
\hline Radish ........ & $+59 \cdot \mathrm{I}$ & †Turnip-cabbage & -5.23 \\
\hline Parsnips $\ldots . .$. & +54.45 & Cabbage & -4.3 .58 \\
\hline Onions ............. & $+42 \cdot 1 \mathrm{r}$ & †Turnip-cabbage & $+\mathrm{I} \cdot 8$ \\
\hline Celery & +36.90 & Turnip & +2.58 \\
\hline
\end{tabular}

'A singular circumstance was that we could not, during the summer, see any difference between the experimental and the control field, and we were on the point of believing that no difference at all would appear in the harvest, but, from the table above, it seems that the difference was very great.

The most remarkable fact in this table is that some of the plants seem as though favoured by the electricity while others derived no benefit and were apparently injured by it. Among these last mentioned cabbage is prominent. It is, however, not necessary to discuss this inequality here, as it was later discovered that it had its cause in the want of water.

The strawberries; planted in pots, were in a greenhouse and ranged in three compartments, separated from each other by walls of cardboard. In every compartment were two pots, and in the first +electricity in the second $-(E)$ was given, the third being without $\mathrm{E}$. The berries ripened in the first batch in 28 days, in the second in 33 days, and in the third in 54 days. The effect of the current was, there-. fore, to shorten in an astonishing manner the time of ripening. Here we have a marked difference between the $+\mathrm{E}$ and the $-\mathrm{E}$, the former having a greater stimulating effect.

In the same summer (I886) a first experiment was performed on the estate of Brödtorp, in the parish of Pojo, in 
the south of Finland, whose owner, the Baron E. Hisinger, I had the good fortune to interest in the experiments, and to whom I am under a great obligation for assistance in all directions given with the utmost courtesy and kindness. The experiments, executed on a wheat field of exceptionally good development, began first on June 2oth, when the wheat was just flowering. When the crop was sifted in first and second qualities the result was :

On the experimental field ( 0.5 hectare). On the control field ( $0^{\circ} 5$ hectare). $1,226 \cdot 2 \mathrm{~kg}$. $\mathrm{r}, 292 \cdot 5 \mathrm{~kg}$.

I $98 . \mathrm{Ikg}$. Ist quality, I,028. Ikg. 2nd. I $26^{\circ} \mathrm{Ikg}$. Ist, I, I66.4 $\mathrm{kg}$. $2 \mathrm{nd}$.

As thejexperiments began as late as the time of flowering of the wheat, an increase of the total crop could not be expected, but only an improvement in quality. That had really been the case, and we find that the first quality is augmented on the experimental field by 57 per cent.

(4) As the experiments hitherto performed had, as shown above, given very encouraging results, we were induced to make an extensive series of experiments at Brödtorp in the year $\mathbf{1 8 8 7}$, to which Baron Hisinger consented and gave, as before, his friendly assistance.

We give below the results obtained, and refer the reader to the extensive treatment of this subject in the Paper "Expériences sur l'Influence de l'Électricité sur les Végétaux":- ${ }^{*}$

Average increase per cent.

Rye ... $\left.\left\{\begin{array}{r}3.7 \% \\ 15.7 \%\end{array}\right\} \begin{array}{r}\text { The experiments came about so late } \\ \text { that the ears began to be formed... }\end{array}\right\}$ 10'0

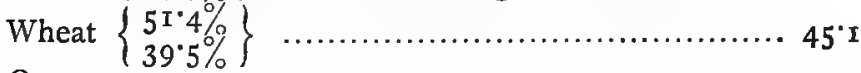

Oats ................................................. $54^{\circ}{ }^{\circ}$

Barley ............................................... $8_{5} 5^{\circ}$

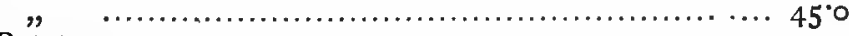

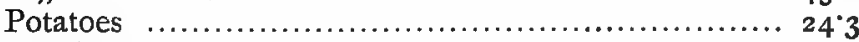

Red beets...................................... $3 \mathbf{I}^{\cdot} 7$

Raspberries ....................................... 95 $95^{\prime}$

* "Commentationes variæ in memoriam actorum CCL. annorum." Edidit Universitas Helsingtorsiensis, I890; and in the Electrical Reviere (London), November 4 and 25 and December 2 and $16,1898$. 
As in the experiments which took place in the field of the Garden Society at Helsingfors, a number of plants showed even here a decided decadence. The most prominent were:-

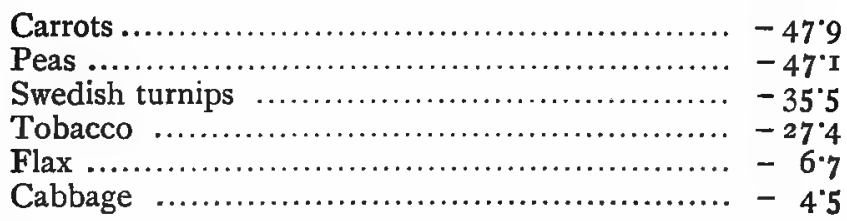

The varieties were partly the same as in the field of the Garden Society, the new ones being flax, tobacco and peas.

(5) The results obtained by the experiments made up to 1887 were very encouraging to a continuation of the studies of the phenomenon; but still many problems were yet to be solved. Among these were the following :-

Do we obtain the same results as in Finland if the experiments should be performed after the same method in another part of the globe, or, in other terms, would the effect be the same independent of the latitude?

Considering the great importance of the whole question, any publication of the results without having given an answer to that question would, perhaps, have been fatal. The first and most important point of all was to raise the necessary funds. That great difficulty was overcome, and by Prof. E. Mascart we were introduced to Baron $A$. Thenard, who gave us permission to perform the experiments on his estate at Castle Laferté, in Burgundy, and also his support where it was needed.

Of the exposition hitherto made, it seems that the greatest difficulty with experiments in the open field is to get a homogeneous soil on both the experimental and control fields. But that is not all. The fields must also be uniformly lighted by the sun. The shadow of a tree can be of great consequence if it falls unequally on both fields, and that circumstance will be more effective in the case of a summer with, in general, bad weather. The summer of 
I 888 was exceptionally bad, and fatal to the experiments on a number of plants, because the field on which they were carried out was not suitable in many cases. It has, therefore, been necessary to exclude a number of doubtful resuits; but for further details we must refer to a more complete publication, "Expériences sur l'Influence de l'Électricité sur les Végétaux."* Here we give only the results which were certain and of consequence for our purpose.

The plants which were objects of suitable experiments were :-

In the garden: Raspberries, peas, onions, carrots and cabbage.

In the field: Wheat, oats, maize, red beets and white beets.

The results gave an augmentation in the following proportions :-

\begin{tabular}{|c|c|c|c|c|}
\hline Wheat.. & ..a & or & $2 \mathrm{I}^{\circ}$ & \\
\hline Oats & $\ldots \ldots$ & , & r 8.6 & \\
\hline Maize & $\ldots$ & ", & $2 \cdot 6$ & \\
\hline Raspberries & $\cdots$ & $"$ & $42 \cdot 8$ & \\
\hline Red beets & & $"$ & 16.4 & \\
\hline Peas & 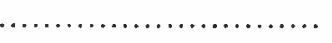 & $"$, & $75^{\circ}$ & \\
\hline Beans ... & , & $\eta$ & $3^{6} \cdot 4$ & \\
\hline
\end{tabular}

Among the plants treated were strawberries, which we must consider separately, because the experiments on them were most instructive. On the experimental field were 3 I 5 plants, and on the control field 392 plants. The experiments began April I8, I888, and were continued day and night. On the plants were, at the beginning, only leaves, but on April 29 appeared the first flowers on the experimental field, and eight days later on the control field. During this interval of I 9 days there were four days of rain, and, as the machines are not effective under conditions of rain and moisture, the time of active action was reduced to I 5 days. The development of the flowers on the experimental field was, therefore, twice as rapid as on the control field, and the plants of the former field possessed an appearance of much greater activity than the latter. This state of things

\footnotetext{
* See Note on page I2.
} 
continued to May 18, but then followed eight days with a burning sun and warmth exceptional even for Burgundy. From this time the plants on the experimental field began to languish, and the berries gathered between June 7 and 2I gave-

Experimental field ............8.065 kg. or 157 g. from one plant

Control ,$\quad \cdots \cdots \cdots \cdots \cdot 7 \cdot 245 \mathrm{~kg}$. or $\mathrm{r} 85 \mathrm{~g}$.

) or 15.1 per cent. less from the experimental field.

A difference in quality was also noticeable, the berries from the control field being fresher and more fragrant, those from the experimental field sweeter. It was evident that the electricity had damaged the plants. Rightly to estimate the damage, the number of fruits was counted to be on the average 16 on every plant on the experimental field, but only eight on the control field ; the fecundity had been twice as great on the experimental field.

The cause of this unexpected change in the development must be sought in the electric current, and the consequence is that the quantity of this agent must be lessened in times of burning sun. But it will be seen that an equal watering of both fields should have altered the result in favour of the experimental field.

We must, then, conclude that electricity is not so harmless that it may be given in an unlimited quantity; the external circumstances must be carefully considered. The same damaging through the burning sun happened with maize, which, in the beginning of May, showed an evident greater activity. on the experimental field than on the control field, but was found afterwards to decline.

In all the series of experiments the results showed that some of the plants were not favoured by electricity. Among these were carrots, cabbage, rooted cabbage, tobacco and peas.

During the experiments in Burgundy it happened that, besides the areas upon the field, there were fields of experiment and control both for carrots and peas in the garden. These four small fields, being of the same size, were equally- 
watered; care was taken that every field should receive the same quantity of water. The result was that the carrots gave an increase of I 25 per cent., and the peas (after careful estimation) 75 per cent.*

The results so far showed, therefore, that, if electricity is applied according to the above-mentioned method, favourable results were obtained equal to an increase of 40 to 80 per cent. It had, besides, been shown that electricity administered at the time of strong sunshine was damaging to the development of the plants. One other experience gained from these experiments is the following :-

The more fertile the soil and the more vigorous the vegetation the more stimulating will the effect of the electric current prove. A number of results show this. We will compare two experiments on potatoes and red beets, the one made on the field of the Garden Society, the other on the field at Brödtorp. The former field possessed all the properties of garden soil, the latter was little better than ordinary farm land :-

\begin{tabular}{ll|l} 
Garden soil. & Field. \\
For potatoes there was an increase of 76.2 per cent. & 24.3 per cent. \\
For red beets " & 65.3, & $3 \mathrm{I}^{\circ} 7, "$
\end{tabular}

Electricity will, in a high degree, accelerate the ripening of fruits, berries and roots, and probably develop more sugar in them. The former effect is well shown by experiments on strawberries and raspberries, the latter will be the object of further investigation. $\uparrow$

In the greenhouse the strawberries under electrical treatment ripened in an average time of 30 days, while 24 days more, or in all 54 days, was necessary for the berries without the benefit of the electric current. The same was the case with raspberries on the open field in Brötdorp, though the difference of time was there only I 7 days. The

* The peas were, shortly before ripening, purbined by pigeons,

t See the analysis of sugar beets in the experiments of the summer of 1902 and 1903 on page 47 . 
development of sugar has been stated in an analysis made in France on white beets, giving an increase of about I 8 per cent. of sugar," to which the remarkable augmentation of the sweetness of the strawberries, in the same place, is additional evidence.

Comparing the experiments made in southern Finland and in Burgundy, we find the results in general to be the same, but the increase seems to be less in Burgundy. We must, however, remember that the weather during the summer of 1888 in Burgundy was exceptionally bad, and, considering the law of greater development in the more vigorous vegetation, we cannot assert that the fact of a less increase per cent. in southern regions is sufficiently proved.

\$ 5. Experiments continued.-After a long interval the experiments were resumed in 1898 . Some of the questions still remained unanswered. Amongst these was the question: What time of the day is the best for applying electricity, and is the effect proportional to the time during which it is applied?

During the interval between the experiments a new type of influence machine had been constructed, with cylinders instead of plates, rotating in the opposite direction. This type of apparatus, which has since been modified again, + came in use in the summer of 1898 , when the experiments were carried out at Villa Kammio, near Helsingfors, where Dr. W. Lybeck had kindly given a piece of land in his garden and a room for the machine. In these experiments the soil for the experimental field, as well as for the control field, was divided into two parts, whereby its properties were equalised. The machine was in motion from 5 a.m. to 9 a.m., and from 4 p.m. to 8 p.m., or about eight hours daily.

The experiments began on June $I 7$ th, and by the middle of July tobacco plants on the experimental field showed so evident a superiority that photographs of both fields were taken, one of the experimental field and one of the control

* See result of the analysis on page 47 . † See Fig. 5, page 21. 
field. Two of these photographs are represented in Figs. I and 2 on the opposite page.

The machine had been at work for I 64 hours when the photographs were taken. The difference between the experimental and control fields was estimated at 40 per cent. The experiments were continued till August 24th, and the harvest gave :

From the experimental field $x 6$ plants weighing $18 \mathrm{~kg}$.

control " I6 " $"$ 13 kg.

or nearly 39 per cent. better result on the experimental field.

The fields were situated on gently sloping ground, and were divided into two sections, an upper and a lower one, of which the upper was watered with 50 per cent. more water than the lower. The results were :

Carrots an increase of 8.7 per cent.
White Beets "
Beans II.2 "

Of the carrots, the upper and more watered field showed the above increase; of the beets, on the contrary, the lower or less watered. The remaining fields showed nearly the same result. The short time (only eight hours daily) during which the machine was in motion exercised a considerable influence on the results.

We must here call attention to a singular circumstance concerning these experiments. It seems that the tobacco plants had by middle July, or during the time I could personally survey the experiments, already given, approximately, the surplus that was attained in the final result. Therefore, it appears as if the electricity had no increased effect over the interval of more than a month during which the experiments were continued. This strange circumstance gives rise to the supposition that a defect, not seen by the person in charge, belongs to these experiments. I suppose that the machine had been running uncharged during the greater part of this time without this fact being observed. I was myself on a journey. 

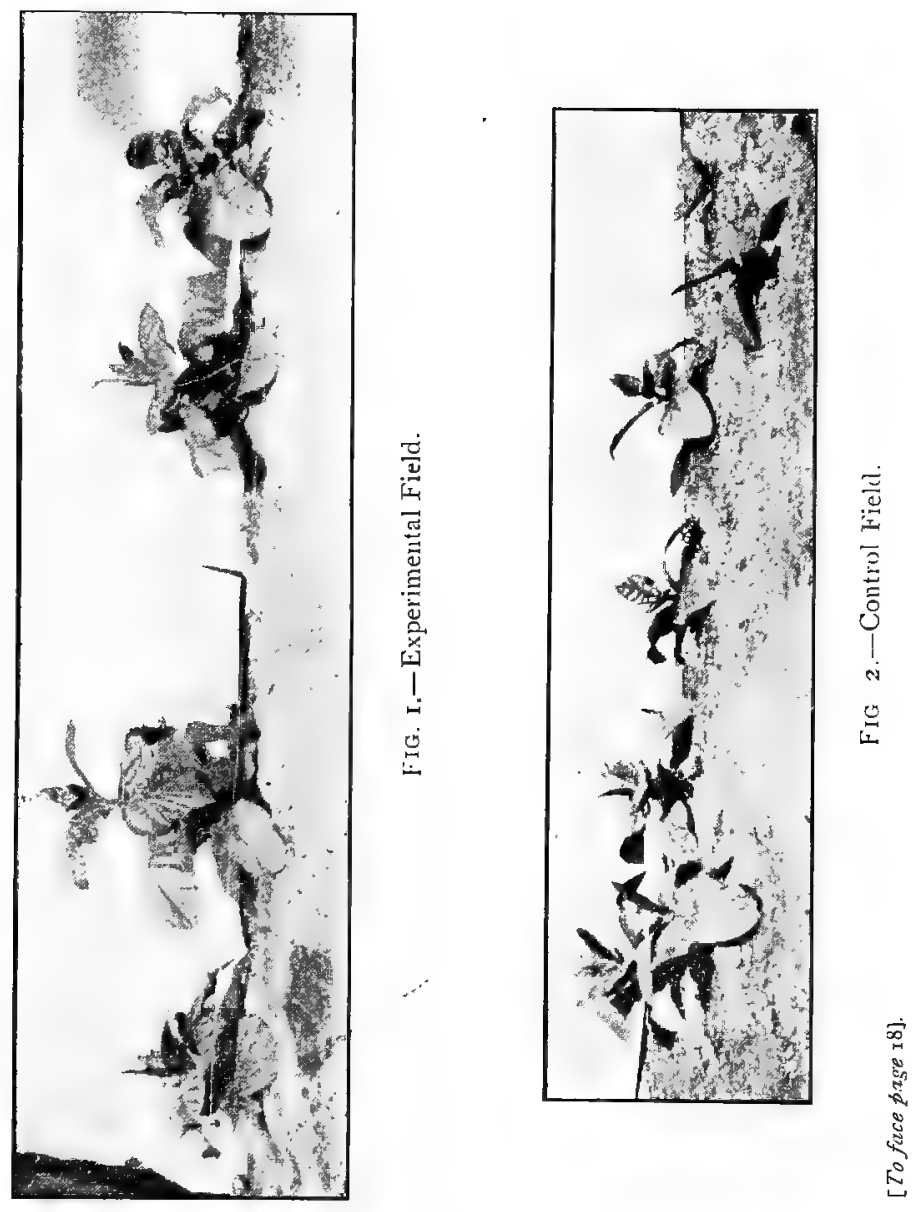

\$6. The following year, in the summer of 1899 , the experiments were again removed to Brödtorp, where Baron E. Hisinger, with his usual benevolence and never-failing interest, gave us some land and caused the necessary work for the culture of the plants to be continued. As stated above, the greatest difficulty in such experiments, when a comparison between the harvest from two fields had to be made, lies in obtaining homogeneous soil-that is, a soil which fully possesses the same qualities of fertility. As this is dependent not only on the elements of which it is composed, but also on the depth of cultivation and humidity of the soil, the choosing of the land is very difficult. In order to overcome these difficulties, at least to a certain degree, the following method was introduced. It will be best illustrated through Fig. 3 below :-

\begin{tabular}{|c|c|c|c|c|c|c|c|}
\hline $\mathrm{C}_{\mathrm{I}}$ & \multicolumn{2}{|c|}{$\mathrm{E}_{\mathrm{I}}$} & \multicolumn{2}{|c|}{$\mathrm{C}_{\mathrm{II}}$} & \multicolumn{2}{|c|}{$E_{I I}$} & $\mathrm{C}_{\mathrm{III}}$ \\
\hline $\mathrm{Cu}$ & $\mathrm{Cu}$ & $\mathrm{Cu}$ & $\mathrm{Cu}$ & $\operatorname{Tr}$ & $\operatorname{Tr}$ & $\operatorname{Tr}$ & $\operatorname{Tr}$ \\
\hline $\mathrm{Go}_{3}$ & $\mathrm{Sb}_{3}$ & $\mathrm{Go}_{3}$ & $\mathrm{SO}_{3}$ & $\mathrm{Ca}_{3}$ & $\mathrm{Ca}_{3}$ & Po & Po \\
\hline $\mathrm{Sb}_{\mathrm{r}}$ & $\mathrm{Go}^{\mathrm{Go}_{\mathrm{x}}}$ & $\mathrm{Sb}_{\mathrm{r}}$ & $\mathrm{Go}_{2}$ & Po & Po & $\mathrm{Ca}_{2}$ & $\mathrm{Ca}_{2}$ \\
\hline $\mathbf{R}_{3}$ & $\mathrm{R}_{2}$ & $\mathrm{Sb}_{3}$ & $\begin{array}{l}\mathrm{Nb}_{2} \\
\mathrm{Sb}\end{array}$ & $\operatorname{Tr}$ & $\mathrm{Be}$ & $\mathrm{Pe}$ & $\mathrm{Pe}_{3}$ \\
\hline $\mathrm{Sb}_{x}^{3}$ & $\mathrm{Sb}_{\mathrm{x}}$ & $\mathrm{R}_{2}$ & $\mathbf{R}_{2}$ & $\mathrm{Pe}_{x}$ & $\mathrm{Pe}_{x}$ & $\mathrm{Be}_{2}$ & $\mathbf{B}_{x}{ }^{j}$ \\
\hline $\begin{array}{l}\mathbf{R}_{\mathbf{Y}} \\
W\end{array}$ & $\begin{array}{l}\mathbf{R}_{x} \\
W\end{array}$ & $\begin{array}{l}\mathrm{Sb}_{2} \\
\mathrm{St}\end{array}$ & $\begin{array}{l}\mathrm{Sb}_{2} \\
\mathrm{St}\end{array}$ & $\mathrm{Be}_{x}$ & $\mathrm{Be}_{x}$ & $\mathrm{Pe}_{2}$ & $\mathrm{Pe}_{2}$ \\
\hline $\mathrm{St}$ & $\mathrm{St}_{\mathrm{x}}{ }^{3}$ & $\mathrm{~W}$ & $W_{2}$ & $\mathrm{~B}_{\mathrm{x}}$ & $\mathrm{B}_{\mathrm{x}}$ & $\begin{array}{l}\mathrm{D}_{3} \\
\mathrm{O}_{2}\end{array}$ & $\mathrm{O}_{3}$ \\
\hline $\mathrm{W}$ & IV & $\mathrm{St}_{2}$ & $\mathrm{St}_{2}$ & $\mathrm{O}_{1}$ & O & $\mathrm{B}_{2}$ & $\mathrm{~B}_{2}^{3}$ \\
\hline
\end{tabular}

FIG. 3.

The plants taken under experiment were

Cereals:- Wheat $=W_{x} W_{2} W_{3}$, Rye $=R_{I} R_{2} R_{3}$, Oats $=O_{x} O_{2} O_{3}$ and Barley $=\mathrm{B}_{\mathrm{x}} \mathrm{B}_{2} \mathrm{~B}_{3}$.

Shell Vegetables :- $\mathrm{Peas}=\mathrm{Pe}_{\mathrm{I}} \mathrm{Pe}_{2}, \mathrm{Pe}_{3}$, and Beans $=\mathrm{Be}$.

Roots:-Sugar Beets $=\mathrm{Sb}_{\mathrm{I}} \mathrm{Sb}_{2} \mathrm{Sb}_{3}$, Carrots $=\mathrm{Ca}_{1} \mathrm{Ca}_{2} \mathrm{Ca}_{3}$, and Potatoes $=$ Po.

Fruits :-Gooseberries $=\mathrm{Go}_{1} \mathrm{Go}_{2} \mathrm{Go}_{3}$, Strawberries $=\mathrm{St}_{1} \mathrm{St}_{2} \mathrm{St}_{3}$. Currants $=\mathrm{Cu}$.

Cliver $=\mathrm{Tr}$, and Cabbage ${ }^{*}=\mathrm{Sb}_{\mathbf{r}} \mathrm{Sb}_{2} \mathrm{Sb}_{3}$.

The tobacco was grown in fields which in August, 1899, were sown with rye, and the raspberries were in fields where

* Cabbage was in the summer o Igoo sown on the lower squares marked $\mathrm{Sb}_{\mathrm{x}} \mathrm{Sb}_{z}$ \& $\mathrm{c}$. 
the wheat was sown. The former had little, the latter no success at all. The columns with superscription $\mathrm{C}_{\mathrm{I}}, \mathrm{C}_{\mathrm{II}}, \mathrm{C}_{\mathrm{III}}$ signify control fields, those with $\mathrm{E}_{\mathrm{I}}$ and $\mathrm{E}_{\mathrm{II}}$ experimental fields: As shown by Fig. 3, every sort of plant had three experimental and three control fields.* Each field was 5 square metres ( 16.5 feet), and the different control and experimental fields were separated by a space 5 metres broad sown with oats. These fields were reaped green.

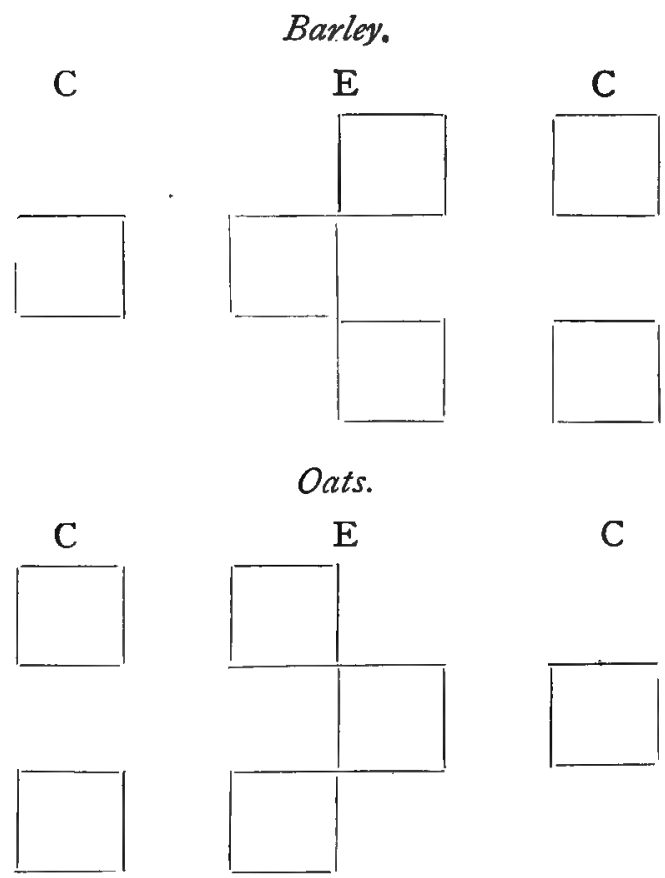

Fig. 4.

Among the plants which were under experiment during the first year results could not be expected from currants, gooseberries, strawberries and clover, or from wheat and rye, which were sown on August 2Ist. For the most

* Except currants, clover and beans, where some fields were missing. 



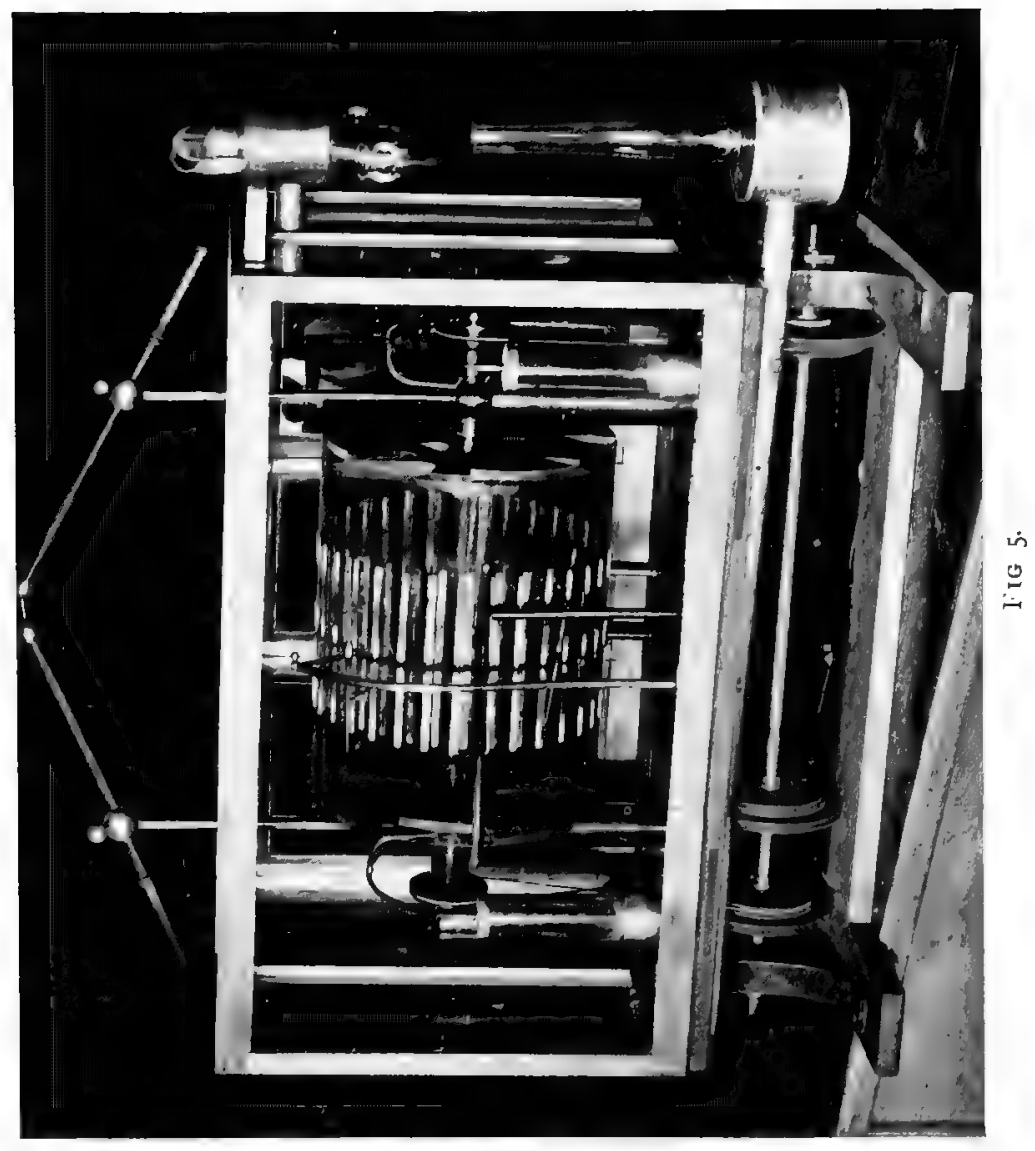


sensitive plants, such as sugar beets, carrots, beans and cabbage, the soil during I 899 was not sufficiently cultivated, and so a result from them could not be expected, particularly when we remember that the greatness of the percentage of increase depends on the vigour of vegetation. There remained this year, therefore, only barley, oats, peas and potatoes.

One might think that all inequalities in fertility would be eliminated when the experimental squares and the corresponding control squares are situated in the manner shown in Fig. 4, where the squares under $C$ are control fields and under $\mathrm{E}$ experimental fields; but that was not the case, for the soil represented in Fig. 3 under the last column, $C_{111}$ showed such a superiority over the soil in the columns marked $\mathrm{C}_{11}$ and $\mathrm{E}_{11}$, that the given results would, without observing this fact, be erroneous. To obtain a reliable result, it will, therefore, be necessary to graduate the soil according to its fertility.

If to all the squares under $E_{11}$ the value $I$ is given, the squares under $C_{111}$ must be put $=I * 4$, and the squares under $C_{11}=0.8$. The harvest from the squares under $C_{111}$ must be divided by $I^{*} 4$, and under $C_{11}$ by $0 \cdot 8$. In this way we shall attain, not the reality, but a minimum of increase.

By this graduation we had a good proportion of oats growth in the fields which lay between $C_{11}$ and $E_{11}$ and between $\mathrm{E}_{11}$ and $\mathrm{C}_{111}$; the growth in the latter was at least twice the former.

The new influence machine was used on these experiments (see Fig. 5), with cylinders of about $30 \mathrm{~cm}$. in diameter and $40 \mathrm{~cm}$. in length. It was kept in motion about eight hours daily, from 7 a.m.-I I a.m. and from 4 p.m.-8 p.m. This rule could not, however, be regularly followed, especially in humid weather. In case of rain the machine ceased to work. On the other hand, the machine was at work during a longer period in cloudy days, when it was not to be 
feared that electricity with sunshine would exercise a damaging effect. In such a way the machine worked

From June $\mathrm{r}_{5}-30$, an average of 6.5 hours daily.

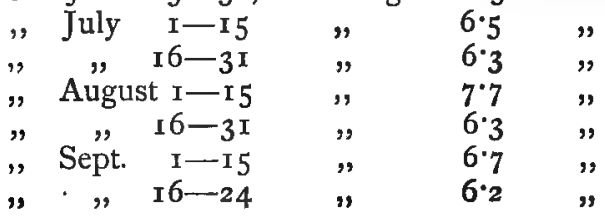

Thefieldsweresown on June I4 and I 5, I899. Watering, as equally as possible, was done on June 28,29 and 30 , July 4, 5, 7, 14, I8 and I9, and on August 2. Rainy days were: During July, 4 ; August, I I ; September, II. The insulated wire net was laid out round the flelds $E_{I}$ and $E_{I I}$ in such a way that a galvanised iron wire of $1.5 \mathrm{~mm}$. in diameter was drawn on posts round the field, and on this wire were extended cross-wires at a distance of $\mathrm{r} \cdot 25$ metres from each other. The wires were fixed on the posts with sheltered insulators of ebonite.

\section{RESULTS.}

Oats.

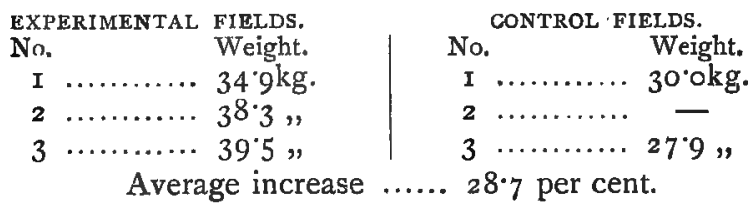

Barley.

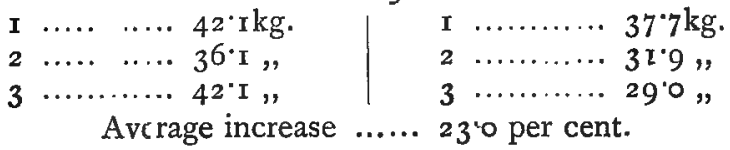

Peas.

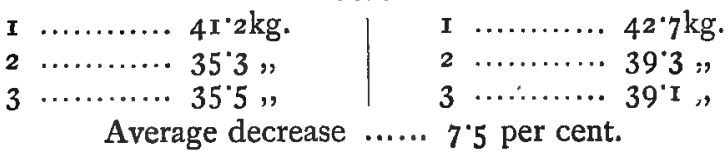

Cabbage.

\begin{tabular}{|c|c|c|c|c|c|}
\hline Number & Weight. & & Number. & & \\
\hline I...... 48 & $53.16 \mathrm{~kg}$. & $\mathrm{I} \cdot \mathrm{I} 67 \mathrm{~kg}$ & I $\ldots \ldots 43$ & $38 \cdot 7 \mathrm{okg}$. & $0.899 \mathrm{~kg}$. \\
\hline $\begin{array}{ll}2 \ldots & 50 \\
& \end{array}$ & $\begin{array}{l}57.37 " \\
48.88\end{array}$ & $\begin{array}{l}\text { I.448," } \\
\text { I.0I } 8, "\end{array}$ & 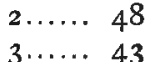 & $\begin{array}{l}73^{\circ} 94, " \\
60.05\end{array}$ & $\begin{array}{l}\text { I.54I } " \\
\text { r.606 }\end{array}$ \\
\hline
\end{tabular}




\section{Sugar Beets.}

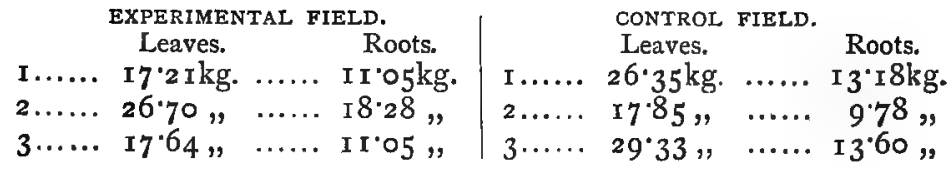

As the number of plants was equally distributed over all the fields, we can here compare the average of the weight of the roots. This gives an increase of IO'4 per cent. for the experimental field; but as the growth in the roots depends upon, besides other circumstances, the greater or less number of leaves which the plant is spreading in the air, it is preferable to compare the squares where the weight of the leaves was nearly alike-that is, the experimental fields $I$ and 3 and the control field 2, and likewise experimental field 2 and control fields $I$ and 3 . The former gives an increase of $13^{\circ} \mathrm{O}$ per cent. and the latter 38.8 per cent.

\section{Carrots.}

Only two squares could be compared with each other, in consequence of the unequal development in the other fields. Number of

EXPERIMENTAL FIELD.

\begin{tabular}{|c|c|}
\hline 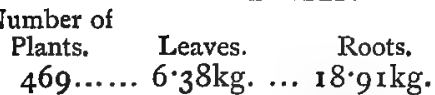 & $\begin{array}{l}\text { Number of } \\
\begin{array}{c}\text { Plants. } \\
502 . . . . .4\end{array} 4^{\cdot 86 \mathrm{~kg} . . . .} \mathrm{I}^{\circ} 7\end{array}$ \\
\hline Weig & Weight of a root, 0.029 \\
\hline
\end{tabular}
showing an increase of 37.5 per cent.

\section{Potatoes.}

EXPERIMENTAL FIELD.

Number of

Plants. Leaves, Roots.

I.... 175 $27^{\circ} \cdot{ }_{3} \mathrm{~kg}$. $53.13 \mathrm{~kg}$.

2.... 187 26.14, 48.24,

3.... 197 23.38, $43^{\circ} 3^{\circ}$,

Average harvest of a plant, $0.27 \mathrm{~kg}$.
CONTROL FIELD.

Number of

Plants. Leaves. Roots. I..... I 75 21.04kg. $3^{6 \cdot 1} 3^{\mathrm{kg}}$.

2..... I I0 I9'I $3,34^{\circ}$ ' İ, $(48.87,)^{*}$

3..... I93 I9.13, 30'36, $(42 \cdot 50, n) *$

Average harvest of a plant, $\circ \mathrm{I} 8 \mathrm{~kg}$.

Per cent. of increase, $50^{\circ} \mathrm{O}$.

* The numbers in parentheses are those actually received 
The remaining plants gave no results, partly because this was their first year of growth, partly from other causes. The beans, for instance, were destroyed by night frosts.

When, in considering these experiments, we take into account the imperfect cultivation of the soil and the late sowing, they show, in general, the same results as during the previous years' experiments.

The decreasing tendency of cabbage and peas has been observed before, and shows only that the watering has been too little, which was the case at the beginning of the experiment during the month of June.

The experiments made in the year I 899 might, in general, be regarded as a preparation for the following year, 1900.

As the growth was under the average, the consequence must be a low increase per cent, according to the law stated above. This had really been the case. Remembering that the electricity was applied only during 6.5 hours daily, we must regard the results as satisfactory.

$\$ 7$. The experiments were continued during the year 1900, and were chiefly undertaken for the purpose of finding out the effect that electricity exercises during the night.

As the wheat and rye were this year observed with special attention from the sowing onwards, we will devote to them a separate description. From I 899 there were in the fields gooseberries, currants, strawberries and clover, which, like the other squares, were manured. The fields were also thoroughly cultivated, beginning in the autumn of 1899 .

The sowing of barley and oats was done on May 3 oth.

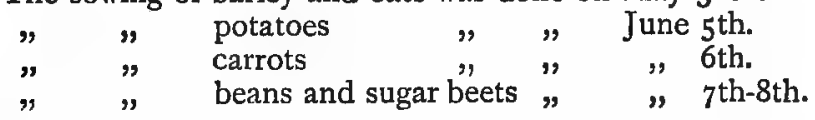

The germinating in the barley and oats squares began at the same time on both the experimental and the control fields. The germinating of sugar beets, carrots and potatoes occurred at the same time, and the flowering also was 
contemporaneous on both fields, so that regarding these no inequality was observed.

The influence machine was at work all the time it could be charged from June and to I 8 th, and likewise from September 6th to $13^{\text {th }}$. During the rest of the time it was at work, with small changes, from 7 p.m. to 7 a.m.

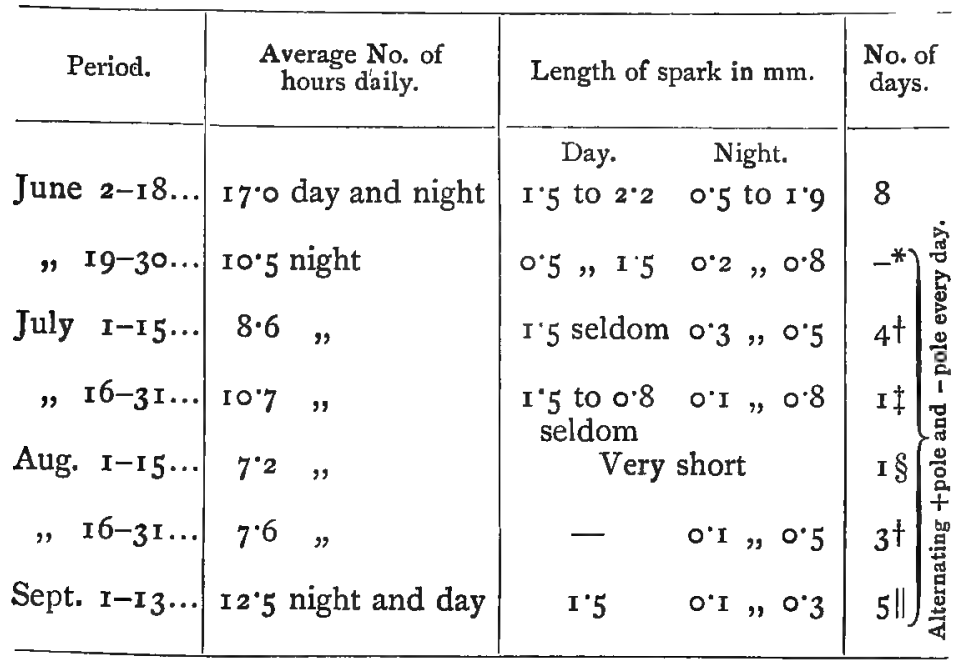

The spark-length between the discharging balls was measured $\pi$ at the time of setting in motion, when it was stopped, and sometimes while it was going on. In general this length is very variable, as will be seen from the above. The spark-length is the measure of the potential to which the wire net can be charged, and depends on external meteorological conditions, the most significant of which is the humidity of the air. The faster the electricity is streaming out from the wire net the lower is the potential to which the wire net can be loaded by means of a machine of given strength. The electricity meets in such a case with smaller resistance in the air-layer between

* The sky often clear. † Clear and half-clear. \$ Cloudy and clear. $\S$ Misty. II Cloudy and halt-clear. If The length of spark was measured in millimetres $=0^{\circ} 04$ in. 
the wire net and the plants. This resistance is, in general, greater in the day, the air being drier, than at night, when the air is more humid. The electrical air-current which goes from the wire net through the plant is, therefore, different during the day than during the night. The plants show in their life cycle essential inequalities during the day and the night. It is for this reason that the electrical treatment was in 1900 restricted to the night hours.

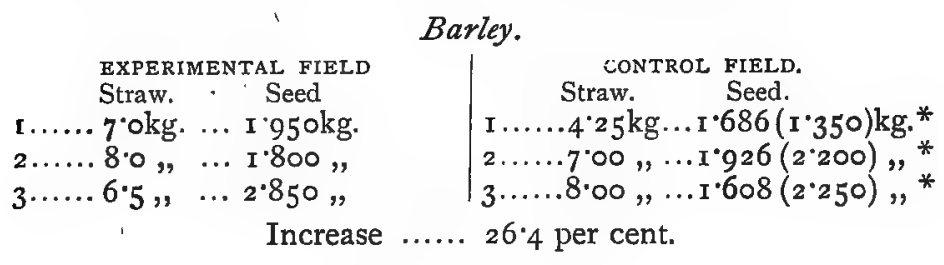

Oats.

The oat fields showed this year such great inequality that no sure results were to be expected from them. They were situated a little higher on the squares where the carrots were planted in 1899 . This inequality was due to an old ditch, which some ten years previously had been filled. This ditch went through two of the experimental squares, and lowered their fertility in such a remarkable way that comparing them with the other squares with a prospect of sure results was out of the question. My opinion is, however, as I had an opportunity of following the whole development during the summer, that the electricity exercised so great an influence that the effect of it was about the same as on the barley above.

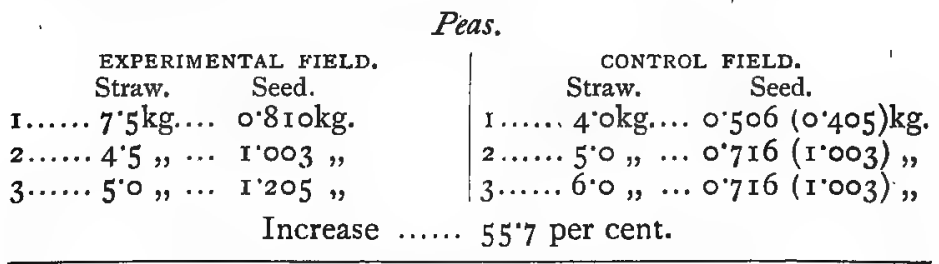

* The numbers actually received are put in parentheses. 


\section{Potatoes.}

\begin{tabular}{|c|c|c|c|}
\hline \multicolumn{4}{|c|}{ Fotatoes. } \\
\hline EXPERIMEN & TAL FIELD. & CONTROL & FIELD. \\
\hline $\begin{array}{l}\text { Number of } \\
\text { Plants. }\end{array}$ & $\begin{array}{l}\text { Weight of } \\
\text { Reaped Potatoes. }\end{array}$ & $\begin{array}{l}\text { Number of } \\
\text { Plants. }\end{array}$ & $\begin{array}{l}\text { Weight of } \\
\text { Reaped Potatoes }\end{array}$ \\
\hline$\ldots \ldots$ I $50 \ldots$ & .... I 9.3okg. & I....... $128 \ldots$ & ... I $6.50 \mathrm{~kg}$. \\
\hline$\ldots$ I 21 & $\ldots 20^{\circ} 50$ & $2 \ldots \ldots \ldots$ II2. & . $\left(37^{\circ} 70\right)$, \\
\hline$\ldots \ldots \ldots$ I27 $\ldots$ & .... I $7 \cdot 40$ & $3 \ldots \cdots \cdots-$ & 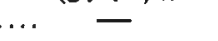 \\
\hline
\end{tabular}

If the control field 2 is excluded, the increase will be seen to be $17{ }^{\circ}$ per cent., a number very little different to that obtained previously. So the result must be regarded as very uncertain.

\section{Carrots.}

EXPERIMENTAL FIET.D.

Leaves. Roots.

I...4'950kg....r3'500kg.

2...8.000,...20.800,

3..6.800,, ...17.700,

CONTROL FIELD.

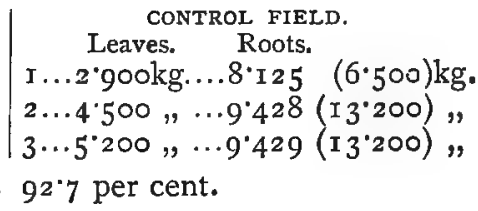

Sugar Beets.

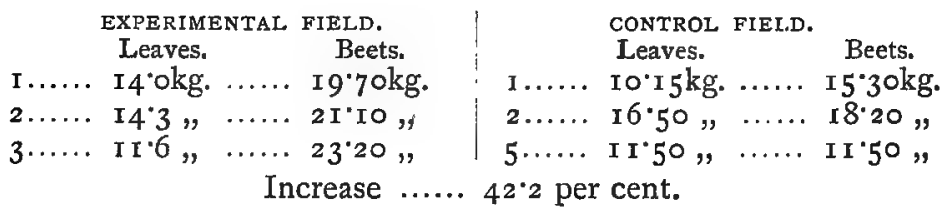

\section{Clover.}

The number of experimental fields was two and of control fields three. One of the experimental fields suffered from the same cause as mentioned above concerning the oats squares, and must, therefore, be left out of consideration. If the second control field is excluded, so that only the two control fields situated on both sides of the experimental field come into consideration, the results will be-

EXPERIMENTAL FIELD.

$$
\text { Hay. Seed. }
$$
I........ ro.okg. ...... 2.20kg.

CONTROL FIELDS.

Hay. Seed.

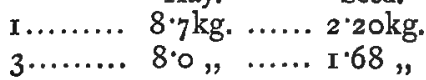

The average gives an increase of 19.8 per cent. hay and I 3.4 per cent. seed. 
We must, however, regard this result as uncertain, because the control field I showed from the beginning a high degree of development, and had to be excluded from comparison. Control field 3 was again situated in the column of squares the fertility of which was too great. When we take that into consideration, and use the same minimum number of reduction as above, or $\mathrm{I}^{4} 4$, the increase will be

$75^{\circ}$ I per cent. hay and $83^{\circ} 3$ per cent. seed.

The uncertainty is, however, great in this experiment, and the percentage of increase can hardly be determined.

\section{Beans.}

EXPERIMENTAL FIELD.

Harvest. No. Weight in g. No. Weight in g. No. Weight in g.

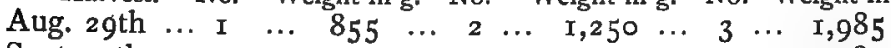
$\begin{array}{llllllllllllll}\text { Sept. } 9 \text { th } & \ldots & \text { I } & \ldots & \text { I, I } 50 & \ldots & 2 & \ldots & \text { I, I70 } & \ldots & 3 & \ldots & 1,280\end{array}$

$$
\frac{-1,15005}{2,420} \quad \frac{3,265}{3,005}
$$

CONTROL FIELD.

$\begin{array}{llllllllllllll}\text { Aug. 2gth } & \ldots & \text { I } & \ldots & 390 & \ldots & 2 & \ldots & 2,850 & \ldots & 3 & \ldots & 1,725\end{array}$ $\begin{array}{llllllllllllll}\text { Sept. } 9 \text { th } & \ldots & \text { I } & \ldots & 9 & 9 \text { ro } & \ldots & 2 & \ldots & \text { I,220 } & \ldots & 3 & \ldots & 1,400\end{array}$

$$
\begin{array}{ccc}
(1,300) & -\overline{(4,070)} \quad \underset{(3,125)}{1,625} \\
2,23^{2}
\end{array}
$$

If the control field 2 is excluded, as the fertility is too great for comparison, and if No. I is divided by 0.8 and No. 3 by I 4 , the increase will be 36.6 per cent.

At the same time, it seems that the first average harvest from the experimental field will surpass that from the control field if the latter is treated in the way recommended, which shows an earlier development on the former.

\section{Currants.}

On the squares planted with currants, the number of bushes which had begun to grow in the experimental field and in the control field was very different, so that, regarding the quantity, no comparable results could be obtained. 
Gooseberries.

Of gooseberries, on the contrary, the following harvest was obtained :-

\begin{tabular}{|c|c|c|c|c|}
\hline EXPERIMENTA & IL FIELD. & CONTROL & FI & ELD. \\
\hline Aug. 23rd... & $\begin{array}{l}\text { Weight in g. } \\
\text { I } \quad \ldots \quad 137\end{array}$ & Aug. 23 rd... & I & $\begin{array}{l}\text { Weight in g. } \\
\ldots \quad 62\end{array}$ \\
\hline$"$ & $\ldots 175$ & " & 2 & $\ldots$ II 2 \\
\hline " & $\begin{array}{lll}3 & \cdots & 75\end{array}$ & " & 3 & $\ldots \simeq 69$ \\
\hline
\end{tabular}

That the effect of electricity has been great is, however, seen from fields I and 2, where the experimental fields have a great overweight. That the control field 3 has such a great overweight over the corresponding experimental field results from the greater development of a couple of bushes. Excluding this number, the increase will be $79^{\circ} 3$ per cent.

\section{Strawberries.}

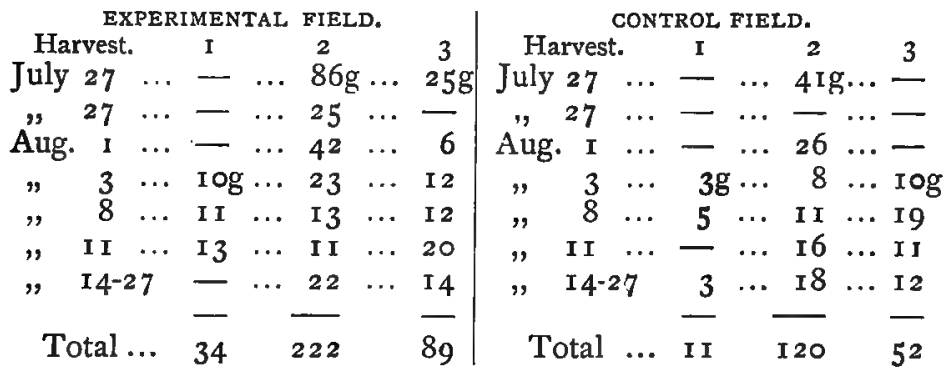

Though the harvest cannot be regarded as good, either from the experimental field or the control field, the increase on the experimental field is of such superiority that the effect of the electricity is evident. The percentage of increase is, on the average, from all three fields, 88.7 per cent. The earlier development is also noticeable.

\$8. On August 2I, I 899, the rye and wheat were sown in rows. The sowing began at 6 a.m., and was finished at 7 p.m., in the following order :-

Control Fields ........ $W_{1} W_{3} R_{1} R_{3}$. Experimental Fields... $R_{3} R_{1} W_{3} W_{1} W_{2} R_{2}$. Control Fields ......... $R_{2} W_{2}$. 
On August 28th the first rye-germs were observed; unfavourable weather delayed the germinating.

On August 29th the rye-germs in the experimental fields were much longer and more numerous than on the control fields.

On August 3oth the wheat had come up in all the experimental fields, but only a few germs were observed in the control fields.

On August 3 Ist the influence machine was stopped.

On September Ist the germs were carefully observed in all the fields. In the experimental fields they were remarkably better and more numerous than in the control fields.

The difference in germinating time was $\mathrm{I} 2$ to 24 hours.

In a square of $40^{\circ} \mathrm{cm}^{2}$. the number of germs were counted and their lengths measured, as follows :-

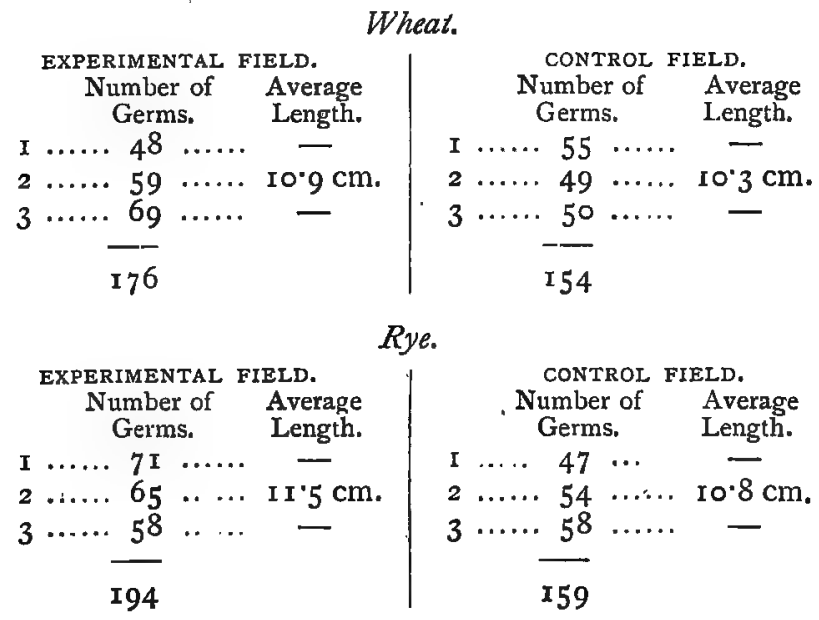

The growth on the experimental fields appeared tighter and more developed.

During the summer of 1900 the experimental fields proved to be superior to the control fields both for wheat and rye. On July Ioth in that year both rye and wheat lay down so that the wire net came to stand higher than 
it ought to have done. The harvest was made on August I6th, and gave the following results in grammes :-

\section{Wheat.}

EXPERIMENTAL FIELD.

Straw and Seed together.

I $\ldots \ldots \ldots \ldots \ldots 24,800$

$2 \ldots \ldots \ldots \ldots \ldots 24,500$

$3 \ldots \ldots \ldots \ldots 27,200$

Seed.

Ist quality. 2nd quality. Total.
CONTROL FIELD.

Straw and Seed , together.

I $\ldots \ldots \ldots \ldots, 20,55^{\circ}$

$2 \ldots \ldots \ldots \ldots, 22,250$

3 20,800

Seed. $\begin{array}{ccccccccccc}6,000 & \ldots & \text { I,620 } & \ldots & 7,620 & \text { I } \ldots & 4,770 & \ldots & \text { I,300 } & \ldots & 6,070\end{array}$ $\begin{array}{llllllllllllllll}2 & \ldots & 5,700 & \ldots & 1,900 & \ldots & 7,600 & 2 & \ldots & 4,370 & \ldots & 2,700 & \ldots & 7,070\end{array}$ $\begin{array}{llllllllllllll}3 & \cdots & 3,770 & \cdots & 1,500 & \cdots & 5,270 & 3 & \ldots & 4,600 & \cdots & 3,150 & \ldots & 7,750\end{array}$

As it seems that the experimental field 3 , which gave the greatest quantity of straw and seed together $(27,200 \mathrm{~g}$. against $24,500 \mathrm{~g}$. and $24,800 \mathrm{~g}$. in both 2 and $\mathrm{I}$ ), has given the least quantity of seed, a mistake has clearly been made. The most probable error is that a clerical mistake has been made in writing $3,770 \mathrm{~g}$. instead of $5,770 \mathrm{~g}$.

Experimental fields $\mathbf{I}$ and $\mathbf{2}$ give an average of .

Control fields I and $2 \quad$ " 4,570 Ist quality seed or an increase of 28 per cent. of Ist quality seed. The combined increase is 16.8 per cent.

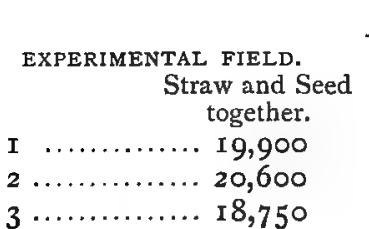

Seed.

1st quality. 2nd quality. Total.

$\begin{array}{llllllll}\text { I } \ldots & 3,460 & \ldots & 2,860 & \ldots & 6,320\end{array}$

$\begin{array}{llllllll}2 & \ldots & 2,380 & \ldots & 4,350 & \ldots & 6,730\end{array}$

$\begin{array}{llllllll}3 & \ldots & 3,670 & \ldots & 2,710 & \ldots & 6,380\end{array}$

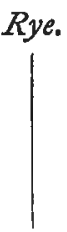

I
2
3

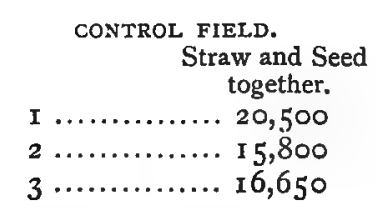

Seed. Ist quality. 2nd quality. Total. ... $2,900 \ldots 3,260 \ldots 6,160$ $\begin{array}{llllllll} & \ldots & 2,250 & \ldots & 2,560 & \ldots & 4,810\end{array}$ $3 \ldots 2,050 \ldots 3,1$, $10 . . .5,160$

The experimental fields give an average of

,control

3,170 ist quality seed. 2,400 "

or an increase of $32 . \mathrm{I}$ per cent of ist quality seed. The combined increase is 28.4 per cent. 
§9. Comparing the results for both the years 1899 and 1900, they appear to be alike for barley and oats, or an increase of 25 to 30 per cent.; for peas the decrease of 7 per cent. has grown to an increase of $55^{\circ} 7$ per cent. ; and for carrots from $37^{\circ} 5$ to $92^{\prime} 7$ per.cent. In general, the percentage of increase was greater during the summer of 1900 . During the summer of 1899 the machine was at work, on an average, for 6.5 hours daily; during the summer of 1900 , principally during the night, for Io hours. The longer time during which the machine was at work in the latter summer will suffice to explain the higher increase, so we cannot conclude from these results whether day or night is more favourable for the electrical treatment.

When all the results received are taken into consideration, the increase appears greater if the application of electricity is continued by day and night. So we seem entitled to suppose that there is a certain dependence between the percentage of increase and the period during which electrical treatment takes place ; but any declaration that they are proportional to each other cannot be made from the experiments hitherto carried out.

As above mentioned, the electric current which goes from the wire net through the plants to the earth is different during the day and the night: during the day, high potential and great resistance; during the night, low potential and little resistance. It must be understood that we here take normal conditions for granted-that is to say, clear days and clear nights. During moist weather the potential is low, and in case of rain the machine can be continued at work only when a nearly constant spark is going on in a gap ( $\mathrm{I} \mathrm{mm}$.) of the circuits to the earth. This was not applied in the above-mentioned experiments, but the machine was stopped.

It might now happen that the changes in the potential and the resistance were such that the intensity of the current was constant, or nearly so; but upon this point our 
knowledge is at present very inadequate. Most probably the intensity in question is very variable. Hence it seems that this relation between the increase per cent. and the period during which the electrical air-current exercises its effects is also a variable quantity, and that the effect of the electric air-current is different under different exterior conditions. This must be taken into consideration in judging the amount of the increase percentage.

As mentioned above, the greatest difficulty in determining this percentage of increase lies in the want of uniformity in the soil. An augmentation of the number of squares might perhaps lead to an equalising of the difference in the average fertility of the soil; but this will lead to another difficulty-namely, that which consists in making out the many squares. Much skill and foresight are necessary to avoid confusion.

As will be seen from the experiments previously described, there were for rye and wheat I 2 squares (six for each). It would have been necessary to prepare each square separately in order to attain positive results. That mistakes might happen here is easy to comprehend, and some have really happened; but they were so apparent that they could be immediately corrected. To prepare the whole soil beforehand would obviously have been too costly.

A relatively satisfactory result could certainly be obtained in the following way:-Two squares of $3 \mathrm{~m}$. (10.8 sq. $\mathrm{ft}$.) are prepared with the soil from the field in which the electrical treatment is to be applied. They must lie at least $5 \mathrm{~m}$. from this field and from each other. The soil on both the squares must be well mixed and put out in equal quantities in every square. One is put under the same electric treatment as the field. If care is taken that the sunshine and the rain will reach both the squares in the same proportions, comparable results can be obtained. The increase per cent. for the whole field can then be calculated. 
The experiments in the summer of 1903 , particularly at Atvidaberg, Sweden, showed it to be necessary to improve the method of control, as the constitution of the soil will have a marked influence, especially in rainy summers. Besides the above-described method it should have a wholly artificial addition of well-mixed earth put into two boxes, $\mathrm{Im}^{2}$. in surface and $\frac{1}{2} \mathrm{~m}$. in depth, the sowing to be as equal as possible in number and at the same depth. One of the boxes should be placed under the electric air-current and the other Iom. apart from the field under the same current. The growth in these boxes will show the effect of this current, and also provide the means to judge if the fields have been of equal fertility.

In connection with these experiments, it is to me an agreeable duty to express my best thanks to Baron E. Hisinger for the warm interest he has taken in the work and for the real support he has given it.

\section{HOW DOES ELECTRICITY EXERCISE ITS}

\section{INFLUENCE ON THE PLANTS?}

\$10. During the summer of 1898 some experiments at the Physical Laboratory of the University of Helsingfors were performed regarding the state of liquids in capillary tubes under the influence of the electrical air-current. These experiments were continued in the spring of 1900 by myself, assisted by a student ( $R$. Bengelsdorff), and in the autumn and winter of IgOI with the aid of another student (V. J. Laine). The most important of these results may here be cited.*

If a capillary tube is lowered into a glass of water united electrically with the earth, and a fine metal point, in conducting connection with the negative pole of an influence

* See the Author, "On the State of Liquids in Capillary Tubes under Influence of Electrical Air-Currents," Ofversigt af Finska Wet. Soc., Förh. Bd. XLIII., 1901. In German : Drudes Annalen. I901, 5 Bd., p. 729. 
machine, is placed above the capillary tube, when the machine is started water-drops will appear after some seconds in the upper part of the tube. It is assumed that the inner surface of the tube has been moistened just before, and that the positive pole of the machine is united with the earth. The water climbs up the walls of the tube and forms one or more drops or small water cylinders. The quantity of water which in such a way ascends in the tube is proportional to the square of the distance of the point from the meniscus of the water pillar in the tube, and is dependent upon the length and diameter of the tube and the resistance in the circuit.

The positive pole exercises no influence, so that this effect is produced by the current from the earth through the liquid in the capillary tube to the point. When the connection with the earth is removed, all effect ceases. Hence it follows that an electric current is produced by which the liquid is drawn up in the positive direction.

The application of this phenomenon on the method used in our experiments on growing plants is as follows:-The electric current produced by the influence machine when its positive pole is earthed goes from the earth through the plants to the points of the insulated wire net and back to the negative pole. This causes an ascent of liquid or juice in the capillary tubes of the plants, and produces in such a way an augmentation of the energy with which the circulation of the juices is going on.

During the experiments made hitherto the insulated wire net had been united with the positive pole of the influence machine, and had thus been made positive; in analogy with Nature itself, where the potential of the air is ordinarily positive. A thorough investigation of the influence machine resulted in detecting the following peculiarity, not before observed by me: As the machine, provided with Leyden jars at both poles and with the one pole earthed, is stopped, after having been again moved and set 
in movement afresh there will occur a change of poles. This change easily escapes the attention of the observer. Such a change of pole might, therefore, have occurred during the experiment by which the wire net had been charged alternately positively and negatively.

For this reason it was very important to make a series of experiments in which strict control over the direction of the current was exercised. The experiments were executed in the same way as the experiments mentioned on pages 9 and Io, with, however, a few modifications.

Sixteen burnt clay pots of middle size $(19 \mathrm{~cm}$. in diameter at the upper side, $14 \mathrm{~cm}$. in diameter at the bottom, and $19 \mathrm{~cm}$. in height) were placed before the windows, four in number, facing south. The pots were placed four in a line before the window. The earth in these pots had been well mixed in a box and distributed alike in all the pots. In each of 12 pots out of the I6 was sown, on May I8th, I9or, I2 grains of wheat, the same of oats and barley-two grains in the middle, and in five symmetrically situated places also two grains. In the four remaining pots were set strawberry plants in the middle, and around them in three places were sown carrots. The pots were placed in four sections, one before each window, so as to stand in a row-the pot with the strawberries and carrots inside, then the pot with wheat, and last that with oats and barley. Every section was separated from the other by screens of white pasteboard, and care was taken that the light was the same for all.

Above the three first sections (I., II., III.) was suspended by a thread of silk a wire net furnished with points $25 \mathrm{~cm}$. broad and $120 \mathrm{~cm}$. long, at a height of $40 \mathrm{~cm}$. above the earth in the pots. Through the holes in the bottom of the pots were introduced equal-sized strips of zinc which were in conducting communication with each other and with the earth in every section. The pots stood on plates of burnt clay, and these on plates of thick glass supported 
by small pieces of ebonite. In Section IV., which ought to serve as control, the pots with their plates stood on the same kind of insulating layer, but with no zinc strips beneath nor wire net above.

After having found a new way to determine the situation of the poles at the influence machine, we could easily control this each time the machine was set in motion. When the machine is allowed to work without Leyden jars, and its poles are at a distance of $1.5{ }^{\circ} \mathrm{cm}$., a stream of light can be observed between the poles. This fine light is violet at the negative pole, ending with a bright point on the surface of the sphere; but it is white and very bright at the positive pole. The change of colour in the light-current does not take place in the middle, but is nearer to the positive pole.

The influence machine used on this occasion was of the new type, with small cylinders $(15 \mathrm{~cm}$. diameter and $20 \mathrm{~cm}$. in length), and enclosed in a glass box, in which was placed a little plate with sulphuric acid for the drying of the air. The machine was set in motion by an electrodynamic motor, into which was led a current of from five to six Daniel elements. The negative pole of the machine was placed in connection:

In Section I., with the zinc strips underneath the pots, the wire net of the same section being led off to earth ;

In Section II., with the wire net above the pots, the zinc strips of this section being led off to earth;

In Section III., with a commutator of ebonite (lying on a plate of glass) through which a leading connection could be produced, one day with the zinc strips and the other day with the wire net, in the same section. At the same time the commutator effected a connection so that one day the wire net and the other the zinc strips were united with the earth ;

In Section IV., no current. 
The machine was kept in motion from 6 to 7 a.m. till 9 to Io a.m., and from 4 to 5 p.m. to 8 to 9 p.m. In cloudy and cold weather, which occurred very seldom, the machine was kept moving a longer time, sometimes even all night.

We worked thus from-

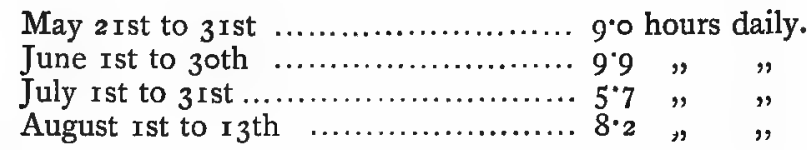

From the middle of June the windows were kept open during the night in order to lessen the warmth. Watering was done every day in measured quantities. For the first two weeks Section II., or the section in which the current went from the plants to the wire net, showed the highest development; but from this time Section I., where the current went in the opposite direction, began to take the ascendency, and kept it till August $\mathrm{r} 3$ th, when the experiments ceased. This refers only to the barley, oats and wheat.

On July Ioth appeared the first ear of oats in Section III., on July I4th in Section II., and on July I6th in Section I.

On July 23rd the brush of a barley-ear began to appear in Section I., and on July $25^{\text {th }}$ in Section II. The wheat could not, however, be brought to form ears.

This proved generally that these kinds of cereal could not be brought to a normal condition of development in the prevailing high temperature, and so the experiments ceased, as I have said, on August I3th.

But the development of the strawberry plants went on normally, except in Section I., where the plant died, probably from the strong effect of the current. In Sections II. and III. the commencement of the flowerings, of which the plants in Section II.showed a powerful growth, were removed.

At the end of the experiments the cereals showed, at an exact estimation, in

Section I. 60 per cent. more development than in Section IV.
" II. 45
"
"
"
(S"ee also Fig. 6 on opposite page). "
"
3) 


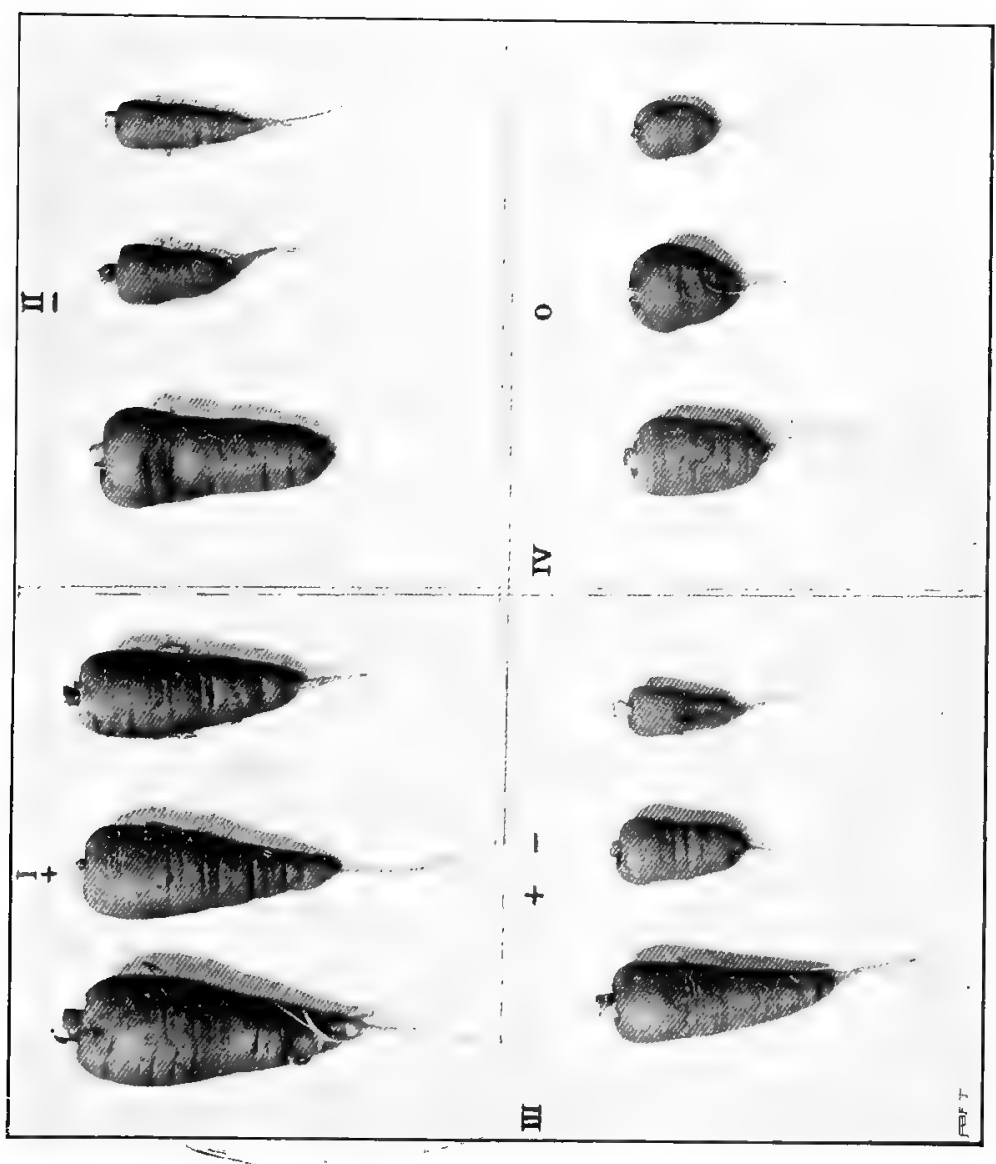

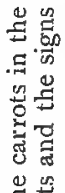

壱

㟧

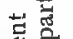

纪泀 을 范 米品

出 0

륨요 吗 范 के تี 동. 5

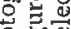
망 我。 का 잉 ธี 4. ब림 : 㙖 ๘ : 空 艺 苛 I. $0:-$ b 

With regard to the strawberry plants, the same progress was observed with both the Sections II. and III.

The carrots showed the following results :-

$$
\text { Leaves. Roots. }
$$

Weight in $\mathrm{g}$. Weight in $\mathrm{g}$.

\begin{tabular}{|c|c|c|c|}
\hline & Weight in & g. Weight in g. & in per cent \\
\hline Section & I. $\ldots 30^{\circ} 90$ & ... 104.60 positive current & $\ldots \times 827$ \\
\hline$"$ & II. $\ldots$ r $55^{\circ}$ & .. $49^{\circ} \circ 0$ negative current & 324 \\
\hline "' & III. ... I6.70 & $\begin{array}{c}42.05 \text { alternately positive } \\
\text { and negative }\end{array}$ & 13.2 \\
\hline " & IV. ... I6.65 & $\ldots 37^{\circ} \circ 0$ no current & 一 \\
\hline
\end{tabular}

Increase in per cent. .. 182 '7

$32 \%$

$3 \cdot 2$

The results of this series of experiments indicates clearly that carrots, which have showed hitherto decreased growth from the electric treatment (except at the experiments in the garden of Laferte in Burgundy and at the experiments made at Brödtorp in 1899 and 1900 , where watering was done during the experiments), were here increased; and this conclusion can be applied to other vegetables which have previously showed a decrease from the electrical treatment. It shows, further, that the positive current in Section $I$. is giving a result which far surpasses the negative one in Section II.

Consequently, it is not only by a mechanical updrawing from the root of the water and dissolved matter within it that the electric circuit operates; it aids the development more powerfully when it goes in the opposite direction.

The question therefore arises: Is the positive current able to exercise a mechanical effect on the plants? Without doubt; for it is known that when a cut branch from a leafy tree is put into water upside down, it can suck up the water and keep living a long time; and it is the same with plants. The positive current introduces into the plants the different elements or compounds of the air, besides oxygen and nitrogen-water, carbonic acid, ozone and nitric acids, ammonia, \&c.* A portion of these compounds is formed

* Experiments executed in the laboratory of physics at the University of Helsingfors show that the electric current which is going out from the points forms the followirg chemical compounds, the nature of which has been determined by chemical analysis: Ozone (in great quantities), nitric acids, nitrous acid, ammonia (doubtful). 
by the passage of the electricity from the points into the air, and the current introduces them in a fresh condition into the capillary tubes of the plant. In this way the effect of the electric air-current can be reduced to a purely mechanical one.

We do not maintain that any other effects than the mechanical may not occur; but our experience does not go so far that we can say anything with certainty on this point.

The effects of the two currents can be determined in the following way :-

The negative current going from the earth to the plants facilitates the drawing-up of water with the dissolved matter through the roots of the plant to its capillary tubes, and thus produces a stronger circulation of the saps.

The positive current brings to the plants the different elements, and introduces them through the openings in their capillary tubes in such a way as to promote vegetation.

This latter effect is, as mentioned above, very much more effective than the former.

In the above-related experiments the effects were produced by an artificial electric air-current; but, as also mentioned above, a continual electric current is going upwards or downwards, certainly in the polar regions and in our latitudes, but probably everywhere ; and this current must evidently exercise a greater or lesser influence on the life of vegetables in the way we have endeavoured to show.

Electricity takes a much larger part in the life of vegetables than it has been presumed to do till now. The amount or value of this influence cannot be determined without examining more exactly the electric currents of the atmosphere. The methods used at present for this purpose cannot lead to this knowledge. New methods must . be introduced, and this question will be one of the most significant in the scientific programme of the future.

We cannot say that the question regarding the influence of the artificially produced electric air-currents has reached 
its solution; but the experiments have led to an admissible explanation, founded on facts, showing the way in which this influence is exercised. They have also effected some advance in our knowledge, which has not yet attained the necessary degree of exactness, but which possesses some importance both to science and to the practical application of our scientific knowledge. We may therefore summarise our present knowledge as follows :-

(a) The real increase per cent. due to electrical treatment has not yet been exactly determined for the different vegetables which have been under experiment. But we are approaching its smallest value in fixing it at 45 per cent. for land of average fertility.

(b) The better and more scientifically a field is cultivated and manured, the greater is the increase per cent. On poor soil it is so small as to be scarcely perceptible.

(c) Some vegetables cannot endure the electrical treatment if they are not watered, but then they will give very high percentage increases. Among these are peas, carrots and cabbage.

(d) Electrical treatment when accompanied by hot sunshine is damaging to most vegetables, probably to all; wherefore, if favourable results are aimed at, the treatment must be interrupted in the middle of hot and sunny days.

(e) As it is very difficult to determine the effect of electricity on most plants, a special arrangement must be made to get an approximate determination of the increase. In this connection we have already set out (page 33) what must be done in order to avoid the uncertainty which arises from the want of homogeneousness in the soil.

Since the preceding part of this book was written, the following experiments have been carried out during the summers of 1902 and 1903 :-

In all the experiments mentioned hereafter, the new type of influence machine, described on page 2 I (see Fig. 5), 
and the new insulators were employed. The size of the machine was also the same, and the whole equipment was made at Helsingfors.

\section{ENGLAND.}

Experiments at Durham College of Science, NeWCASTLE-ON-TyNE.-Summer, 1902.

After a long correspondence with Mr. Hogarth, of Kirkcaldy, I was induced to erect an installation for experiments to be made at Durham College of Science. After having corresponded with Mr. R. B. Greig, I got the conditions for my experiments settled, and it was determined that they should begin as early as possible. As a matter of fact, they could not begin before May 24th, I902, after all plants had been sown. This work was completed on May 22nd. The machine employed was driven by an electromotor.

Our intention was to put under experiment the following plants:-Barley, oats, sugar-beets, mangolds, potatoes, beans, carrots, turnips, swedes, clover, rye grass and strawberries.

After the electric current had been applied some days (from May 24th to June ind) it could be seen on nearly all plants that germination and vegetation were much better on the experimental fields than on the control fields. Especially was this the case with strawberries, and the barley showed a much richer development under current than without it. But after the commencement of June the bad weather-the rain and the low temperature-began to exercise their strongest influence.

The following meteorological observations, taken at Cockle Park, Morpeth, may be set out to give a true idea of the weather during the summer of 1902 :-

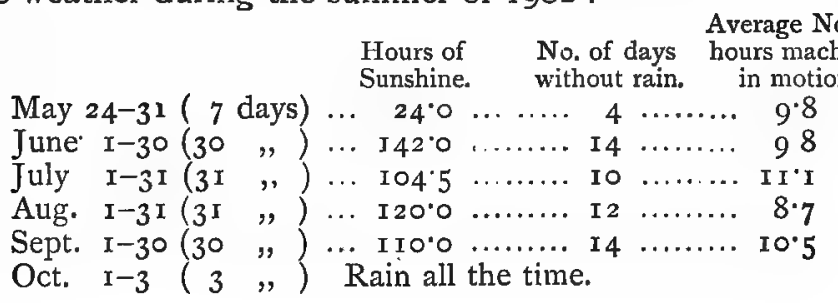


As the rule is certain that the better the vegetation the higher the increase per cent., a good result was not to be expected, in consequence of diminished vegetation generally. But from another cause-viz., that the machine has none or little effect shortly before, during, and shortly after rain, a lowered result must be the consequence. From the majority of plants no harvest could be obtained, because they had not sufficient time to ripen; others were destroyed by insects, and so on. It is therefore to be regarded as somewhat astonishing that the results have been as good as the following table shows :-

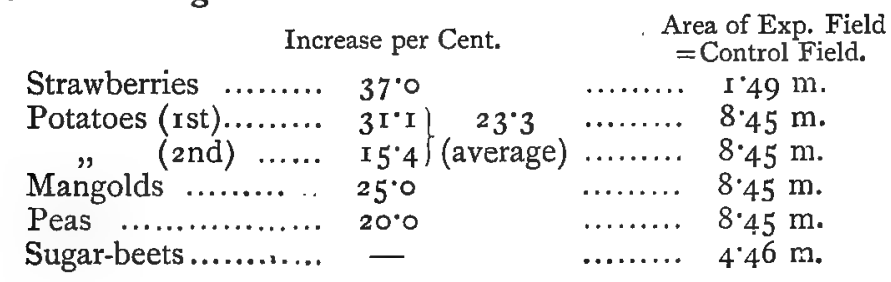

A chemical analysis of the sugar-beets made by $\mathrm{Mr}$. S. H. Collins at Durham College of Science gave the following results :-

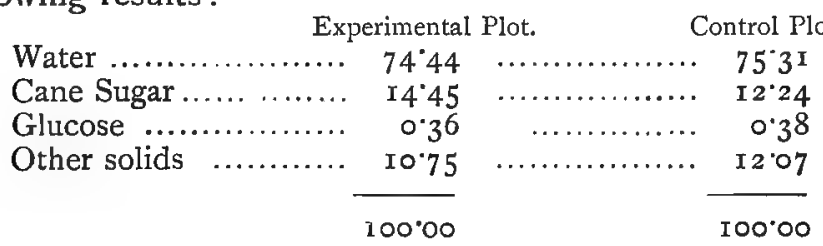

Or an increase of 2.21 per cent.-Or 18.05 per cent. of that of the control field - of cane sugar on the experimental field. This analysis agrees fully with an analysis executed in Burgundy in 1888 .

One kind of plant, the rye-grass, gave a negative result; but as all the experimental fields were situated lower than the control fields, the former received the water flowing from the latter, and, during such a summer as that of 1902, the effect of this was considerable. The control fields had also the advantage of having been more recently manured, 
and were, in consequence, in a better condition than the experimental fields.

Remarks. - The increased percentage of produce on the experimental plots compared with the control plots has here, as always, been determined in the following way:-

When the produce on the experimental plots is called $a$, and on the control plots $b$, the formula will be $\frac{(a-b) \text { roO }}{b}$ for the increase per cent. When the sign - is put before the figures in the tables, it signifies that the produce on the experimental plot has been less than on the control plot, the formula being, in this case, $\frac{(a-b) \text { IOO }}{b}=$ decrease per cent.

\section{GERMANY.}

Experiments at Kryschanowitz, NEAR BreslaU, Germany, by Dr. Otto Pringsheim. Summer, 1902.

Dr. Pringsheim, who employed a machine of the same size and type as that previously mentioned, obtained the following results from the electrical treatment :-

Increase per Cent.

Strawberries ......... 50. $0^{\circ}$

Carrots in Garden*. I $3^{\cdot I}$

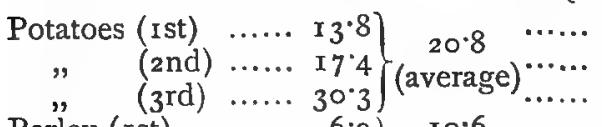

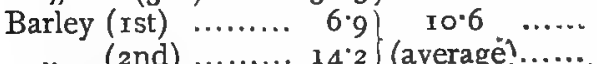

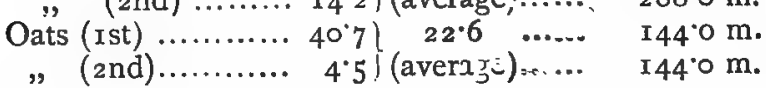

Area of Exp. Field $=$ Control Field.

I $3.4 \mathrm{~m}$.

No. of plants respectively 775 and 667 $8.84 \mathrm{~m}$. $144.4 \mathrm{~m}$. $144^{\circ} 4 \mathrm{~m}$. $288^{\circ} \circ \mathrm{m}$. $288^{\circ} \circ \mathrm{m}$.

The machine was driven by an electric motor fed by accumulators, and worked on an area of I, I 75 square metres.

The weather was about the same as at Durham College of Science, Newcastle, England, but perhaps a little warmer.

* The experimental field was more in shade than the control field. The part of the experimental field which was in shade gave shorter roots. 
The machine was at work about Io hours, mostly at night. By these experiments it is shown that the abnormal weather has exercised a fatal influence on the vegetation.

\section{SWEDEN.}

Experiments in Åtvidaberg, by Baron Theodore

Adelsvãrd. Summer, 1902.

Meslin (barley, oats, peas, \&c.) an increase of $20^{\circ} 9$ per cent. Beets (cattle food)

Carrots

$" \quad " \quad 26.5 \quad ", \phi$

The machine worked here on an area of $3^{\circ} 40$ ha. $=8.4$ acres.

As the insulated wire net in these experiments had a great extension, their signification with regard to the use and application of the method is very important; but the rainy and cold weather caused much damage, so that it was almost impossible to obtain sure results. The rain was so abundant that the ground here and there could not absorb all the water, and, in consequence, the vegetation showed an inequality which made the comparison of the two fields very uncertain.

\section{ENGLAND.}

\section{Experiments at Durham College of Science,} NeWCASTlE-ON-Tyne. Summer, I903.

The results of these experiments were as under :Date of harvest 1903 . Crop.

-Crop per cent.--

Tops or straw per cent. $\begin{array}{lllllllll}\text { Oct. I6 .. Turnips ...... } 99^{\circ} \circ & \ldots & 49^{\circ} 5 & \ldots & 99^{\circ} 2 & \ldots & 67^{\circ} \circ\end{array}$ $\begin{array}{llllllll} & 16 . . . \text { Sugar Beets.. } 40^{\circ} 0 & \ldots & 49^{\circ} 6 & \ldots & 60^{\circ} 3 & \ldots & 66.6\end{array}$ $\begin{array}{llllllllll} & 13 . . . & \text { Mangels ...... } & 0.2 & \ldots & 33^{\circ} 2 & \ldots & 20^{\circ} 9 & \ldots & 39^{\circ} 8\end{array}$ Sept. $22 \ldots$ Rape ........ $27^{\circ} 6$

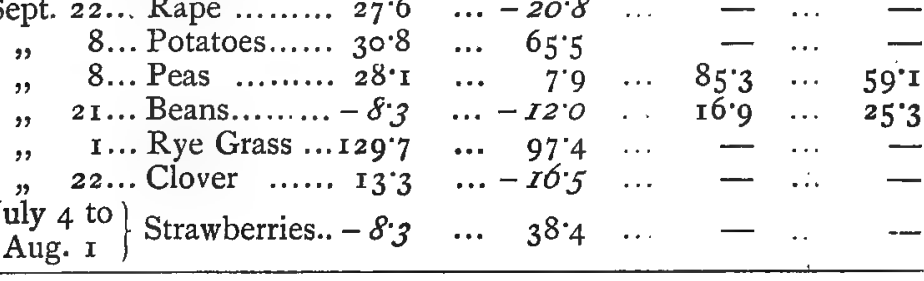

* Other plants which were under treatment could not be examined, and are, therefore, omitted. 
Second experimental and control plots gave for potatoes, -26.5 per cent. ; peas, 9.4 per cent. ; pea straw, $-2 \mathrm{I}^{\circ} 4$ per cent. ; beans, -8.9 per cent. ; straw -0.3 per cent.

The machine worked on an area of $100 \mathrm{~m}^{2}$.

It is shown by this table that turnips, rape, peas, rye grass and clover have been improved by the watering, but not so sugar-beets, mangels, potatoes and strawberries, on all of which watering had a marked deleterious influence. Especially was this the case with strawberries, the experimental plot of which had suffered much from the rain in the summer of 1902.

On the unwatered control plot the harvest of strawberries was, to July 20 th, II $870 z$; on the unwatered electrified plot, on the contrary, 18.250z., which shows the earlier ripening of the fruits on the electrified plot.

Remarks.-In considering the results of these experiments it must be kept in mind that the control field had not been manured within the last four years, while the field in which were the experimental plots had not been manured during the last five years, or a year earlier. The experimental plots also lie about $0.3 \mathrm{~m}$. lower than the control plots, and, therefore, may have lost more by washing during the rainy season of 1902 than the higher lying plots. The remainder of the active force of the soil, which evidently existed chiefly at the bottom, was therefore carried away in a higher degree from the experimental than from the control fields. The soil on these fields was mixed in the spring of 1903, but as this could not reach the bottom itself the experimental squares were in a more unfavourable position than the control squares. The whole field should have been manured in order to produce the best result from the electrical treatment, but the manuring was omitted in order to prevent inequality in the sub-soil.

The soil was too pcor to give a high increase per cent., for it is the general rule that the richer the soil and the more luxuriant the vegetation the greater the influence of the electrical current upon the produce. 
With the turnips and the sugar beets the surplus of leaves is equal to the surplus of roots, while with the mangold this is not the same, and with the peas and beans the straw and the stalks are far more developed than the fruit itself; this with the peas has given a positive result, but with the beans a negative one. This shows that the soil has become poorer and yet poorer on the experimental fields than on the control fields, and this is confirmed by the circumstance that on the second experimental field potatoes and beans have given negative results and peas a low positive one. This poverty of the soil appears most striking in the reduction of the percentage of sugar, which the chemical analysis shows, concerning sugar beets, to be :-

Control Experimental ---Increase.

fields. fields. Absolute. Relative.

Per cent. Per cent. Per cent. Per cent.

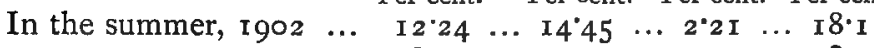

$\begin{array}{lllllllllll}\prime \prime & \quad & \text { r903 } & \ldots & 8.71 & \ldots & 9.43 & \ldots & 0.72 & \ldots & 8 \cdot 3\end{array}$

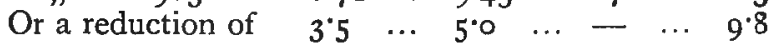

GERMANY.

EXPERIMENTS IN KRYSCHANOWITZ, NEAR BRESLAU.-

Summer, 1903.

Per cent. Per cent.

Strawberries showed an increase of ... $\quad$ I $28^{\circ} 0$

Sugar beets ......... No. I increase

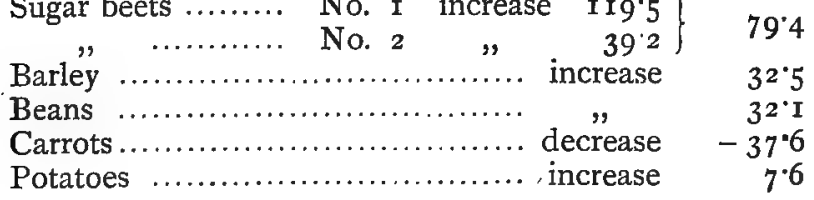

The machine actèd upon an area of $517 \mathrm{~m}^{2}$.

Owing to a misunderstanding the machine had got a velocity about four times greater than was necessary. This acted badly upon the carrots, which were not watered. This crop has always, under such circumstances, given a negative result. Whether this too great velocity had any noteworthy influence on the other plants cannot 
be ascertained with certainty. On both the experimental and the control field in the results given under No. 3 (sugar beets), the earth had been mixed, and again laid out in equal quantity on both fieldis. A chemical analysis of the sugar beets, duly made in a sugar refinery, gave an increase of the percentage of sugar from I4. $I$ to I $5^{\prime} I$, or $7 \cdot 24$ per cent. of the whole.

Remarks.-This quality of the electric air current (or electrical treatment) of increasing the percentage of sugar in the sugar beets has occurred in the following cases:-

At Durham College in $1902 \ldots \ldots \ldots \ldots \ldots . .2 .21=18.05$

" $"$ in $1903 \ldots \ldots \ldots \ldots \ldots .72=8.4$

In Åtvadaberg in $1903 \ldots \ldots \ldots \ldots \ldots \ldots \ldots . \ldots \ldots \ldots$

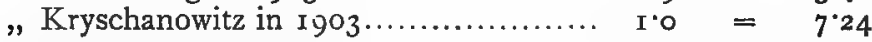

We may regard it, therefore, as sufficiently proved.

\section{SWEDEN.}

ThE EXPeriments in ÅtVADABerg.-Summer, I903.

We give below a table showing the function of the machine during the different months:-

\begin{tabular}{|c|c|c|c|c|c|c|}
\hline $\begin{array}{l}\overbrace{\text { Nor }}^{\text {Wor }} \\
\text { days. }\end{array}$ & $\begin{array}{l}\text { king.- } \\
\text { No. of } \\
\text { hours. }\end{array}$ & $\begin{array}{l}\text { No. of } \\
\text { hourss } \\
\text { in day. }\end{array}$ & & $\begin{array}{l}0.0 \\
\text { ys A }\end{array}$ & $\begin{array}{l}\text { rkin } \\
\text { No. } \\
\text { lays }\end{array}$ & \\
\hline (from 23 rd) 9 & I 50 & 16.7 & $\ldots$ & 0 & 0 & \\
\hline une $\ldots \ldots \ldots \ldots 26$ & $45^{\circ}$ & I 7:3 & $\ldots$ & 2 & 2 & $\mathrm{I}, 2,3, \mathbf{I} 8$ \\
\hline$\ldots 23$ & $3^{69}$ & $16 \cdot 6$ & & $\mathbf{I}$ & 7 & $3,7,16,17,20-23$ \\
\hline$\ldots 17$ & 3 I I & I $8 \cdot 2$ & & 8 & 6 & I $5-I 7,23-27$ \\
\hline pt. (until I 4th) 5 & 97 & I9:4 & ... & 7 & 2 & $2,7-I I, I 4$ \\
\hline
\end{tabular}

A, On account of rain. B, from other causes.

From September I 5 th no attempt was made to use the machine.

We see by this table that the machine by the month of July begins to show slight irregularities, but that the greatest irregularities occur in the latter part of August and in September. Therefore it seems to serve a practical purpose to divide the plants which were under treatment 
into two groups. In the first group come corn, rye, barley, oats and meslin, and in the second group the root crops-potatoes, sugar beets, carrots and beets. The former were reaped in the month of August (oats the I $4^{\text {th }}$ September), the latter in the first week of October, except the potatoes, which were reaped in the middle of September. The most important time of development comes, for the former in the months of June, July and August, for the latter in July, August and September. The machine worked very well during the months of May, June and July; but during August and September together for not more than 22 days out of $6 \mathrm{I}$, of which $\mathrm{I} 7$ days were during August and only five days during September. These circumstances appear clearly from the tabulated results.

For each kind of plants three squares of $16 \mathrm{~m}^{2}$, situate as shown in Fig. 4 (middle part), page 20, were chosen for the experimental field, and three squares situated in the same way for the control field, within a distance of about $5 \mathrm{~m}$. In each pair of squares (except for the rye, which was autumn corn) the earth from both fields was dug to a depth of $30 \mathrm{~cm}$, mixed, and laid out afresh in equal quantity on each square.

The machine acted upon an area of $4^{\circ} 03$ hectares, and the large extension of the wire net in these experiments will give them a particular interest.

\section{The First Group-Corn.}

From Åtvidaberg I got samples of all species of corn which had been under electrical treatment. There were two samples for each species, one taken from the harvest on the experimental field, the other from the harvest on the control field. The weight of the sample was about $80 \mathrm{gr}$. All the flattened and half grains, and of the oats and barley all those without a shell, having been picked out, 
these samples had to undergo treatment in a separator constructed for the purpose.*

The rye was thus divided into three qualities-Ist, and and 3 rd quality-and each had a weight of 1,000 grains. Barley and oats were only in Ist and 2nd qualities.

The operation was as follows: The corn from the control field was at first separated, the threads of the spiral having been disposed of at a convenient distance from each other. Then the corn from the experimental field was separated, the distance between the threads of the spiral being the same.

\section{Rye.}

From the field sown in the autumn of 1902 squares were taken for the experimental field as well as for the control field. The harvest, calculated by the hectare ( 247 acres) was :-

\begin{tabular}{|c|c|c|c|c|c|c|c|c|}
\hline \multirow[b]{2}{*}{ - } & \multirow[b]{2}{*}{$\begin{array}{l}\text { Crop } \\
\text { kg. }\end{array}$} & \multirow{2}{*}{$\underset{\mathrm{kg} .}{\text { Straw }}$} & \multicolumn{2}{|c|}{ Ist Quality. } & \multicolumn{2}{|c|}{ 2nd Quality. } & \multicolumn{2}{|c|}{ 3rd Quality. } \\
\hline & & & $\begin{array}{c}\text { Per } \\
\text { cent. }\end{array}$ & \begin{tabular}{|c|} 
Weight \\
of I,ooo \\
grains \\
in g.
\end{tabular} & $\begin{array}{l}\text { Per } \\
\text { cent. }\end{array}$ & $\begin{array}{l}\text { Weight } \\
\text { of r,ooo } \\
\text { grains } \\
\text { in g. }\end{array}$ & $\begin{array}{l}\text { Per } \\
\text { cent. }\end{array}$ & $\begin{array}{l}\text { Weight } \\
\text { off,roo } \\
\text { grains } \\
\text { in g. }\end{array}$ \\
\hline & $\begin{array}{l}\mathrm{I}, \mathrm{g} \\
\mathrm{I}, \mathrm{C} \\
\mathrm{I} 9\end{array}$ & & $\begin{array}{r}47^{\circ} \cdot 6 \\
38^{\circ} 3 \\
9 \cdot 3\end{array}$ & $\begin{array}{r}28.85 \\
27^{\circ} 04 \\
\mathrm{I} \cdot 8 \mathrm{I}\end{array}$ & $\begin{array}{l}27.8 \\
3^{2} \cdot 5 \\
-\end{array}$ & $\begin{array}{l}22^{\circ} .03 \\
21^{\circ} 7^{2}\end{array}$ & $\begin{array}{l}24^{\circ} 5 \\
29^{\circ} 2 \\
-\end{array}$ & $\begin{array}{l}16.3^{8} \\
16.04 \\
-\end{array}$ \\
\hline
\end{tabular}

The electric air currents had thus augmented the rye harvest by 19.5 per cent. and improved the quality of the corn so that we obtained of Ist quality 9.3 per cent. more on the experimental field, or under the current, than on the

* The separator consisted of a spiral cut out of a brass tube (I2.2 $\mathrm{cm}$. long and $57 \mathrm{~cm}$. in diam.), which could be shortened or lengthened. Through this the distance between the threads of the spiral could be enlarged or diminished as required. The threads of the spiral had a breadth of $0.36 \mathrm{~cm}$. and a thickness of $0.18 \mathrm{~cm}$., and their edges were kept sharp. The spiral was furnished with bottom ends with circular holes in the middle, and was, when in a horizontal position, pushed on to the axis of a centrifugal machine, which was kept by an electric motor in slow rotation (I revolution in 2 seconds) to avoid the effect of centrifugal force. 
control field. But, besides that, the weight of $1, \infty 00$ grains had augmented by 1.81 gr. on $27^{\circ} 04$, or by 6.7 per cent.

According to the statement of the Manager, Mr. Tillberg, the yearly average of produce per hectare for the three last years was in Atvidaberg $2,347 \mathrm{~kg}$, and was this year 3I. 7 per cent. lower than this average. This circumstance also caused a diminishing of the increase per cent., according to the rule already mentioned that "the better the vegetation the higher the increase per cent.".

\section{Barley.}

This crop was sown on the experimental and control fields on which the soil had been, as above mentioned, mixed. Calculated per hectare, there was obtained :-

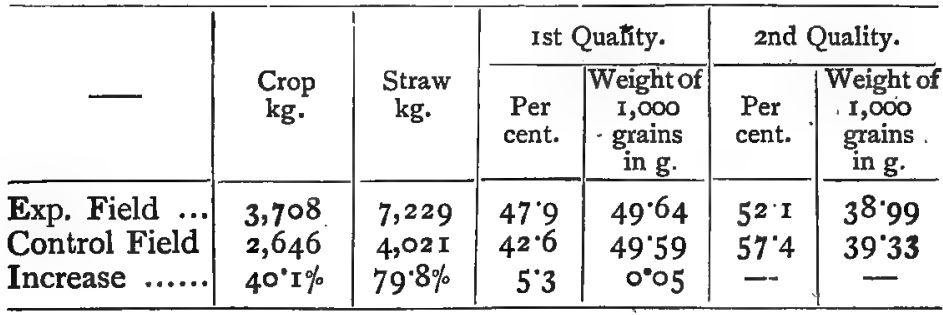

The barley had thus given a surplus crop of $40^{\circ} \mathrm{I}$ per cent. and a 5.3 per cent. increase of first quality on the experimental as against the control field. The surplus weight of $\mathrm{I}, 000$ grains is here only $0.05 \mathrm{~g}$.

Oats.

The experimental and control fields were treated in the same way as for barley. The harvest, calculated per hectare, was :-

\begin{tabular}{|c|c|c|c|c|c|c|}
\hline & \multirow[b]{2}{*}{ - Crop } & \multirow[b]{2}{*}{$\begin{array}{c}\text { Straw } \\
\text { kg. }\end{array}$} & \multicolumn{2}{|c|}{ Ist Quality. } & \multicolumn{2}{|c|}{ 2nd Quality. } \\
\hline & & & $\begin{array}{c}\text { Per } \\
\text { cent. }\end{array}$ & $\begin{array}{l}\text { Weight of } \\
\text { I,ooo } \\
\text { grains } \\
\text { in } \dot{g} .\end{array}$ & $\begin{array}{l}\text { Per } \\
\text { cent. }\end{array}$ & $\begin{array}{l}\text { Weight of } \\
\text { I, }, 00 \\
\text { grains } \\
\text { in g. }\end{array}$ \\
\hline Exp. Field ... & 2,271 & 2,521 & $76 \cdot 5$ & $50 \cdot 20$ & 23.5 & $27 \cdot 16$ \\
\hline $\begin{array}{l}\text { Control Field } \\
\text { Increase ...... }\end{array}$ & $\begin{array}{l}1,25^{8} \\
16.0 \%\end{array}$ & $\begin{array}{l}2,521 \\
0^{\circ} 0 \%\end{array}$ & $\begin{array}{r}67 \cdot 9 \\
8 \cdot 6\end{array}$ & $\begin{array}{r}49.45 \\
0.75\end{array}$ & $32^{* 1}$ & $29^{\prime} 44$ \\
\hline
\end{tabular}


The harvest of oats shows the singularity that the harvest of straw is the same on both fields, although there is an increase of crop of $160^{\circ}$ per cent. For the other species of corn the increase of crop is accompanied more or less by an increase in straw. The explanation partly lies in the improvement of the crop which the electric air current had caused (the percentage of first quality on the experimental field exceeding that on the control field by $8.6 \%$, and also the weight of 1,000 grains on the former field over that of 1,000 grains on the latter by $0.75 \mathrm{~g}$.) ; but this does not seem sufficient to explain the above-mentioned singularity. We must therefore suppose that the number of grains of oats on each straw has been greater on the experimental field. A fault in the drainage of this field was observed during the summer, which had reduced the fertility of the field, and thus a falling off of the increase per cent.

\section{Meslin.}

This consisted of barley and oats, and occupied the greatest part of the field, or $2^{\circ} 52$ hectares $(=5.06$ acres $)$. It was observed that the net over this field became from time to time in contact with the plants, and had to be carefully looked after in this respect. During these interruptions the current was stopped; thus the current acted for a shorter time on this field. Another cause of the shortening of time was that the net was twice destroyed by straying horses. On the first occasion the damage was repaired in nine days, so that the current was not operating upon this field from May 3 Ist to June $\mathrm{I}$ Ith (in all twelve days, of which three days was from another cause). The second time there was no current from June 29th to July ist.

For the meslin there were two experimental fields and two control fields, of the same size and quality as for 
barley and oats; and again, on these fields the soil was mixed. The samples were taken from both fields, which we will call A and B. For the purpose of examining the corn, the oats were separated from the barley, and showed the following proportions :-

\begin{tabular}{|c|c|c|c|c|}
\hline & \multicolumn{2}{|c|}{ A } & \multicolumn{2}{|r|}{ B } \\
\hline $\begin{array}{l}\text { Barley ....... } \\
\text { Oats ......... }\end{array}$ & $\begin{array}{c}\text { Exp. Field. } \\
\text { Per cent. } \\
64^{\circ} 5 \\
35^{\circ} 5\end{array}$ & $\begin{array}{c}\text { Cont. Field } \\
\text { Per cent. } \\
57^{\cdot 8} \\
42 \cdot 2\end{array}$ & $\begin{array}{c}\text { Exp. Field. } \\
\text { Per cent. } \\
34^{\circ} \mathrm{r} \\
65^{\circ} 9\end{array}$ & $\begin{array}{l}\text { Cont. Field. } \\
\text { Per cent. } \\
33^{\circ} \circ \\
67^{\circ} \circ\end{array}$ \\
\hline
\end{tabular}

From this we see that the barley on A represented about two-thirds and on B one-third, and the oats one-third and two-thirds respectively. After deciding the proportion between barley and oats, the corn was cleaned in the way previously mentioned. The harvest from the first fields was :-

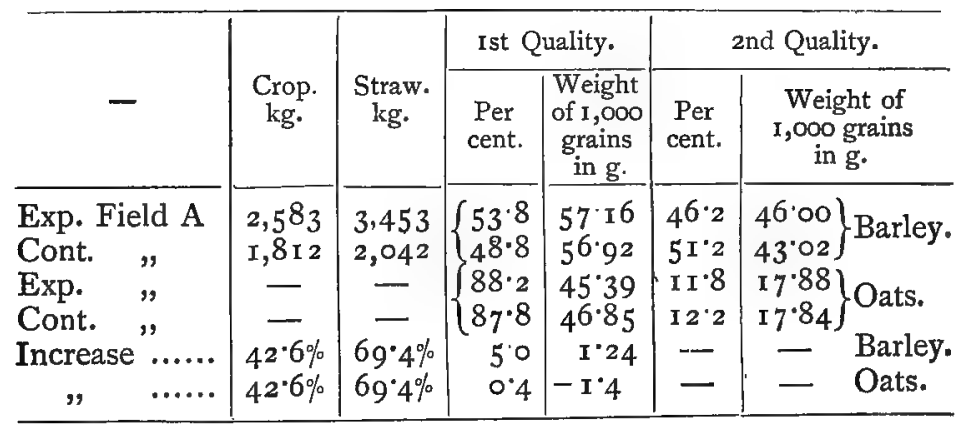

The meslin has thus given an increase of 42.6 per cent. for barley and oats together; but whilst the barley shows a surplus of 5 per cent. on first quality, the surplus for oats is 'only 0.4 per cent., which we may regard as equal zero; and while barley, for a weight of 1,000 grains, gives a surplus of $\mathrm{I} \cdot 24 \mathrm{~g}$, this is reduced for oats to a negative of $-\mathrm{I} 4 \mathrm{~g}$. 
On the experimental field $B$ the harvest was as follows :-

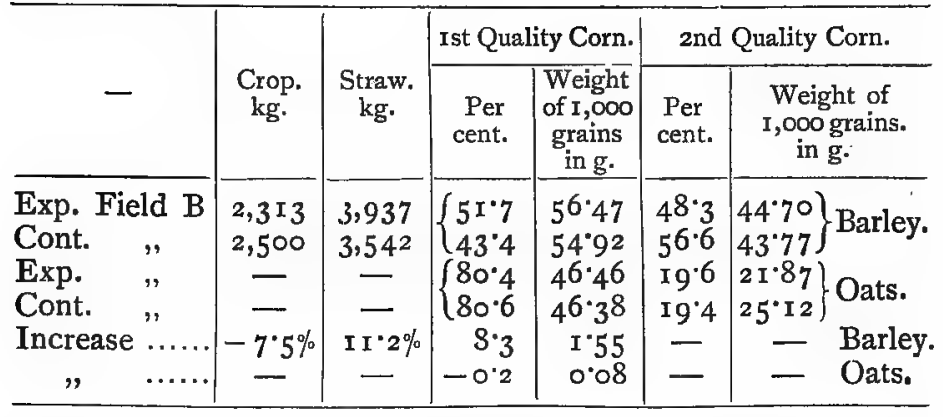

The barley on the experimental field $B$ thus gave a surplus of 8.3 per cent. first quality and of $\mathrm{r} .55 \mathrm{~g}$. in the weight of $I, 000$ grains, whereas the corresponding quantities for oats were -0.2 and 0.08 ; or almost equal to zero. Oats, which, when cultivated alone, show so important an improvement as 8.6 per cent. increase in first quality and $0.75 \mathrm{~g}$. in the weight of 1,000 grains, show, when cultivated along with barley, under electrical treatment, no such improvement, which is a most remarkable result. Probably the cause is that the barley was grown taller than the oats, and thus received more of the electric current. The whole quantity of oats is, nevertheless, increased in the same proportion as the barley.

These two second experimental and control fields give a negative result of $-7^{\circ} 5$ per cent. in crop, but I I 2 per cent. surplus in straw. The cause of this lies in the exceptionally large harvest which the second control field has given, this surpassing the harvest from the first control field by $688 \mathrm{~kg}$., or about 38 per cent., and the yearly average harvest of meslin, which during the last three years had been $2,047 \mathrm{~kg}$. per hectare, by $453 \mathrm{~kg}$, or 22' I per cent. This unusual fertility seems to depend on chance, and therefore the results of the second experimental and control fields are wholly excluded from the account, especially as the barley 
on this experimental field shows the same improved qualities as that on the first experimental field.

We must now call attention to the difficulties which always arise in the choice of experimental and control fields. Already at these experiments, which embrace only four different cornfields, accidental circumstances have, in two cases, diminished the increase per cent. or have transformed this into a minus quantity. In the first case it was a fault in the drainage, in the second case an unusually great fertility of a control field. And this notwithstanding the previous careful mixing of the soil. Unfortunately, the quality of the subsoil seems to be of such great consequence to the success of the experiments that this method has not been a sufficient safeguard. It will therefore be necessary to improve the method to ensure a regular increase per cent. (see pages 33 and 37).

If all circumstances are taken into consideration we must conclude that the increase per cent. during 1903 has been between 35 and 40 per cent. for the corn crop, added to the improved quality of the corn, shown not only by the Tables above, but especially by the chemical analysis of the crops (pape 60).

Second Group Roots.

\begin{tabular}{|c|c|c|c|c|c|}
\hline \multirow[b]{2}{*}{ Crop. } & \multirow[b]{2}{*}{$\begin{array}{l}\text { Increase } \\
\text { per cent. }\end{array}$} & \multicolumn{2}{|c|}{ On the Exp. Field. } & \multicolumn{2}{|c|}{ On the Control Field. } \\
\hline & & $\begin{array}{l}\text { No. of } \\
\text { Roots. }\end{array}$ & $\begin{array}{l}\text { Mean } \\
\text { Weight } \\
\text { of One } \\
\text { Root } \\
\text { in g. }\end{array}$ & $\begin{array}{l}\text { No. of } \\
\text { Roots. }\end{array}$ & $\begin{array}{l}\text { Mean } \\
\text { Weight } \\
\text { of One } \\
\text { Root } \\
\text { in g. }\end{array}$ \\
\hline Potatoes ..... & $4 \cdot 8$ & $\ldots$ & $\cdots$ & $\cdots$ & $\ldots$ \\
\hline Sugar beets ... & $6 \cdot 22^{*}$ & $39^{8}$ & 357 & 406 & 337 \\
\hline Fodder beets & -24 & $3 \circ 5$ & 803 & 326 & 823 \\
\hline Carrots ......... & $-8 \cdot 9$ & 578 & $35^{8}$ & 549 & 393 \\
\hline
\end{tabular}

A chemical analysis of the sugar beets gave as the percentage of sugar of the beets from the experimental field an

* The increase per cent. is determined by the mean weight of one root. 
increase of 1 ' 9 per cent, or from 14.2 per cent. to I $6 \cdot 1$ per cent., which makes 13.4 per cent. increase on the percentage of sugar in the sugar beets from the control field.

The increase percentages are small for potatoes as well as for sugar beets, and it comes near the fact to suspect the cause to be a greater fertility of the control fields, in analogy with the second experimental and control fields in the case of the meslin. It is known with certainty that, on the mixing of the soil, the subsoil of the fields showed very different constituents. In favour of this view also there is the negative result with the fodder beets, which always previously have given a fairly high increase per cent. If the fertility of the two fields had been the same, and if the electric air-current had had no effect, the harvest ought to have been the same from both fields, but the negative result shows a smaller fertility of the soil of the experimental field. Carrots, which have always been a delicate crop, cannot here serve as a proof.

At all events, the summer was so wet in the latter half of August and the earlier part of September that the condition of the subsoil had a marked influence on the fertility of the soil. That the electric current had exercised an influence on the roots during a long period, and ought thus to have produced a higher increase per cent., if both fields had been of an equal fertility, is shown by the great increase of the percentage of sugar in the sugar beets, for such a condition is not produced suddenly.

The chief cause, however, of the low ncrease per cent. lies in the circumstance that the influence machine from ist August to I 5 th September had not been at work for more than 22 days, hence there were 23 days of inactivity. From 15th September to 8th October, or 23 days further, the machine was out of use owing to a misunderstanding of the skilled manager in Atvidaberg, Mr. Tillberg, who, with never-failing interest, exercised the supervision and direction of these experiments. He reported on the I 5 th September 
that, because only sugar beets, fodder beets and carrots were unripened, he did not think it worth while to let the machine work. There were in all 46 days of inactivity, among them 15 rainy days, during which it was indifferent whether the machine worked or not. Altogether, therefore, we have $3^{8}$ days when the machine was out of use. There was a further eight days of inactivity, three being in consequence of necessary repairs and three days because of great conducting power of the air due to its humidity.

During two of the eight days this humidity of the atmosphere caused another difficulty, due to radio-activity. This quality of the air was discovered by Elster and Geitel in I902-1903, and acts chiefly in such a manner that the air has a great conducting power for electricity. When this condition of the air arrives the only thing to do is to wait for its cessation, which happens generally after some few hours, or at most one day. During June and July it occurred but three times. Mr. Tillberg tried to neutralise the effect of this radio-activity by putting new cylinders on the machine and by varnishing the old cylinders, \&c. This work might have been avoided, however, for, after having ascertained conclusively that the air in the room is quite dry, and after having given the cylinders a careful drying by warming them, we can but wait for the cessation of the conducting power in the air before resuming operations.

According to information from Àtvidaberg, the weather during the latter part of September was not actually wet, but humid. It is, therefore, probable that the machine could have been kept in activity during 14 days more. Remembering that the effect of the electric air current is nearly the same as that of sunlight, it is very likely that a continuance of the electrical air current treatment during these two weeks would have augmented to a perceptible degree the increase per cent. of the roots. One consequence of the experiments this year is evident, namely, the necessity of improving the method of control. (See pages 33-34.) 
We will now make a comparison between some of the plants which on the different places have been under treatment during I903.

\begin{tabular}{|c|c|c|c|c|c|}
\hline \multirow{2}{*}{ Place. } & \multicolumn{3}{|c|}{ Increase per cent. } & \multicolumn{2}{|c|}{$\begin{array}{l}\text { Increase per cent. of } \\
\text { sugar in sugar beets. }\end{array}$} \\
\hline & Barley. & Sugarbeets. & Potatoes. & Absolute. & Relative. \\
\hline Kryschanowitz & $\begin{array}{c}\text { Per cent. } \\
3^{2} 5\end{array}$ & $\begin{array}{c}\text { Per cent. } \\
79^{\circ} 7\end{array}$ & $\begin{array}{c}\text { Per cent. } \\
7.6\end{array}$ & $\begin{array}{c}\text { Per cent. } \\
\text { I'o }\end{array}$ & $\begin{array}{l}\text { Per cent. } \\
\qquad 7^{\circ} 2\end{array}$ \\
\hline lege, England & $\cdots$ & $49^{\circ} 6$ & $65^{\circ} 5$ & 0.7 & $8 \cdot 4$ \\
\hline Ätvidaberg ... & $40^{\circ} I$ & $6 \cdot 2$ & $4 \cdot 8$ & $I^{\circ} 9$ & I 34 \\
\hline
\end{tabular}

As the machine has worked in these places on very different areas we could understand if the increase per cent. had a relation to the area; but this is not the case, for in Kryschanowitz, near Breslau, where the machine worked on an area of $517 \mathrm{~m}^{2}$, there was an increase per cent. of barley of 32.5 per cent., whilst in Atvidaberg, where the machine worked on an area of $40,300 \mathrm{~m}^{2}$ ( 4.03 hectares), the same crop gave $40^{\circ} \mathrm{I}$ per cent., or 7.6 per cent. more. W'e must therefore conclude that the wet weather which prevailed in Àtvidaberg during August and September caused this small increase of the roots, and also that a greater fertility prevailed there on the control fields for the same plants. This remarkable fact is also observable in the harvest of potatoes. In Kryschanowitz there was $7^{\circ} 6$ per cent., and in Átvidaberg $4^{\circ} 8$ per cent. ; but at Durham College, where the machine worked on an area of only $100 \mathrm{~m}^{2}$, the increase was 65.5 per cent. The machine at Kryschanowitz had a speed of 3.5 turns per second, at Atvidaberg 2.5 turns, and at Durham College about I'O turns ; the quantity of electricity generated, and therefore distributed, is almost proportional to the number of turns per second.

The main cause contributing to this unequal result is, without doubt, to be found in the inequality of the soil of the experimental and control fields, and therefore it is 
necessary to improve the method of controlling, as previously stated.

If all the above enumerated conditions had been duly attended to during the experiments, it is very probable that the increase per cent. for the roots would have been about the same as for the crops, in addition to the improvement in the quality of the roots.

It is a great pleasure to me to express to the professors and teachers at Durham College of Science, England, my best thanks for all their kindness in assisting me, but especially to $\mathrm{Mr}$. R. B. Greig, who has given me so much of his valuable time; and to Dr. Thornton, who helped me with the arrangement of the electric motor and its adaptation for my purposes. Mr. Greig having been transferred to the University of Aberdeen, Prof. Gilchrist had the kindness to allow the experiments to be continued, and Mr. Bryner Jones undertook the onerous task of supervising the experiments and sending me the results. For all this I beg to express to them my best thanks.

To Dr. Pringsheim, to whom I stand in such great obligation, not only for the indefatigable care he devoted to the experiments and to their carrying out at Breslau, but also for the great kindness and hospitality shown me by Mr. and Mrs. Pringsheim during my stay in Breslau, and particularly at Kryschanowitz, I am very happy to express my sincerest thanks.

It is also a pleasant duty to me to express my deep thankfulness to Baron Adelsvärd for his goodwill and assistance in placing his land at my disposal for the experiments. I am all the more grateful to Baron Adelsvärd, as he gave me a conscientious and active assistant in the person of his skilled and interested manager, Mr. Knut Tillberg, who carried out and supervised in an able manner the experiments, and also provided me with all necessary workmen for my purpose. 


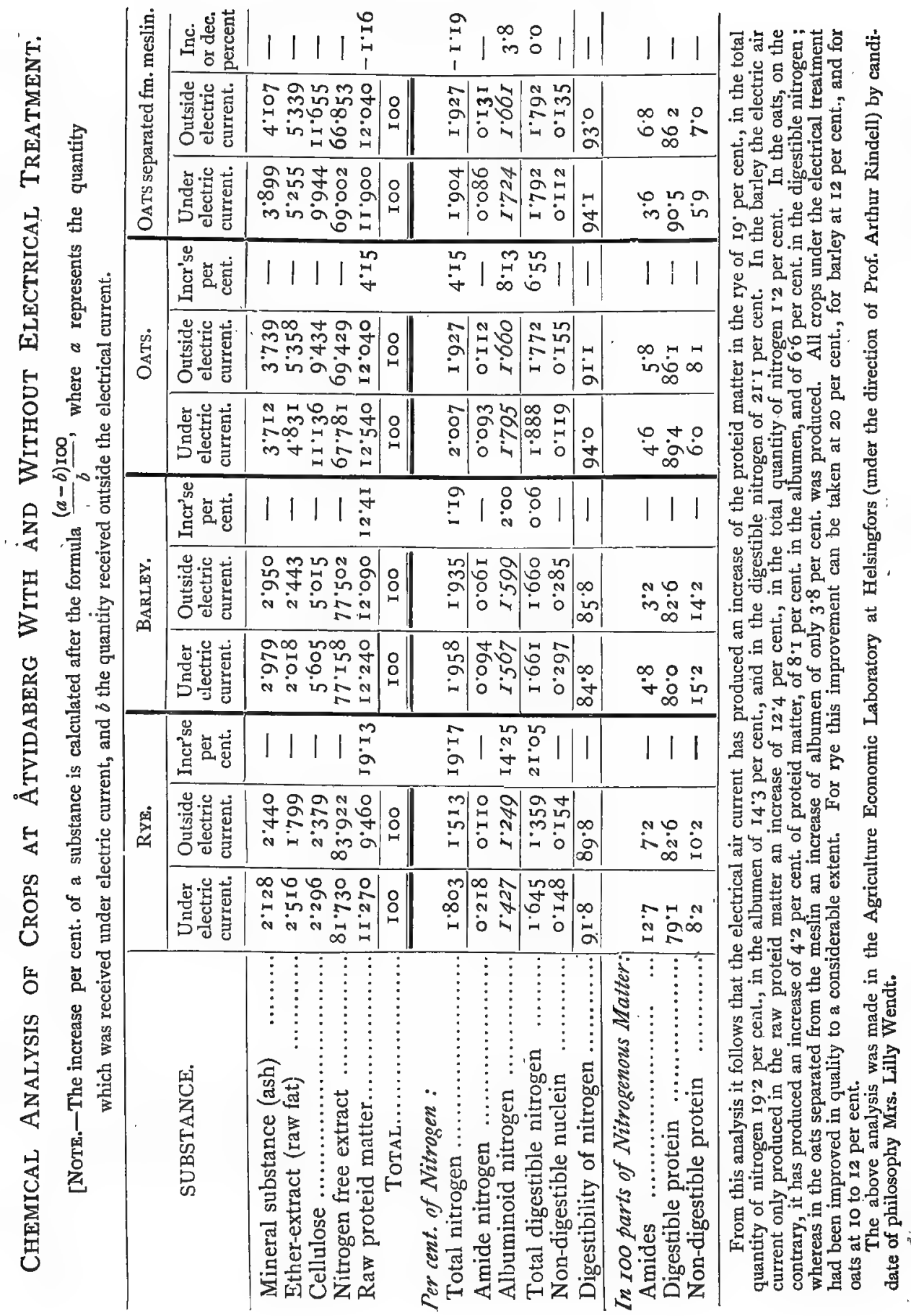





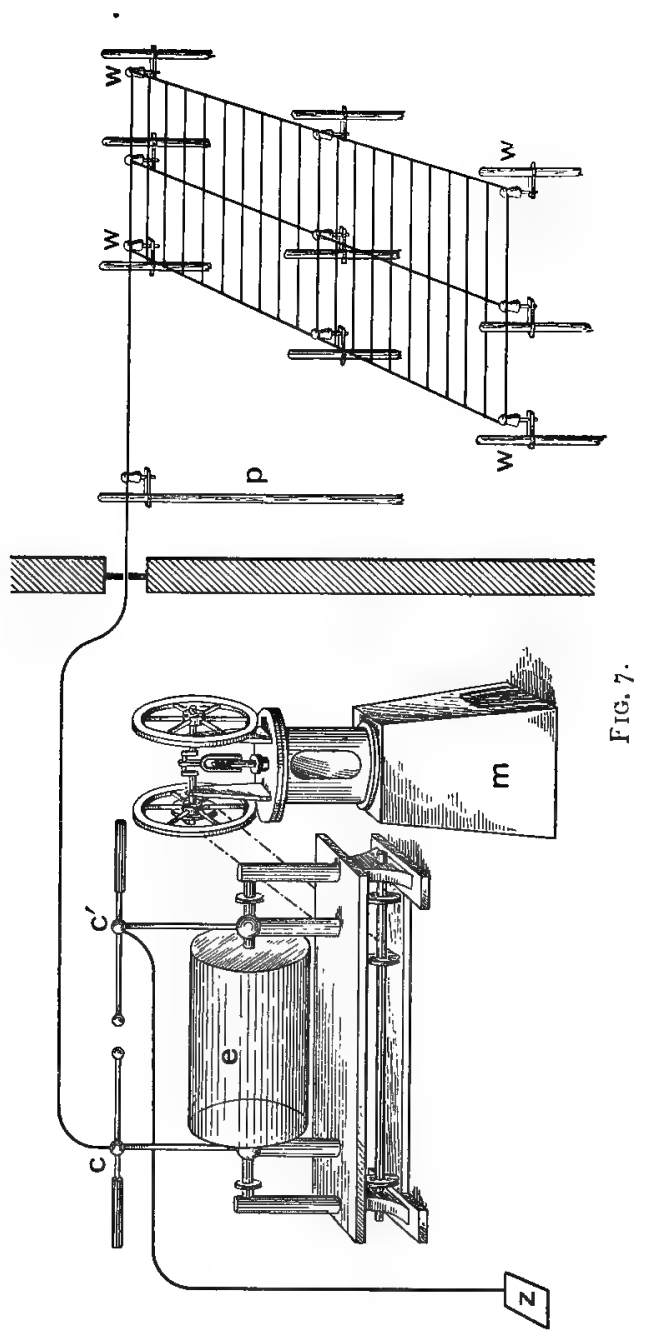

5
5
5
5
0
5
5
0 


\section{RULES FOR APPLYING THE ELECTRICAL AIR-CURRENT ON GROWING PLANTS.}

Introduction.-The principal manner in which electricity, or an electrical air current, exercises its influence on growing vegetables has been discovered to consist (I) partly in producing ozone and nitric compounds and introducing them into the capillary tubes of the plants when the current is going from the points of the wire-net to the earth (positive); and (2) partly in drawing up the sap from the roots upwards when the current is going from the earth to the points (negative), ${ }^{*}$ the former effect being about 30 per cent. greater than the latter. If we suppose that the former or positive current is applied, it will be easy to apply it for the purpose, and to give clear rules for this application. The lengthy experience I have had in these experiments enables me to give these rules, which, if they are intelligently applied, will lead to favourable results.

I.

The whole scheme of the experiments will be easily understood from the diagram (Fig. 7) on the opposite page.

From the positive pole $c$ of the influence machine is coriducted an insulated copper wire through a hole in an ebonite disc fixed in the wall, over the posts $p$ to the insulated wire net $w w w w$ over the growing plants. The negative pole $c$ is conducted to a zinc plate, $z$, in humid soil. Following are details of :-

I. The electric influence machine, its installation, and the motor.

2. The experimental and control fields.

3. Putting the wire-net on the insulators and their fixing.

4. Remarks.

5. Cost of the experiments.

- See "On the State of Liquids in Capillary Tubes under the Influence of an Electrical Air-Current." By the Author. (See p. 34). 
II.

The Electric Infuence Machine and its Installation.-As the old machines of Holtz and Wimshurst have shown, especially on prolonged use, many inconveniences, I have constructed the type represented in Fig. 5 (facing p. $2 \mathrm{I}$ ), in which these inconveniences are, for the most part, removed. This machine consists of two cylinders of glass or ebonite, $E$, rotating in opposite directions, one within the other, and provided with metallic (tin) boats fixed on strips of tinfoil. Over the machine is placed a cover fitted with a drying apparatus not shown in the figure. The glass cylinders are covered with a special varnish to protect them from humidity, and the brushes are made of silver-thread.

The machine is best charged if first put in rotation by some turns in the wrong direction, the outer cylinder going from the brushes of the transverse conductor against the points of the collector, and afterwards in the right direction-that is to say, the outer cylinder rotating from the collector against the brushes, causing sparks to go between the separate spheres of the discharger. The spheres must be separated at least $2 \mathrm{~cm}$., and some sparks taken before the machine comes to full charge. In experiments on the land the machine must be installed in a dry room, preferably on an upper floor, but always some height over the soil. In this room the temperature must be kept always some degrees higher than the outside. In such places the drying apparatus referred to above is not necessary, but the cover must always be kept over the machine to protect it from dust.

The machine charging the positive pole must be connected to the insulated wire net by means of insulated copper wire, and the negative pole with a plate of zinc $\left(\mathrm{O}^{\circ} 5 \mathrm{~m}^{2}\right.$.) in humid soil.

The method of distinguishing the negative from the positive pole is simple. Take away the connection of the Leyden jars with the poles on the one side and also the 
conducting wire (to earth or the insulated wire net), and put the spheres of the discharger at a distance apart of about $I^{\prime} 5 \mathrm{~cm}$. If the machine is moved a stream of light is seen between the spheres, violet on the side of the negative pole, with a small bright spot on the sphere, white and very bright, on the positive side. The machine is easily made to perform this experiment. As the machine, when stopped, very frequently changes its poles, this experiment must always be repeated and the machine continue in motion before fixing the conducting wires.

The new machine does not give so long a spark as the older one, but the quantity of electricity generated and given out is much greater. If a machine of the new type, of medium size, with glass cylinders of $40 \mathrm{~cm}$. length and about $30 \mathrm{~cm}$. diameter, gives IOO, the Wimshurst, with plates of $45 \mathrm{~cm}$. diameter, gives only 27 , and in some cases only 22; while the old Holtz machine, with four plates $46 \mathrm{~cm}$., gives 30 . But the greatest advantage of this new type of machine is that it can be kept in motion for three months if necessary, cleaning the glass cylinders. between the tin strips with a linen cloth only being necessary from time to time. After long use the glass. cylinders must be thoroughly cleaned up and fitted afresh with new tin strips and boats, if necessary, and be also covered with new varnish.

The Motor-Any small motor-electric, hot-air or otherwise-is suitable to do the little work required to move the machine. If an electric motor is used it can be battery-driven. Small hot-air motors are suitable for this work. The machine, $b$, shown in the illustration (Fig. 7) has an output of $\frac{1}{10}$ th of a horse-power and costs about $t 8$ sterling, or, say, $\$ 4 \mathrm{I}$. It is easily managed.

The Field.-If the purpose is to apply the electricity in such a way that the results can be brought clearly forward for comparing the yield on two fields, of which the one 
is under electrical treatment (experimental field), the other serving as the control field, we have to observe the following points :-

\section{(a) CHOICE OF FIELD.}

The qualities of the soil must, as far as possible, be the same throughout the whole field-of the same composition, the same humidity, the same fertility, and of about the same height over a common level. The field must, further, be in the same way exposed to the sun, so that no shadow at all (e.g., from growing trees) falls upon it. We will suppose that the experiments are to be made on six kinds of plants, and we then divide the field into squares, as shown in Fig. 8.

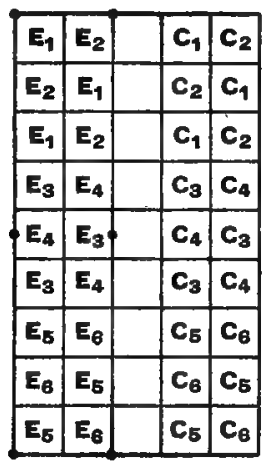

FIG. 8 .

The side of every square is $5 \mathrm{~m}^{2}$, making the area $25 \mathrm{sq} . \mathrm{m}$. When the experiments are made in a garden the squares can be arranged in two beds or layers, with a pathway between them. Such paths must be made between the ranges of squares. In Fig. 8 the squares marked $\mathrm{E}_{1}, \mathrm{E}_{2}$, \&c., represent experimental fields, and the squares marked $\mathrm{C}_{1}, \mathrm{C}_{2}$, \&c., the corresponding control fields. Between the two ranges of fields is left a space of $5 \mathrm{~m}$., which can be sown with any sort of plant, but must be out of consideration so far as the experiment is concerned. 
If we number the kinds of plants with which experiments are to be made,

$$
\begin{array}{llllll}
\text { I } & 2 & 3 & 4 & 5 & 6
\end{array}
$$

it is safest to sow them as indicated in the figure. The plants No. I are sown where we have $E_{1}$ and $C_{1}$, \&c. In such an arrangement we shall get three experimental fields and three control fields for every sort. If there is any inequality in the soil it will, for the most part, be eliminated by the results from the three fields."

The seed must, of course, be chosen with much care, and must be as equal às possible for both kinds of fields.

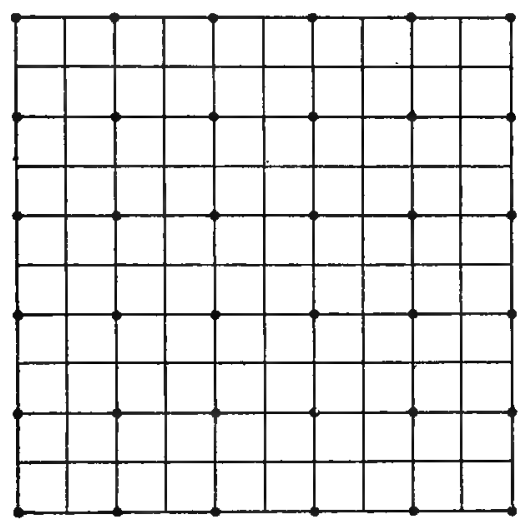

FIG. 9.

If a general application of electricity is to be given, the posts are to be fixed as shown in Fig. 9. In this figure the round dots signify posts provided with insulators, as described below. Along these insulators the wire is carried.

\section{III.}

Fixing the Wire Net and Insulators.-Along each range of the experimental squares posts, $25 \mathrm{~m}$. in length and about $6 \mathrm{~cm}$. in diameter, are rammed in the ground very firmly to a depth of $\frac{1}{2} \mathrm{~m}$. and at a distance apart of $143 \mathrm{~m}$.

\footnotetext{
* See the remarks made on pages 33 and 34 .
} 
Every corner-post must have on the inner side (the side of the experimental field) a short stout support to resist the strain of the iron wire. The insulators (Fig. Io) have now to be firmly fixed to the posts, pulting the ring $b$ around the post and drawing the screw.

When the insulators are well fixed, galvanised iron wire (of $\mathrm{I}^{\circ} 5 \mathrm{~mm}$. diameter) is carried with a medium tension along the posts, over the porcelain bell of the insulator. The wire is put round the bell and fixed with a separate short wire.

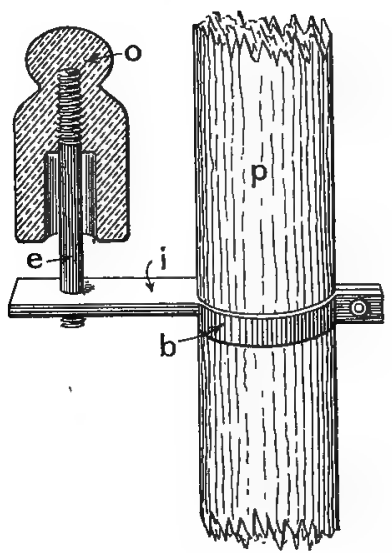

FIG. I0.- $b$, ring ; $e$, ebonite tube ; $i$, iron bar ; 0 , porcelain bell ; $p$, post.

When these conducting wires have been fixed all round the experimental field, cross-wires of about $0.6 \mathrm{~mm}$. diameter are laid on them from one side to the other at a distance of about $\mathrm{r} .25 \mathrm{~m}$., and in this way eight cross-wires cover ro $\mathrm{m}$. This finer wire must be furnished, at $\mathrm{I} \mathrm{m}$. apart, with small points $2 \mathrm{~cm}$. in length, nearly similar in appearance to the well-known barbed wire.

The wire net, being now fully insulated from the posts, is, as stated above, connected by means of a well insulated conducting wire to the positive pole of the electric machine, the negative pole being conducted to earth by means of a 
wire and a zinc plate. When the wire between the net and the machine is led through a wall it must be insulated with a round plate of ebonite $(4 \mathrm{~cm}$. diameter), as shown in Fig. 7.

After some sparks have been taken between the spheres of the discharger, the spheres are to be put in contact and the wires connected with $c$ and $c^{1}$. Here, after the spheres are separated, the wire net is charged. To prove this the spheres of the discharger are brought to within a short distance of one another ( $\mathrm{I} \mathrm{mm}$. or less), and a small spark will be seen between them, notifying that the net is charged, well insulated, and fitted for its purpose.

The height of the wire net above the plants must be about $0.4 \mathrm{~m}$. at its lowest point, and this height must be increased as the plants are growing. This raising needs to be done only once or twice, by loosening the rings of the insulators, lifting them up and again fixing them.

The wire net must be carefully examined to see that it does not touch the plants, as all the electric current will be conducted away by such contact.

As the electricity, if given in too large quantity, may damage the plants, especially if administered at periods of burning sumshine, it is best to apply the current on sunny days for only four hours in the morning (from $6 \mathrm{a} . \mathrm{m}$. or 7 a.m. to Io a.m. or II a.m.) and for four hours in the afternoon (from 4 p.m. or 5 p.m. to 8 p.m. or 9 p.m.).

On cloudy days, however, it can be given the whole day, and even during the night when the weather is moist. During rainy days it is useless to keep the machine in motion, because the wire net then loses its charge instantly.

In very dry periods, with burning sun, it is best to interrupt the applications of the electricity, or to administer for only one or two hours a day.

When the air is very moist the machine will speedily lose its charge, because the electricity is going from the wire net almost instantly. On such occasions it will be advisable 
to put the spheres of the discharger so near that sparks are intermittently passing between them. These sparks are very small, but they will keep the machine charged; a Leyden (Lane)* jar in the conductor to earth will have the same effect.

Remarks.-During the experiments with this installation attention must always be directed to the insulation of the wire net and the charging of the machine.

The insulators must be carefully observed every day, because spiders make their webs over from the wire net to the posts. This web must be cleared away.

When the electric machine is kept in a dry room, it will be charged at the first turns. In the summer it sometimes happens that the air in the room is colder than that outside. In this case a condensation of watery vapour begins within the machine, and its insulation is rlestroyed. (This has not hitherto been observed, because the older machines have never been used for continuous work, and have always been kept in an ordinary room with dry air.) The best course is, therefore, to put the machine, together with the motor, in a small room on an upper floor (about 2 square metres in area), provided with a small fireplace with the fire laid ready to be lighted, or a small heating apparatus with source of heat outside, care being taken that the temperature inside the room is always two or three degrees higher than that outside.

The best method to observe, with regard to the supply of the electric current, is to construct, as it were, a central supply station, to branch out conductors $5 \mathrm{~km}$. on all sides around it, and to sell the electricity as an ordinary article of commerce. In this way the cost of current will be ascertainable, and this is most desirable from all points of view.

\section{COST OF THE INSTALLATION.}

The cost of an installation for the application of electricity to growing plants on a field of an area of Io hectares

* A Leyden jar transformed into a Lane jar is a jar with which the length and the number of sparks can be measured. 
(equal to 24.7 acres), or on I hectare (equal to 2.47 acres), would be as follows :-

Electrical Machine and Motor-

$\begin{array}{cc}\text { For } & \text { For } \\ \text { Io Hectares. } & \text { I Hectaie. }\end{array}$

One influence-machine of medium size, with reverse rotating glass cylinders of about $30 \mathrm{~cm}$. (I I $\frac{3}{8} \mathrm{in}$.) in diameter and $40 \mathrm{~cm}$. (15 $\frac{3}{4} \mathrm{in}$.) in length ...............................

One hot-air motor, one-tenth horse power

$\begin{array}{rrrrrr}E_{32} & \circ & \circ & E_{32} & \circ & 0 \\ 10 & 0 & 0 & 10 & 0 & 0\end{array}$

Insulators, Wires and Posts-

640 insulators for the field and ro for the conductor to the field (at Is. Id each)

13,800 metres galvanised iron wire $\begin{array}{llllll}35 & 4 & 2 & 3 & \text { I } 3 & 9\end{array}$ of $1.5 \mathrm{~mm}$. in diam. (weighing ${ }_{1} 3.4 \mathrm{~kg}$. per $\mathrm{r}, 000 \mathrm{~m}$., equal to r $8.5 \mathrm{~kg}$.), at $7{ }^{\circ} \mathrm{d}$ d. ................. $81,000 \mathrm{~m}$. galvanised iron wire ( $\mathrm{I}, 000 \mathrm{~m}$. weighing $2.48 \mathrm{~kg}$., equal to $20 \mathrm{I} \mathrm{kg}$ ) at $1.1 \frac{1}{2}$ d.

Labour for placing points on this wire $(150 \mathrm{~m}$. in one hour equals 540 hours at 4 d.)

640 posts $2.5 \mathrm{~m}$. in leng th and $7 \mathrm{~cm}$. in diam.

ro posts $5 \mathrm{~m}$. in length and $8 \mathrm{~cm}$. to $\mathrm{Io} \mathrm{cm}$ : in diam.................

Installation of machinery, motor, \&c.

$\begin{array}{llllll}5 & 18 & 8 & 0 & \text { II } & 11\end{array}$

$\begin{array}{llllll}9 & 12 & 8 & 0 & 19 & 3\end{array}$

$9 \circ 0 \quad 0 \quad 18 \quad 0$

$\begin{array}{llllll}2 & 1 & 3 & 0 & 5 & 2\end{array}$

$\circ$ 10 $0 \quad 0050$

$\begin{array}{llllll}4 & 0 & 0 & 4 & 0 & 0\end{array}$

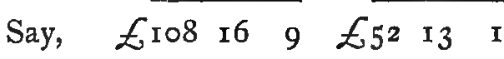

Annual Charges -

For

For

Setting up and taking down wire net each season

Inspection and supervision ( 2 hours Io Hectares. I Hectare.

daily)

Contingencies, renewals, \&c..........

$E_{3} \quad 6 \quad 8 \quad E^{I} \quad \circ \quad \circ$

Interest, 10\% on capital, £ I08 I6 9

\begin{tabular}{rrrrrrr}
5 & 0 & 0 & & I & 0 & 0 \\
4 & 0 & 0 & & I & 0 & 0 \\
10 & 16 & 10 & & 5 & 5 & 3 \\
\hline 23 & 3 & 6 & & \pm 8 & 5 & 3 \\
\hline
\end{tabular}


REVENUE.

We will take the wheat as a crop at medium price to estimate the revenue from the application of the electrical air-current. A field sown with wheat gives, speaking generally, 34 bushels per acre as an average crop on ordinary good wheat land; then an increase of 45 per cent. on 25 acres, or say io hectares, is equal to 383 bushels.

$\begin{array}{llllll}383 & \text { bushels at } 3 \text { s. } 6 \text { d. per bushel equals... } & £ 67 & 0 & 6\end{array}$

Less the yearly cost........................ ${ }_{23} 3 \quad 3 \quad 6$

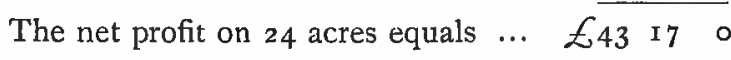

Or more than four-tenths of the whole cost of the complete installation will be realised in the first year.

As the cost of the installation does not increase in direct proportion to the area of land treated, it follows that on larger areas the profits would be greater, whereas on a very small area (I or 2 acres) the increased crop would not pay for the application of the electric current.

In the case of horticulture, however, it is an entirely different matter. The produce has a much higher value, and the electrical treatment will always repay the cost when the area is not too small and is very intensively cultivated. In this department of agricultural work, therefore, the future for the electrical treatment of growing crops has a most promising future.

Remarks.-In other countries, where the wheat prices are much higher, this process of calculation will give, generally speaking, 30 hectolitres* per hectare, or 300 hectolitres for Io hectares. In these countries also the capital cost and maintenance charges are, speaking generally, lower than in the United Kingdom. The electrical treatment gives an increase of 45 per cent. Therefore

I35 hectolitres at I5'35. per hectolitre, equals ${ }^{\prime} £$ I03 56

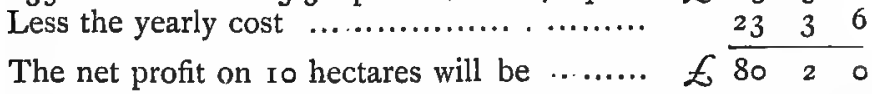

or nearly three-quarters of the whole cost of the complete

* One hectolitre equals 2'75 I bushels. 
installation. This great difference comes from the very low price of wheat in Great Britain. The price per bushel varies very much :-

New York. Berlin. Stockholm. Helsingfors. s. d. s. d. s. d. s. d. s. d. s. d.

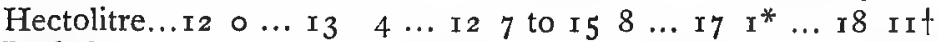

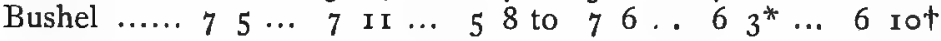

Though the above calculations on the financial side of the question are merely approximate there will undoubtedly be great pecuniary advantage in applying the electrical treatment, when we take into consideration not only the increase in the harvest but also the improvement of the crops, as shown by the chemical analyses. That the electrical air-current will prove of great service in orchards and on large market growing lands, by inducing earliness and rapid maturity as well as increased crops, seems to be clearly demonstrated.

The cost of the installation includes the electrical machine, which is put down for a sum of $£_{32}$, or $\$ 164$, and this sum may be regarded as very high in comparison with the cost of the older machines. But my own experience will here be useful. He who would avoid the troubles I experienced in working with the older machine will not hesitate to use the new type, with its opposite-direction rotating cylinders. This new type of influence-machine has the following advantagesin comparison with the older ones:-

The New Machine.

(Glass cylinders $40 \mathrm{~cm}$. in length and $30 \mathrm{~cm}$. in diam.)

I. It never fails to be charged.小

2. It can be kept at work during several months continuously.

3. It can be used on a greater area (say up to ro hectares).
The Older Machine.

(45 cm. plates.)

I. The older machine fails very often to be charged, especially in the summer, when the air is sultry and humid.

2. When at work it must be cleaned every third day.

3. It can only be used upon an area not exceeding $2 \cdot 5$ hectares.

+ Russian wheat.

\# Excepting when the air is radio-active, which will occur very seldom, say four or five times in the summer, and then only for a few hours. 
These advantages of the new machine are so great, especially No. I, that the superiority of this new type of apparatus is fully proved, and its use justified.

To prevent mistakes and subsequent trouble, it will always be best to order the machines and the necessary tools from an actual manufacturer, and to have the installation made by skilled workmen. Everything naturally depends, in so new an application, upon the skilful first installation and the subsequent careful use of the mechanism and the materials employed. 

TABLES OF METRICAL NEASUREMENTS, WMTI EMGGSH EQUIVALENTS.

\section{THERMOMETER SCALE.}

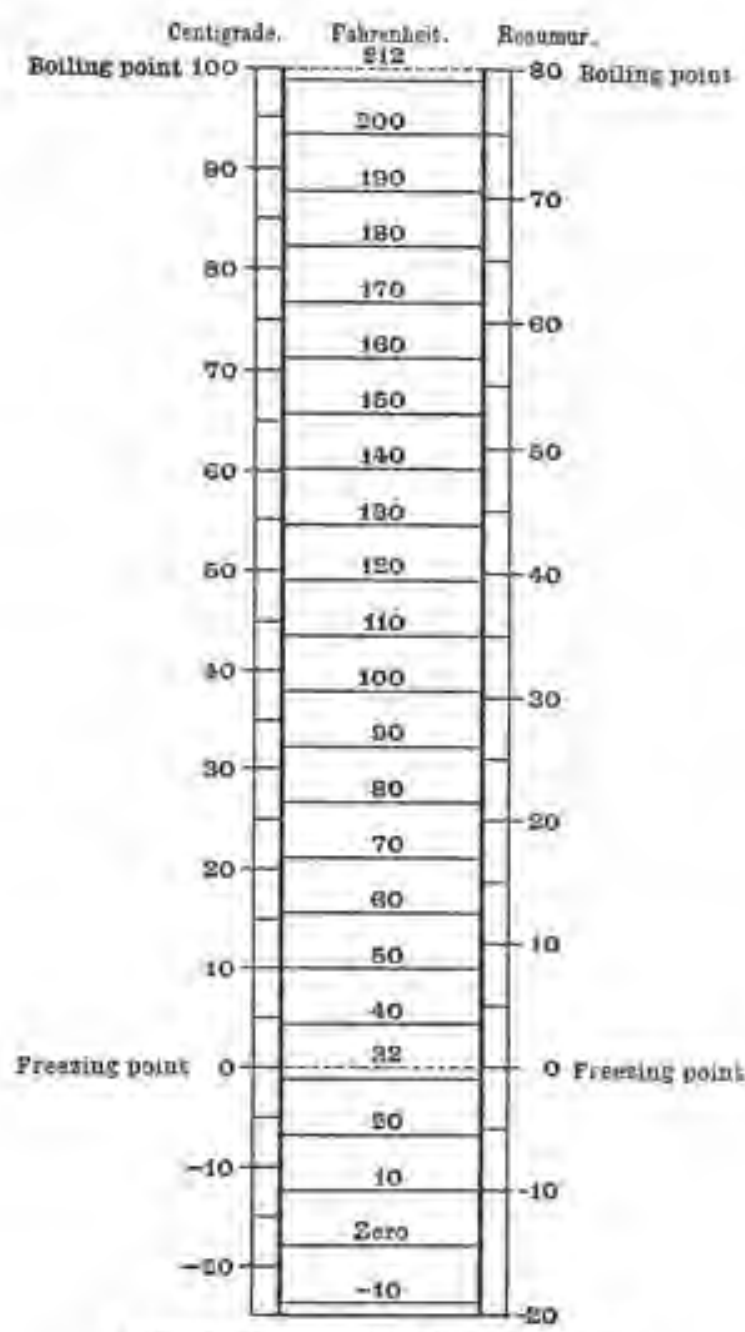

Pormulas tor eopvering from one systen

$8=\frac{96}{6}+83$

$\mathrm{C}=\frac{5(\mathrm{~B}-39)}{\mathrm{g}}$.

$R=\frac{4(F-39)}{9}$

\section{LINEAL MEASURE WTTH WAYDTS TS TNCDES}

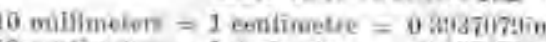

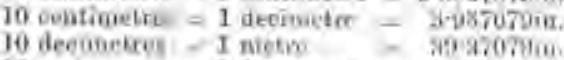

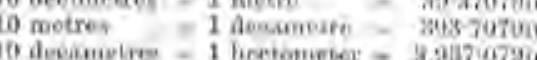

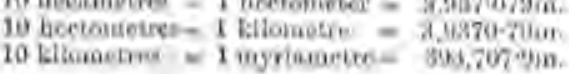

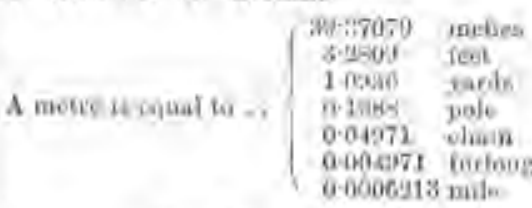

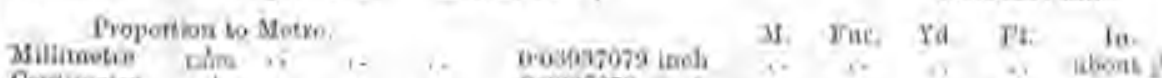
mingetre

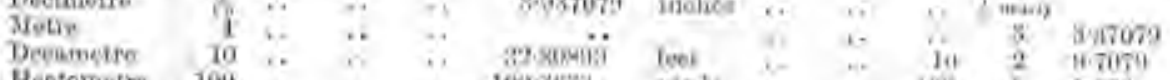

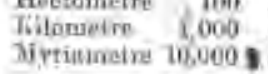

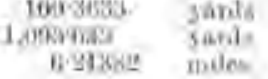

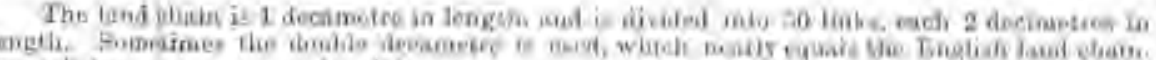

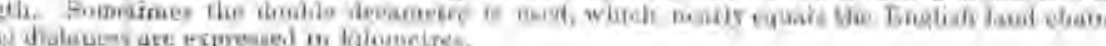

\begin{tabular}{|c|c|c|c|c|c|c|c|c|c|c|}
\hline \multicolumn{3}{|c|}{ 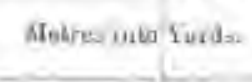 } & \multicolumn{3}{|c|}{ 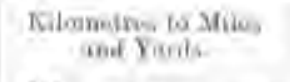 } & \multicolumn{2}{|c|}{ 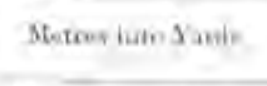 } & \multicolumn{3}{|c|}{ 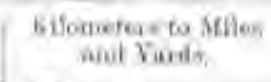 } \\
\hline Meirot & & Sant=- & $\begin{array}{l}\text { bote: } \\
\text { unitre }\end{array}$ & Wilite & Coowe & Share & Furdo & Ein & shituse & $\operatorname{tand}$ \\
\hline I & and & 1.984 & 1 & 0 & 1,089 & Q6 & Masis & 50 & 12 & $7 \mathrm{~s}$ \\
\hline$\frac{\pi}{3}$ & el & D. & $\frac{10}{8}=$ & 1 & 127 & $\begin{array}{ll}50 \\
40\end{array}$ & andent & ain. & $3 x$ & 1,1, \\
\hline$i$ & ... & $\sin x$ & 4 & $\therefore$ in & $\log 21$ & sio & सis? & 30 & $\therefore \frac{n+1}{31}$ & 1,5 \\
\hline$\pi$ & as & 6.16\% & 5 & is is & J84 & riat & Li: & bio & it & is \\
\hline & 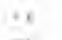 & $6 \sin 2$ & a. $=$ & C. & 6,282 & กI & 265 554 & in & $\therefore 4$ & $x i 1$ \\
\hline${ }_{n}^{7}$ & $\vec{i}$ & $\lim _{w \rightarrow 0}$ & $7+1$ & 1: & bis & No & 879 & $(\infty 1)$ & 1. III & 1,48 \\
\hline & ... & 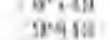 & 3 & $i$ & 1,09 & & & & & 1,62 \\
\hline in & $\rightarrow$ & 960 แล\% & wi & 6 & 30 & & & & & \\
\hline
\end{tabular}

\section{BQUARE MLESORE.}

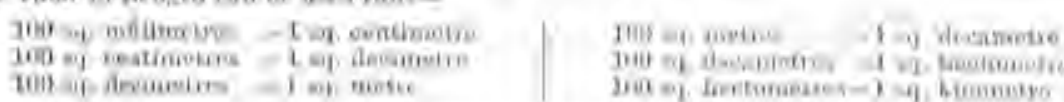

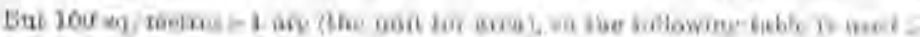

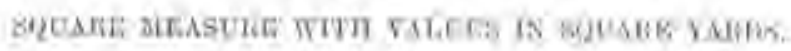

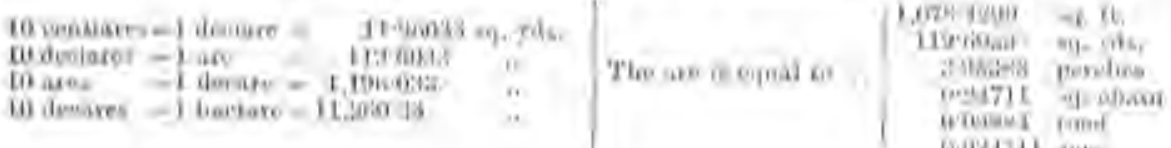

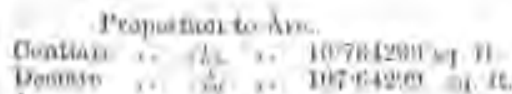

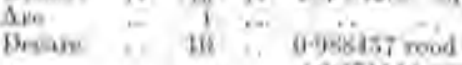

Weation

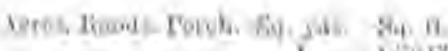

$$
\text { to aros are about an nem. }
$$

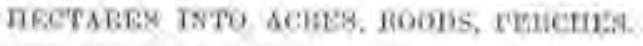

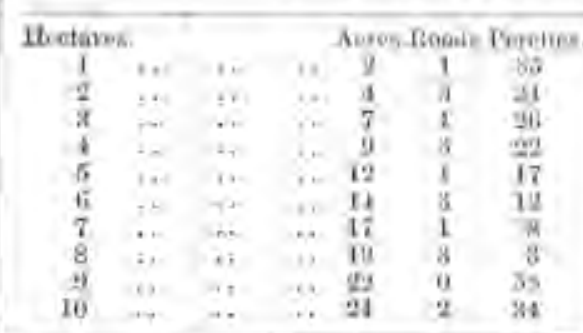

\begin{tabular}{|c|c|c|c|c|c|}
\hline & & & 1 & & \\
\hline & & & & & \\
\hline w & 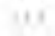 & & 71 & 0 & \\
\hline$\because$ & • & & 144 & 9 & \\
\hline$\therefore$ & & 11 & & 1 & \\
\hline & . & $\therefore$ & 182 & 3 & \\
\hline$\because$ & & & 117 & " & 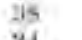 \\
\hline$\ddot{\ddot{z}}$ & 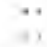 & & $\begin{array}{l}2999 \\
417\end{array}$ & & \\
\hline
\end{tabular}

100 i 1009

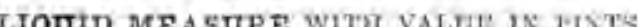

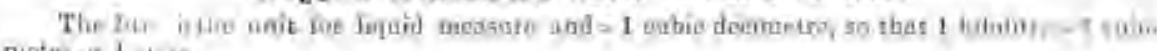

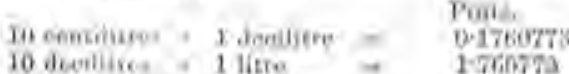

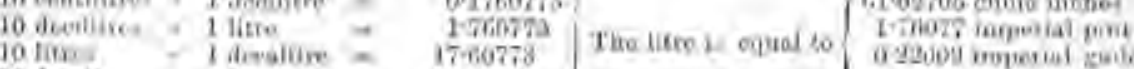

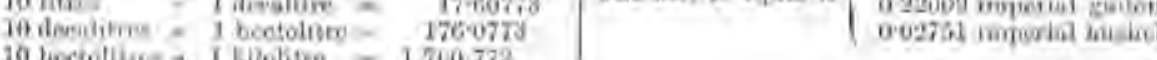

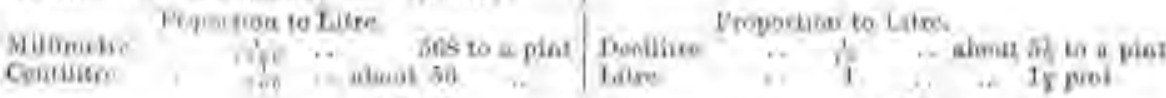

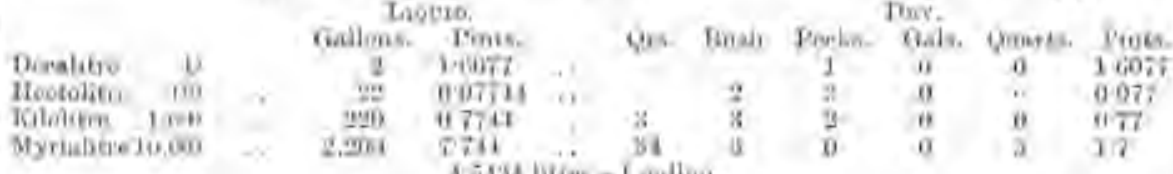

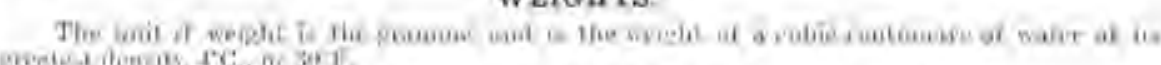

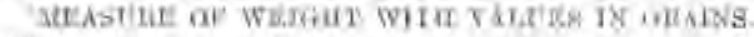

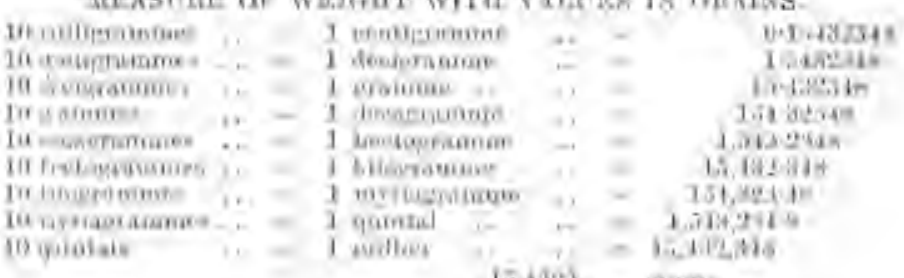

to youis:

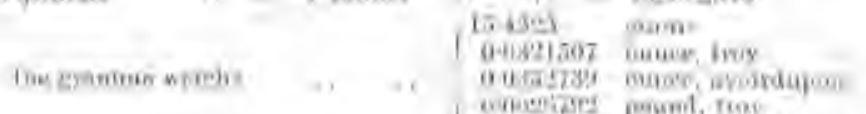

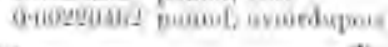

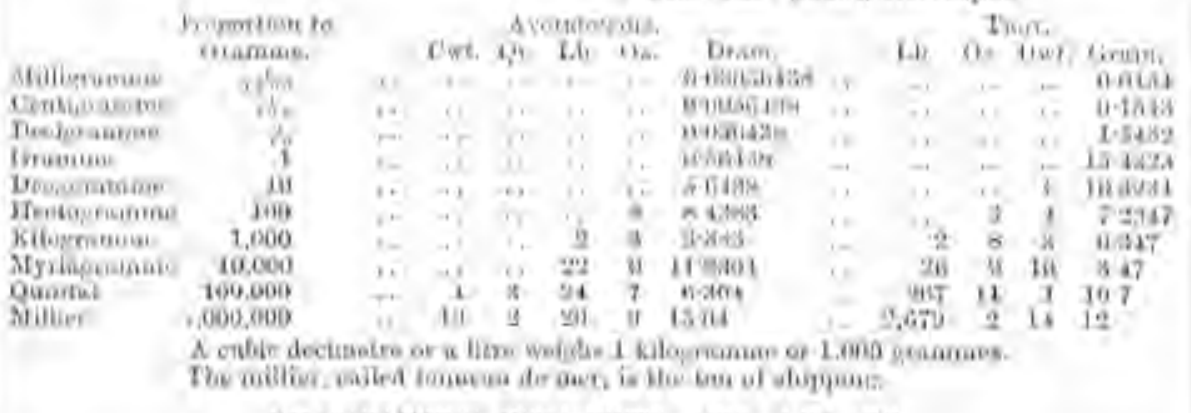

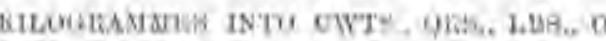

\begin{tabular}{|c|c|c|c|c|c|c|}
\hline \multirow{2}{*}{\multicolumn{2}{|c|}{ 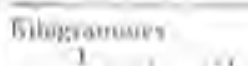 }} & 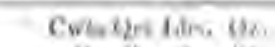 & \multicolumn{3}{|c|}{ 6ilogrambies } & 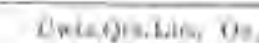 \\
\hline & & & & $x$ & & 年 \\
\hline 3 & $\rightarrow$ & 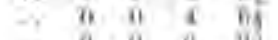 & aiv & $\therefore$ & $\therefore$ & $0=70 \quad 8$ \\
\hline$\therefore$ & & $\therefore \quad \begin{array}{llll}0 & 0 & a & 1 / 1\end{array}$ & in & - & $\because$ & 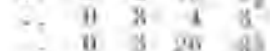 \\
\hline$\dot{\gamma}$ & & $\because \quad 0 \quad \pi \quad \pi$ & tis & ... & ... & $\therefore \quad 1 \quad 0 \quad 20$ \\
\hline$\therefore$ & & $\begin{array}{c}a-0 \\
\therefore\end{array}$ & 20 & $\ldots$ & $\therefore$ & 1 is $2 b^{2}$ \\
\hline .. & ... & $\therefore \quad \begin{array}{llll}0 & 0 & 1 & \pi\end{array}$ & ता & $\ldots$ & + & $2 \%$ \\
\hline$\therefore$ & $\ddot{\theta}$ & 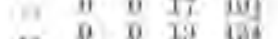 & tion & it & *. & 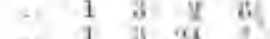 \\
\hline iii & & & & & & \\
\hline
\end{tabular}





\section{"THE ELECTRICIAN" SERIES}

\section{OF STANDARD BOOKS.}

\section{"The Electrician"-Every Friday, price 6d., post free $6 \frac{1}{2} \mathrm{~d}$.}

"The Elrctrician" is the oldest electrical joumal published, First series, I86o; second series, 1878 . It has always bornc the same title, been the same size, and been published weekly. Consequently the Volumes form a unique set of uniform appearance. In the volumes of "THE ELECTRICIAN" will be found the most valuable collection of original Papers and articles by nearly every leading writer on every branch of electrical engineering, science and industry, besides all Papers read before the principal Electrical Institutions throughout the world by men eminent in the Electrical Profession, and authenticated reports of the discussions thereupon. Original articles appearing in "THE EIBCTRICJAN" are written by gentlemen baving no interest whatever in particular electrical systerns, and with but one object-the advancement of electrical knowledge and electro-technology generally. Many of these original series of articles have since been revised and amplified, and published in book form. These form the nucleus of the well-known "ELECTRICIAN" SERIRS.

Much space is devoted in every weekly issue to fully illustrated, technical descriptions of the Electricity Supply Works and Electric Tramways owned by Local Authorities and Companies, and in the very full record of Municipal Notes, the progress and development of Municipal Electrical Enterprise, including detailed analyses of the Accounts of Electric Lighting and Tramway Undertakings, is given. The Municipal Notes of "THE ELrctrician" are more numerous, more complete, and more up-to-date than those of any other technical or trade journal in the world.

In addition to the above, "The Electricras" contains a complete record of all the legal causes which have occupied the attention of the Courts of Justice for the past 26 years. It is customary for "THE ELECTRICIAN" to occupy a prominent position in the Courts as an authority upon all legal questions affecting the Electrical Profession"and Industry.

A regular feature in "THe ELeCTRICIAN" has"always been the verbatim reports of meetings of Electrical Companies and Corporations.

Finally, "The ELECTRICIAN" has been of incalculable service to technical education, and has done much to make the general study of electricity the reality it has undoubtedly become. No aspirant to honour and renown in the electrical profession can hope to keep abreast of the never-ceasing stream of discoveries of new applications of electrical science to every-day com, mercial pursuits who does not diligently peruse the colums of "THE ELECTRICIAN," which is pre-eminently the leading electrical journal.

TrRms of SUBScription (post free):

YEAR, HaLF-YEAR, QuARTER,

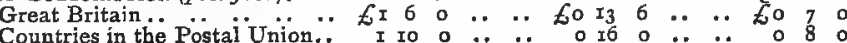

Bound Volumes (April and October) 17s. 6d. each, post free $18 \mathrm{~s}$. 6d, abroad extra.

\section{"THE ELECTRICIAN" ELECTRICAL TRADES' DIRECTORY}

AND HANDBOOK. Established I88x. The cheapest largest and only reliable Directory published for the Electrical and Kindred Trades. (THE BIG BLUE BOOK.) Published first week in February in each year. Royal 8vo., about $x, 700$ pages. SUBSCRIPTION PRICE 7s. 6d. nett, post free 8s, 3d.; British Colonies, 9s. 6d.; abroad, Ios. After date of pubiication, I5s. nett, post free I5s. gd. (British Colonies, r7s., post free ; U.S.A., I8s. 6d., post free'; other countries, I8s.)

This Directory and Handbook is well known throughout the Electrical, Engineering and Allied Trades in all parts of the World, and no expense is spared to make the work really reliable. New Names and corrections to existing entries in the DIREctorial portion of the book are received up to the end of January. Extra insertions are made in the Classified Trades' Section at low rates. In addition to more than 600 pages of purely Directorial matter, the HANDBOOK portion contains a mass (about 650 pages) of interesting information, the great part of which cannot be obtained elsewhere, and in the Biographical Division appear about 300 sketches of the lives of well known men in the Electrical World, with many excellent portraits.

\section{Ayrton-THE ELEC'TRIC ARC. By Mrs. Ayrton, M.I.E.E. Now Ready. Very fully Illustrated. Price a2s. 6d.}

Abstract from Author's Preface.-This book owes its origin to a series of articles published in The Electrician in $1895^{-6}$. In experimenting on the arc my aim was not so much to add

"THE ELECTRICIAN" PRINTING \& PUBLISHING CO,, LTD., I, 2 and 3, Salisbury Court, Fleet Street, London, E.G. 
to the large number of isolated facts that had already been discovered, as to form some idea of the bearing of these upon one another, and thus to arrive at a clear conception of what takes place in each part of the arc and carbons at every moment. The attempt to correlate all the known phenomena and to bind them into one consistent whole led to the deduction of new facts, and opened up fresh questions, to be answered in their turn by new experiments. Thus the subject grew and developed into what may almost be termed a natural way. The experiments of other observers have been employed in two ways : ( I) In confirmation of theory developed from my own experiments, and (2) as the basis of theory for which further tests were devised. M. Blandel's interesting and systematic researches, the admirable work of Mr. A. P. Trotter, and Prof. Ayrton's Chicago Paper were all laid under contribution, and the deductions drawn from them tested by new experiments. The excellent us in England, including Nebel, Feussner, Luggin, Granquist and Herzfeld, has been utilised, and in Chapter II. I have given short abstracts of most of the important Papers on the direct-current arc that appeared up to the end of the nineteenth century.

\section{Baines-BEGINNER'S MANUAL OF SUBMARINE CABLE} TESTING AND WORKING. By G. M. Baines. Second Edition. Cloth Bound, 7s. $6 \mathrm{~d}$. nett; post free, $8 \mathrm{~s}$.

This book has been written to meet the requirements of those about to commence the study of Submarine Telegraphy. All subjects demanding attention bave been brought within the scope of the volume and bave been dealt with at sufficient length to enable an intelligible idea to be obtained of them. With regard to the al gebraical portion of the study, all the formulre have been worked out step by step, and, where convenient, have been supplemented by arithmetical equivalents. The book is divided into I 8 chapters, and deals with : Batteries, Ohm's Law, Joint Resistance, Wheatstone Bridge, Bridge Measurements, Insulation Test by Direct Deflection, Inductive Capacity, Internal Resistance of a Battery, \&c., E.M.F. of a Battery, \&c., Current Strength in Wheatstone Bridge, \&c., Tests of Broken or Faulty Cables, and Description of Apparatus, \&c.

Beaumont-THE STEAM-ENGINE INDICATOR AND INDI-

CATOR DIAGRAMS. Edited by W. W. Beaumont, M.I.C.E., M.I.M.E., \&c. 190 pages, II6 illustrations. Price 3s. 6d., post free.

The object of this book is to place in the bands of students and practical men a concise guide to the oljects, construction and use of the indicator, and to the interpretation of indicator diagrams. Lengthy discussion of theoretical or hypothetical matters has been avoided. The behaviour of steam and its expansion under difforent conditions have been treated in a simple manner so far as tbese questions are important to the consideration of indicator diagrams in their most usual practical applications.

\section{Bond-RATING OF ELECTRIC LIGHTING, ELECTRIC} TRAMWAY AND SIMILAR UNDERTAKINGS. By W. G. Bond, A.I.E.E. Now ready, cloth, 8vo, price $2 s$. 6 d. net.

This little book is intended for the use of Directors, Secretaries, Engineers and other Officials connected with Electric Traction, Lighting and Power Distribution Companles. The chief object of the Autbor has been to enable those who are not familiar with the principles and practice of rating to ascertain for themselves whether the Rateable Value of their property is reasonable or excessive, and thus avoid unnecessary expense at the outset.

\section{Carter-MOTIVE POWER AND GEARING FOR ELECTRICAL}

MACHINERY: A Treatise on the Theory and Practice of the Mechanical Equipment of Power Stations for Electric Supply, and for Electric Traction. By E. Tremlett Carter, C.E., M.I.E.E., F.R.A.S., F.P.S. (Lond.) \&c. 650 pages, 200 Illustrations, Scale Drawings and Folding Plates, and over 80 Tables of Engineering Data. In one volume. Price 12s. 6d., post free; abroad, r3s. New edition, roo4.

Part I.-Introductory. Part II.-The Steam Engine. Part III.-Gas and Oil Engines.

Part IV.-Water Power Plant. Part V.-Gearing. $\quad$ Part VI.-Types of Power Stations. This work presents to consulting engineers, contractors, central-station engineers and engineering students the latest and most approved practice in the equipment and working of mechanical plant in electric power generating stations. Every part of the work has been brought completely up to date; and especially in the matter of the costs of equipment and working the latest available informatfon has been given. The treatise deals with Steam, Gas, $\mathrm{Oil}^{\mathrm{B}}$ and Hydraulic Plant and Gearing; and it deals with these severally from the three standpoints of (1) Theory, (2) Practice and (3) Costs.

"Motrve Power and Gearing for Electrical Machinery" is a handbook of modern electrical engineering practice in all parts of the world. It offers to the reader a means of comparing the central station practice of the United Kingdom with that of America, the Colonies or other places abroad; and it enables him to study the scientific, economic and financial principles upon which the relative suitability of various forms of practice is based, and to apply these principles to the design or working of plant for any given kind of work, whether for electrical supply or for electric traction. It is a treatise which should be in the hands of every electrical engineer throughout the world, as it constitutes the only existing treatise on the Economics of Motive Power and Gearing for Electrical Machinery.

"THE ELECTRICIAN" PRINTING \& PUBLISHING CO., LTD., $I_{1}, 2$ and 3 , Salisbury Court, Fleet Street, London, E.C. 
COOper-PRIMARY BATTERIES: THEIR CONSTRUCTION

AND USE. By W.R. Cooper, M.A. Fully lllustrated. Price ics. 6d. nett.

Author's Preface-Extract.-Primary. Batteries form a subject from which much has been hoped, and but little realised. But even so, it cannot be said that the advance has been small ; and consequently no apology is offered for the present volume, in which the somewhat scattered literature of the subject bas been brought together. Kecent years have seen important additions to the theory of the voltaic cell, and tberefore a considerable number of pages have been devoted to this part of the subject, although it is impossible to do more than give a superficial sketch of the theory in a volume like the present. With regard to the practical part of the subject, this volume is not intended to be encyclopredic in chanacter; the object has been ratber to describe those batteries which are in general use, or of particular theoretical interest. As far as possible, the Author has drawn on his personal experience, in giving practical results, which, it is hoped, will add to the usefulness of the book. Owing to the importance of the subject, Standard Cells have been dealt with at some length. Those cells, however, which are no longer in general use are not described; but recent work is summarised in some detail so as to give a fair idea of our knowledge up to the present time. It has also been thought well to devote a chapter to CarbonConsuming Cells. Very little has been written upon this subject, but it is of great interest, and possibly of great importance in the future.

\section{Curtis-Hayward-A DIGEST OF THE LAW OF ELECTRIC} LIGHTING, ELECTRIC TRACTION AND OTHER SUBJECTS. By A. C.

Curtis-Hayward, B.A., A.I.E.E. Price 3s, 6d., post free. Published annually in March.

Being a full critical abstract of the Electric Lighting Acts, I882 and 1889 , of the Tramways Act, 1870 , and of the documents issued from time to time by the Board of 'irade dealing with Electric Lighting, Electric Traction, \&c., including the Rules as to the procedure in connection with applications to the Light Railway Commissioners for Orders under the Light Railways Act, 1896, and forms of accounts for Board of 'Trade returns for Electricity Supply Undertakings. The Digest treats first of the manner in which persons desirous of supplying electricity must set to work, and then of their rights and obligations after obtaining Parliamentary powers; and gives in a succinct form information of great value to Local Authorities, Electric Light Contractors, \&c., up to date. The Board of Trade Regulations as to the Supply of Electrical Energy, the London County Council Regulations as to Overhead Wires, Theatre Lighting, \&c., together with the Byelaws enforced in pursuance of Part II. of the Public Health Acts Amendment Act, 189o, by the various Urban Sanitary Authorities are also given.

\section{Ewing-MAGNETIC INDUCTION IN IRON AND OTHER}

METALS. By Prof. J. A. Ewing, M.A., B.Sc., F.R.S., Professor of Mechanism and Applied Mechanics in the University of Cambridge. 382 pages, 173 Illustrations. Price Ios. 6d., nett. Third Edition.

Synopsis of Contents.-After an introductory chapter, which attempts to explain the fundamental ideas and the terminology, an account is given of the methods which are usually employed to measure the magnetic quality of metals. Examples are then quoted, showing the results of such measurements for various specimens of iron, steel, nickel and cobalt. A chapter on Magnetic Hysteresis follows, and then the distinctive features of induction by rery weak and by very strong magnetic forces are separately described, with further description of experimental methods, and with additional numerical results. The influence of Temperature and the influence of Stress are next discussed. The conception of the Magnetic Circuit is then explained, and some account is given of experiments which are best elucidated by making use of this essentially modern method of treatment.

Fisher-THE POTENTIOMETER AND ITS ADJUNCTS.

Universal System of Electrical Measurement.) By W. Clark Fisher. Price 6s., post free ; abroad, 6s. 6d.

The extended use of the Potentiometer System of Electrical Measurement will, it is hoped, be sufficient excuse for the publication of this work, which, while dealing with the main instrument, its construction, use and capabilities, would necessarily be incomplete without similar treatment of the various apparatus which, as adjuncts, extend the range and usefulness of the whole system.

The engineer or practical man demands that he shall be shown results quickly, plainly and accurately with a minimum of trouble, understanding, and consequently "Time," and on that account prefers-like all good mechanics-to have one good instrument, which, once understood and easily manipulated, can be used in a variety of ways to suit his needs. It is to this fact, undoubtedly, that the "Potentiometer" method of measurement owes its popularity. Its accuracy" is raxely, if ever, impugned. Measurements made by it are universally accepted amongst engineers, and it might be well termed a "universal "instrument in "universal " use.

Fisher and Darby-STUDENTS' GUIDE TO SUBMARINE CABLE TESTING. By H. K. C. Eisher and J. C. H. Darby. New and Enlarged

Edition. Fully Illustrated. Price 75.6 d. nett, post free; abroad 8s.

The Authors of this book have, for some years past, been engaged in the practical work of of Stbmarine Cable 'Testing in the Eastern Extension Telegraph Company's service, and have embodied their experience in a Guide for the use of those in the Telegraph Service who desire to qualify themselves for the examinations which the Cable Companies have recently instituted. To those desirous of entering the Cable Service, Messrs. Fisher and Darby's book is indispensable, as it is now necessary for probationers to pass these examinations as part of the qualification for service.

A valuable set of Questions and Answers is added to the New and Enlarged Edition.

“THE ELECTRICIAN" PRINTING \& PUBLISHING CO., LTD., I, 2 and 3 , Salisbury Court, Fleet Street, London, E.C. 
Fleming-A HANDBOOK FOR THE ELECTRICAL LAB-

ORATORY AND TESTING ROOM. By Dr. J.A. Fleming, M.A., F.R.S., M.R.I.,

\&c. Vol. I., price r2s. 6 d. nett, post free i3s. Vol. II. I4s, nett.

This Handbook has been written especially to meet the requirements of Electrical Engineers in Supply Stations, Electrical Factories and Testing Rooms. The Book consists of a series of Chapters each describing the most approved and practical methods of conducting some one class of Electrical Measurements, such as those of Resistance, Electromotive Force, Current, Power, \&c., \&c. It does not contain merely an indiscriminate collection of Physical Laboratory, processes without regard to suitability for Engineering Work. The Author has brought to its compilation a long practical experience of the methods described, and it will be found to be a digest of the best experience in Electrical Testing. The Volumes contain a Chapter on the Equipment of Electrical Laboratories and numerous Tables of Electrical Data, which will render it an essential addition to the library of every practical Electrician, Teacher or Student.

VoL. I.

Chapter I.-Equipment of an Electrical Testing Room.

"II.-The Meastrement of Electrical Resistance.

"III.-The Measurement of Electric Current.

"IV.-The Measurement of Electromotive Force.

"V.-TheMeasurement of ElectricPower.
Vot. II.

Chapter I,-The Measurement of Electric Quantity aud Energy.

II.-The Measurement of Capacity and Inductance.

, III.-Photometry.

"IV.-Magnetic and Iron Testing.

"V.-Dynamo, Mlotor and Transformer Testing.

\section{Fleming-ELECTRICAL LABORATORY NOTES AND FORMS.}

Arranged and prepared by Dr. J.A. Fleming, M.A., F.R.S., Professor of Electrica

Engineering in University College, London.

These "Laboratory Notes and Forms" have been prepared to assist Teachers, Demonstrators, and Students in Electrical Laboratories, and to enable the Teacher to economise time. They consist of a series of (about) Twenty Elementary and (about) Twenty Advanced Exercises in Practical Electrical Measurements and Testing. For each of these Exercises a four-page Report Sheet has been prepared, two pages of which are occupied with a condensed account of the theory and practical instructions for performing the particular Experiment, the two other pages being ruled up in lettered columns, to be filled in by the Student with the observed and calculated quantities. When simple diagrams will assist the Student, these have been supplied. These Exercises are for the most part based on the methods in use in the Electrical Engineering Laboratories of University College, London; but they are perfectly general, and can be put into practice in any Electrical Laboratory.

Each Form is supplied either singly at 4 d. nett or at $3 \mathrm{~s}, 6 \mathrm{~d}$, per dozen nett (assorted or otherwise as required); in sets of any three at. Is. nett; or the set of (about) Twenty Elementary (or Advanced) Exercises can be obtained, price 5s.6d, nett. The complete set of Elementary and Advanced Exercises are price Ios. $6 \mathrm{~d}$. nett, or in a handy Portfolio, I2s. nett, or bound in strong cloth case, price I2s. 6 d. nett.

Spare Tabulated Sheets for Observations, price Id. each nett.

Strong Portfolios, price 15. 6d. each.

The very best quality foolscap sectional paper (I6in. by I3in.) can be supplied, price is. per dozen sheets nett.

NOW READY.-Cbeaper edition of "Electrical Laboratory Notes and Forms." These cheaper Forms have been prepared for the use of students and teachers at the Polytechnic and other science classes throughout the country. These new Forms, which differ only from the higher priced set in being printed on smaller and cheaper paper and with less space for tabulated records, are issued at half the price of the above set. Bound in strong case, $7 \mathrm{~s} .6 \mathrm{~d}$.

Fleming.-ELECTRIC LAMPS AND ELECTRIC LIGHTING. By Prof. J. A. Fleming, M.A., D.Sc., F.R.S., M.R.I., Professor of Electrical Engineer, ing in University College, London. New and Cheaper Fdition. Very fully illustratedhandsomely bound, on good paper, price $6 s$, nett.

The original aim of a course of four lectures by Prof. J. A. Fleming on "Electric Illumination " was to offer to a general audience such non-technical explanations of the pbysical effects and problems concerned in the modern applications of electricity for illumination purposes as might serve to further an intelligent interest in the subject. In this, the second edition of the book, the author has brought the original edition in to line with recent practice without departing from the elementary character of the work.

\section{Fleming-THE ALTERNATE C.URRENT · TRANSFORMER}

IN THEORY AND PRACTICE. By J. A. Fleming, M.A., D.Sc., F.R.S., M.R.I., \&cc., Professor of Electrical Ingineering in University College, London, New EditionAlmost entirely Rewritten, and brought up to date. More than 600 pages and 213 illustrations, 12s. $6 \mathrm{~d}$. post fres; abroad $\mathrm{r}_{3} \mathrm{~s}$.

Since the first edition of this Treatise was published, the study of the properties and applications of alternating electric currents has made enormous progress. . . The Author has, accordingly, rewritten the greater part of the chapters, and availed himself of various criticisms, with the desire of removing mistakes and remedyigg defects of treatment. In the hope that this

"THE ELECTRICIAN" PRINTING \& PUBLISHING CO., LTD., I, 2 and 3 , Salisbury Court, Fleet Street, London, E.C. 
will be found to render the book still useful to the increasing numbers of those who are practically engaged in alternating-current work, he has sought, as far as possible, to avoid academic methods and keep in touch with the necessities of the student who has to deal with the subject not as a basis for mathematical gymnastics but with the object of acquiring practicaly usefull knowledge.

Dr. Fleming's manual on the Alternate_Current Transformer in Theory and Practice is recognised as the text book on the subject. Vol. I. which deals with "The Induction of Electric Currents," has passed through three editions, each. edition having, in its turn, passed through severąl issues. This volume consists of $6 \mathrm{I}_{3}$ pages, and has $2 \mathrm{I}_{3}$ illustrations.

\section{Fleming-THE ALTERNATE CURRENT TRANSFORMER} IN THEURY AND PRACTICE, By J. A. Fleming, M.A., D.Sc., F.R.S., M.R.I., \&c., Professor of Electrical Engineering in University College, London. Third Issue. More than 600 pages and over 300 illustrations. Price I2s. $6 \mathrm{~d}$., post free; abroad, I3s.

Vol. II. treats of "The Utilisation of Induced Currents." This volume has also pissed through numerous issues, consists of about 600 pages, and has $3 r_{3}$ illustrations.

Fleming-THE CENTENARY OF THE ELECTRIC CURRENT. I799-I899. By Prof. J. A. Fleming, F.R.S. With Illustrations of early apparatus and interesting Chronological Notes. In neat paper covers is. rett, post free is. $3 \mathrm{~d}$. Bound cloth 2s, nett, post free.

\section{Fleming-THE ELECTRONIC THEORY OF ELECTRICITY.}

By Prof. J. A. Fleming, M.A., D.Sc., F.R.S. Price Is. 6d. post free.

Extract from the Author. In this sketch of the Electronic Theory the author has made no attempt to present a detailed account of discoveries in their historical order, or to connect them especially with their authors. The object has been to show the evolution. of the idea that electricity is atomic in structure, and that thus these atoms of electricity called electrons attach themselves to material atoms and are separable from them. Lorentz, Helmholtz, Thomson and others have shown that such a conception of atomic structure enables us to explain many electro-optic phenomena which are inexplicable on any other theory. The Electronic Theory of Electricity, which is an expansion of an idea originally due to Weber, does not invalidate the ideas which lie at the base of Maxwell's theory that electric and magnetic effects are due to the strains and stresses in the aether, but supplements them by a new conception-that of the electron or electric particle as the thing which is moved by electric force, and which, in turn, gives rise to magnetic force as it moves. All the facts of electricity and magnetism are capable of being restated in the terms of the idea.

\section{Geipel and Kilgour-A POCKET-BOOK OF ELECTRICAL}

ENGINEERING FORMUL $Æ$, \&c. By W. Geipei and H. Kilgour. 8co pages. 7s. 6d. nett, post free, at home or abroad, 7s. gd.

With the extension of all branches of Electrical Engineering (and particularly the heaviex branches), the need of a publication of the Pocket-Book style dealing practically therewith increases; for while there are many such books referring to Mechanical Engineering, and several dealing almost exclusively with the lighter branches of electrical work, none of these suffice for the purposes of the numerous body of Electrical Engineers engaged in the application of electricity to Lighting, Traction, Transmission of Power, Metallurgy, and Chemical Manufacturing. It is to supply this real want that this most comprehensive book has been prepared.

Compiled to some extent on the lines of other pocket-books, the rules and formula in general use among Electricians and Electrical Engineers all over the world have been supplemented by brief and, it is hoped, clear descriptions of the various subjects treated, as well as by concise articles and hints on the construction and management of various plant and machinexy.

No pains have been spared in compiling the various sections, to bring the book thoroughly up to date; and while much original matter is given, that which is not original has been carefully selected, and, where necessary, corrected. Where authorities differ, as far as practicable a mean has been taken, the different formula being quoted for guidance.

\section{Gore-ELECTRO-CHEMISTRY. By George Gore, LL.D., F.R.S.}

Second Edition. Price as., post free,

At the time when this book first appeared ( 1885 ) no separate treatise on Electro-Chemistry existed in the English language, and Dr. Gore. whose books on electrometallurgy, electrodeposition and lother important branches of electro-technical work are known throughout the world, has collected together a mass of useful information and has arranged this in consecutive order, giving brief descriptions of the known laws and general princlples which underlie the subject of Electro-Chemistry. A very copious index is provided.

\section{Gore-THE ART OF ELECTROLYTIC SEPARATION OF}

METALS (Theoretical and Practical). By George Gore, LL.D., F.R.S. The only book on this important subject in any language. Over 300 pages, I06 illustrations. Price ros. 6d., post free.

No other book entirely devoted to the Electrolytic Separation of Metals exists in any language, those dealing with electro-metallurgy being all more or less devoted to electro-plating. Dr. Gore's work is, therefore, of the utmost servite in connection with all classes of electrolytic work connected with the refining of metals. The book contains both the science and the art of

“THE ELECTRICIAN" PRINTING \& PUBLISHING CO., LTD., I, 2 and 3 , Salisbury Court, Fleet Street, London, E.C. 
the subject (both the theoretical principles upon which the art is based and the practical rules and details of technical application on a commercial scale), so that it is suited to the requirements of both students and manufacturers.

\section{Heaviside-ELECTROMAGNETIC THEORY. By Oliver Heavi-}

side. Vol. I. Second issue, 466 pages. Price r2s. 6d, post free, 13s. Vol. II. 568 pages.

Price r2s. 6d., post free; abroad, 135 . Vol. III. in preparation.

Extract from Preface to $V_{0 Z}$. $I$. - This work is something approaching a connected treatise on electrical theory, though without the strict formality usually associated with a treatise. The following are some of the leading points in this volume. The first chapter is introductory. The second consists of an outline scheme of the fundamentals of electromagnetic theory from the Faraday-Maxwell point of view, with some small modifications and extensions upon Maxwell's equations. The third chapter is devoted to vector algebra and analysis, in the form used by me in former papers. The fourth chapter is devoted to the theory of plane electromagnetic waves, and, being mainly descriptive, may perhaps be read with profit by many who are unable to tackle the mathematical theory comprehensively. I have included in the present volume the application of the theory (in duplex form) to straight wires, and also an account of the effects of selfinduction and leakage, which are of some significance in present practice as well as in possible future developments.

Extract from Preface to Vol, II.-From one point of view this volume consists essentially of a detailed development of the mathematical theory of the propagation of plane electromagnetic waves in conducting dielectrics, according to Maxwell's theory, somewhat extended. From another point of view, it is the development of the theory of the propagation of waves along wires. But on account of the important applications, ranging from Atlantic telegraphy, through ordinary telegraphy and telephony, to Hertzian waves along wires, the Author has usually preferred to express results in terms of the concrete voltage and current, rather than the specific electric and magnetic forces belonging to a single tube of flux of energy. The theory of the latest kind of so-called wireless telegraphy (Lodge, Marconi, \&c.) has been somewhat anticipated, since the waves sent up the vertical wire are hemispherical, with their equatorial bases on the ground or sea, which they run along in expanding. (See 360 , Vol. I. ; also 8,393 in this volume.) The author's old predictions relating to skin conduction, and to the possibilities of long-distance telephony have been abundantly verified in advancing practice; and his old predictions relating to the behaviour of approximately distortionless circuits bave also received fair support in the quantitative observation of Hertzian waves along wires.

\section{Jehl-CARBON MAKING FOR ALL ELECTRICAL PUR-}

POSES. By Francis Jehl. Fully illustrated. Price ıos. 6d. Postage free. This work gives a concise account of the process of making High Grade and other Carbon for Electric Lighting, Electrolytic, and all other electrical purposes.

Chapter I.-Physical Properties of Carbon.

"II.-Historical Notes.

" III.-- Facts concerning Carbon

"IV.-The Modern Process of Manufacturing Carbons.

"V.-Hints to Carbon Manufacturers and Electric Light Engineers.

"VI.-A "New" Raw Material.

"VII.-Gas Generators.

"VIII.-The Furnace.

"IX.-The Estimation of High Tem. peratures.
Chapter X.-Gas Analysis.

"XI.-On the Capital necessary for starting a Carbon Works and the Profits in Carbon Manufacturing.

"XII.-The Manufacture of Electrodes on a Small Scale.

, XIII.-Building a Carbon $F$ actory.

", XIV.-Soot or Lamp Black.

, XV.-Soot Factories,

Kennelly and Wilkinson-PRACTICAL NOTES FOR ELEC-

TRICAL STUDENTS. Laws, Units and Simple Measuring Instruments. By A. E. Kennelly and H. D. Wilkinson, M.I.E.E. 320,pages, I55 illustrations, Price 6s. 6d., post free.

Chapter I.-Introductory.

Contents.

II.-Batteries.

III.-Electromotive Force and Potential.

IV.-Resistance.

V.-Current.

Chapter V1.-Current Indicators.

VII.-Simple Tests with Indicators.

VIII.-Calibration of Current Indicators.

IX.-Magnetic Fields and their Measurement.

These instructive Practical Notes for Electrical Students were started by Mr. A. E. Kennelly prior to his departure from England to join the staff of Mr. Edison in the United States, and were continued and completed by Mr. H. D. Wilkinson, who has prepared a work which is of great service to students. The volume contains 155 illustrations, and deals mainly with Laws, Units and Simple Measuring Apparatus.

\section{Lemström-ELECTRICITY IN AGRICULTURE AND HORTI-}

CULTURE. By Prof. S. Lemström. With illustrations. Price 3s. 6त, nett.

Extract from Author's Introductory Remarks. - It is well known that the question which is the subject of this book has been a favourite field of investigation for a century past. As the subject is connected with no less than three sciences-viz, physics, botany and agricultural physics-

"THE ELECTRICIAN" PRINTING \& PUBLISHING CO., LTD., I, 2 and 3, Salisbury Court, Fleet Street, London, E.C. 
it is in itself not particularly attractive. The causes which induced me to begin the investigation of this matter were manifold, and I venture to hope that an exposition of them will not be without general interest.

\section{Lodge-WIRELESS TELEGRAPHY.-SIGNALLING ACROSS}

SPACE WITHOUT WIRES. By Sir Oliver J. Lodge, D.Sc., F.R.S. New and Enlarged Edition. Second Issue. Very fully illustrated. Price 5s, nett., post free 5s. 3d.

The new edition forms a complete Illustrated Treatise on Hertzian Wave Work. The Full Notes of the interesting Lecture delivered by the Author before the Royal Institution in June, 1894, form the first chapter of the book. The second chapter is devoted to the Application of Hertz Waves and Coherer Signalling to Telegraphy, wiile Chapter III. gives Details of otber Telegraphic Developments, In Chapter IV. a history of the Coherer Principle is given, including Professor Hughes' Early Observations before Hertz or Branly, and the work of M. Branly. Chapters are also devoted to "Communications with respect to Coherer Phenomena on a Large Scale," the "Photo-Electric Researches of Drs. Elster and Geitel," and the Photo-Electric Researches of Prof. Righi.

Phillips-THE BIBLIOGRAPHY OF X-RAY LITERATURE AND RESEARCH. Belng a carefully and accurately compiled Ready Reference Index to the Literature on Röntgen or X-Rays. Edited by Charles $\mathbf{E}$. S. Phillips. With an Historical Retrospect and a Chapter, "Practical Hints," on X-Ray work by the Editor. Price 5s., post free.

Ram-THE INCANDESCENT LAMP AND ITS MANUFACTURE. By Gilbert S. Ram. Fully Illustrated. Price 7s. 6d. post free. Nezw edition, ro04.

Raphael-THE LOCALISATION OF FAULTS IN ELECTRIC IIGHT MAINS, By F. Charles Raphael. New Edition. Price 7s.6d. nett.

Although the localisation of faults in telegraph cables has been dealt with fully in several hand-books and pocket-books, the treatment of faulty electric light and power cables has never been discussed in an equally comprehensive manner. The conditions of the problems are, however, very different in the two cases; faults in telegraph cables are seldom localised before their resistance has become low compared with the resistance of the cable itself, while in electric light work the contrary almost always obtains. This fact alone entirely changes the method of treatment required in the latter case, and it has been the Author's endeavour, by dealing with the matter systematically, and as a separate subject, to adequately fill a gap which has hitherto existed in technical literature.

The various methods of insulation testing during working have been collected and discussed, as these tests may be considered to belong to the subject.

\section{Raphael-WIREMAN'S POCKET-BOOK. A Manual for the}

Wiring Contractor, the Mains Superintendent and the Wireman. Edited by F. Charles Raphael. Price 5s. nett, post free 5s. 3d.

EDIToR's NotR. - When the preparation of this Pocket-Book was commenced, the original intention of its Editor was to collect in a handy and useful form such Tables, Instructions and Memoranda as would be useful to the Electric Light Wireman in his work. This bas been carried out in Section A of the Pocket Book in its present form. During the past few years, however, many enquiries have been received for a good book of reference with regard to the laying of underground mains, and with matters connected with insulated conductors generally. It was decided, therefore, to extend greatly the area covered by the book, and to treat the whole subject of erecting and laying electrical and conducting systems in such a manner that the tables, diagrams and letterpress might be useful to engineers in charge of such work, as well as to the wireman, jointer, and foreman. In fact, the section on Underground work has been compiled largely with a view to meeting the requirements of Mains Superintendents, Central Station Engineers and those occupied in designing networks.

In addition to the tables, instructions and other detailed information as to cables, ducts, junction boxes, \&c., contained in the section on Underground Mains, it has been deemed advisable to add a chapter briefly describing the various systems employed for public distributing networks. In this, the essential practical information is alone given; two and three-phase systems are dealt with, as well as continuous current and single phase, and the method of calculating the size of the conductors and the fall of pressure from the number of lamps or horse-power of motors is made clear without the elaboration of clock-face diagrams or algebraical exercises.

Diagrams for the connections of telephones are given in Section D, including those for subscribers' instruments on the new Post Office exchange system in London; and it is belicved that neither these diagrams nor those for bell connections have hitherto been published together in convenient pocket-book form. The various conversion factors in the Miscellaneous Section and the arrangement of the wages table are those with which the Editor has himself found the most useful in practice.

\section{Snell-ELECTRIC MOTIVE POWER. By Albion T. Snell,} Assoc.M.Inst.C.E., M.I.E.E. Over 400 pages, nearly 250 illustrations. Price ros.6d., post free; abroad, ris. New edition, roo4.

The rapid spread of electrical work in collieries, mines and elsewhere has created a demand for a practical book on the subject of transmission of power. Though much had been written,

"THE ELEC'TRICIAN" PRINTING \& PUBLISHING CO., LTD., I, 2 and 3 , Salisbury Court, Fleet Street, London, E.C. 
there was no single work dealing with the question in a sufficiently comprehensive and yet practical manner to be of real use to the mechanical or mining en ineer; either the treatment was adapted for specialists, or it was fragmentary, and power work was regarded as subservient to the question of lighting. The Author has felt the want of such a book in dealing with his clients and others, and in " ELBCTR.IC Motive PowBr" has endeavoured to supply it.

In the introduction the limiting conditions and essentials of a power plant are analysed, and in the subsequent chapters the power plant is treated synthetically. The dynamo, motor, line and details are discussed both as to function and design. The various systems of transmitting and distributing power by continuous and alternate currents are fully enlarged upon, and much practical information, gathered from actual experience, is distributed under the various divisions. The last two chapters deal exhaustively with the applications of electricity to mining work in Great Britain, the Continent and America, particularly with reference to collieries and coalgetting, and the results of the extensive experience gained in this field are embodied.

In general, the Author's aim has been to give a sound digest of the theory and practice of the electrical transmission of power, which will be of real use to the practical epgineer, and to avoid controversial points which lie in the province of tbe specialist, and elementary proofs which properly belong to text-books on electricity and magnetism.

Soddy-RADIO-ACTIVITY : An Elementary Treatise from the Standpoint of the Disintegration Theory. By Fredk. Soddy, M:A. Fully Illustrated, and with a full Table of Contents and extended Index. 6s. 6d. nett.

Extract from Author's Preface.- In this book the Author has attempted to give a con. nected account of the remarkable series of investigations which have followed $M$. Becquerel's discovery in 1896 of a new property of the element Uranium. The discovery of this new property of self-radiance, or "radio-activity," has proved to be the beginning of a new science, in the development of which physics and chemistry have played equal parts, but which, in the course of only eight years, has achieved an independent position. . . Radio-activity has passed from the position of a descriptive to that of a philosophical science, and in its main generalisations must exert a profound influence on almost every other branch of knowledge. It has been recognised that there is a vast and hitherto almost unsuspected store of energy bound in, and in some way associated with, the unit of elementary matter represented by the atom of Dalton. Since the relations between energy and matter constitute the ultimate groundwork of every philosophical science, the influence of these generalisations on allied branches of knowledge is a matter of extreme interest at the present time. It would scem that they must effect sooner or later important changes in astronomy and cosmology, which have been long awaited by the biologist and geologist.

The object of the book bas been to give to Students and those interested in all departnents of science a connected account of the main arguments and chief experimental data by which the results so far attained bave been achieved.

Wade-SECONDARY BATTERIES : THEIR MANUFACTURE

AND USE. By E. J. Wade. Now ready. 500 pages. 265 Illustrations. Price ros.6d. nett. In this work the Author deals briefly with the Theory and very fully with the Chemistry, Design, Construction and Manufacture of Secondary Batteries or Accumulators. Prospectuses, post free, on application.

The scope of Mr. Wade's important work covers the whole class of apparatus embraced in the theory, construction and use of the secondary battery. The major portion of the book treats the accumulator purely from the point of view of an appliance which fulfils an important and definite purpose in electrical engineering practice, and whose manufacture, use and properties must be understood just as fully as those of a generator or a transformer. The concluding chapter (X.) gives a complete description of all modern electrical accumulators, The book contains 265 illustrations and a yery copious index:

\section{Weymouth-DRUM ARMATURES AND COMMUTATORS} (THEORY AND PRACTICE). By F. Marten Weymouth. Fully Illustrated. Price 7s. 6d. post free.

Wilkinson-SUBMARINE CABLE-LAYING AND REPAIRING.

By H.D. Wilkinson, M.I.E.E., \&c. Over 400 pages and 200 specially drawn illustrations. Price i2s. 6d. post free, Neru edition, September, root.

This work describes the procedure on board sbip when removing a fault or break in a submerged cable and the mechanical gear used in different vessels for this purpose; and considers the best and most recent practice as regards the electrical tests in use for the detection and localisation of faults, and the various difficulties that occur to the beginner. It gives a detailed technical summary of modern practice in Manufacturing, Laying, Testing and Repairing a Sub. marine Telegraph Cable. The testing section and details of boardship practice bave been prepared with the object and hope of helping men in the cable services who are looking further into these branches. The description of the equipment of cable ships and the mechanical and electrical work carried on during the laying and repairing of a submarine cable will also prove to some not directly engaged in the profession, but nevertheless interested in the enterprise, a means of informing themselves as to the work which bas to be dono from the monent a new cable is projected until it is successfully laid and worked.

"THE ELECTRICIAN" PRINTING \& PUBLISHING CO., ITD. I, 2 and 3 , Salisbury Court, Fleet Street, London, E.C. 
Young-ELECTRICAL TESTING FOR TELEGRAPH ENGI-

NIERS. By J. Elton Young. Very fully illustrated. Price zos, 6d. Post free xis.

This book embodies up-to-date theory and practice in all that concerns everyday work of the Telegraph Engineer.

Chapter I-Remarles on Testing Appara

"II.-Measurements of Current, Poten tial, and Battery Resistance.

" III.-Natural and Fault Current.

"IV.-Measurement of Conductor Resistance.

V.-Measurement of Insulation $\mathrm{Re}$ sistance.

, VI.-Corrections for Conduction and Insulation Tests.

Chapter VII.-Measurement of Inductive Capacity.

,VIII._Localisation of Disconnections.

"IX.-Localisation of Earth and Cantacts.

"X -Corrections of Localisation Tests,

"XI.-Submarine Cable Testing during Manufacture, Laying and Working.

"XII,-Submarine Cable Testing during Localisation and Repairs.

In the Appendices numerous tables and curves of interest to Telegraph Engineers are given.

THE MANUFACTURE OF ELECTRIC LIGHT CARBONS. A Practical Guide to the Establishment of a Carbon Manufactory. Fully illustrated, Price Is. 6d., post frec Is. gd.

The object of $\mathrm{Mr}$, O. G. Pritchard in preparing this work for publication was to enable British manufacturers to compete with those of Frauce, Austria, Germany and Bohemia in the production of electric arc carbon candles. The book is fully illustrated and gives technical details for the establishment and working of a complete carbon factory.

ELECTRICITY SUPPLY, ELECTRIC POWER AND TRACTION. Complete Group of Statistics, \&c., for Lncal Authorities, Supply Station Engineers, Consulting and Contracting Engineers, Manufacturing and Supply Houses, \&c. Local Authorities will find these documents of great value for reference in discussions upon questions relating to Electricity Supply for Lighting, Tramways, Power Transmission, \&c.

Full printed particulars post free on application.

ELECTRICITY IN MINES.-Under the new Rules and Regulations concerning the Use of Electricity in Mining Operations, it is compulsory that directions for the effective Treatment of Cases of Apparent Death from Electric Shock be conspicuously placed in certain prescribed positions in the Mines.

A set of these DIRECTIONS, with illustrations showing the method of their application, accompanied by PRECAUTIONS to be adopted to prevent danger from the electric current, can be supplied.

Prices :-On paper, isin. by r2tin. .. .. 3d. each; 2s. 6d. per dozen.

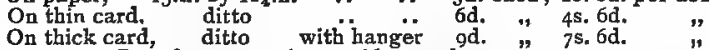
Post free or carriage paid in each case."

“THE ELECTRICIAN" PRIMERS. (Fully Illustrated.) A Series of Helpful Primers on Electrical Subjects for the Use of those seeking a Knowledge of Flectricity-Theoretical and Practical. New and Greatly Enlarged Edition in Preparation.

"The Electrician" Primers were originally published in I89r and had a large sale. They were published with the object of meeting the demand for a correctly-written series of scientific leaflets on the Theory and Practice of Electricity to replace the inaccurate and misleading pamphlets and newspaper articles which were then being issued broadcast, and which it was felt were calculated to do much harm to students and others who consulted them for information concerning electrotechnical subjects.

In this way "The Electrician" Primers met a real want. The great advances made in Electrical Science and Practice have now demanded the complete revision of the "Primers," and their extension to embrace the numerous additional subjects which come within the range of the studies of the student and others seeking a knowledge of Electricity-Theoretical and Practical.

The New Edition will, therefore, be entirely rewritten to bring the original Papers up to date, and the number of Primers will be greatly extended, embracing all additional subjects which have come to the front since the first edition was published. This will necessitate three Volumes. Vol. I. will, as before, be devoted to "Theory," and will consist of about 23 Primers; Vol. II. will treat of "Practice," in relation to Engineering (about zo Primers); and Vol. III. to the lighter branches, Telegraphy, Telephony, Electro-Chemistry, Electro-Metallurgy, ElectroTherapy, and Mis iellaneous.

\section{MINUTES OF THE PROCEEDINGS AT THE HULL}

TELEPHONE INQUIRY. Price 35 . nett, post free $3 \mathrm{s.} 6 \mathrm{~d}$.

The full T'ext of the important Proceedings in the Telephone Inquiry held at Hull in August, rgo3, in Blue-Book form.

MINUTES OF THE PROCEEDINGS AT THE PORTSMOUTH

TELEPHONE INQUIRY. Price Is. 6d. nett, post free is. gd.

The full Text of the important Proceedings in the Telephone Inquiry held at Portsmouth in September, Igo3, in Blue-Book form.

“THE ELECTRICIAN" PRINTING \& PUBLISHING CO., LTD., I, 2 and 3, Salisbury Court, Fleet Street, London, E.C. 
THE POST OFFICE TELEPHONE SERVICE. An illustrated description of the Exchanges of the Post Office Metropolitan Telephone Service, giving much interesting information concerning these Exchanges. Now ready, 8vo, very fully illustrated. Price 2s. net.

In this work an illustrated description is given of the Trunk, Central and other Exchanges of th॰ British Post Office Telephone Service in the London Metropolitan area. The descriptions of the various exchanges are complete, and the illustrations show the disposition of the plant and the types of all the apparatus used. In view of the early acquisition by the Post Office of the undertaking of the National Telephone Company this work is of considerable interest.

STEELPLATE PORTRAITS. Price Is. each; post free on Roller, Is. zd. India mounts rs, extra. Or framed in neat Black Pillar or Brown Ornamental Frames, price 4s. 6d.; carriage paid (U.K.) 5 s. If with móunts xs, extra.

Michael Faraday (Is. extra).

William Sturgeon.

LORD KRLVIN, F.R.S.

Sir William Crookes,F.R.S.

Sir Oliver J. Lodge, D.Sc.,

HERMaNN VON HeLMHOLTZ.

LORD RAYLEIGH, F.R.S.
Prof. J. J. Thomson, F.R.S.

HEINRICH HERTZ.

Prof. W. E. AYrton.

DR. JoHn HorkinsoN, M.A.,

Joseph WILSON SWak.

WERNER VON SIEMENS.

Alexander Siemens.
R. E. B. Crompton

Sir John Pender, G.C.M.G.

SIR JAMES ANDERSON, J.P.

CYRUS W. FIELD.

SiR W. H. Prekce, K.C.B., F.R.S. Sir Henry C. Mance, C.I.E. C. H. B. PAtey, C.B.

\section{NEW VOLUMES AND EDITIONS IN PREPARATION.}

Anderson-BOILER FEED WATER: ITS IMPURITIES, ANALYSIS AND PURIEICATION, By Fred. A. Anderson, B.Sc. (Lond.), F.I.C., F.C.S.

Lemström-ELECTRICITY IN HORTICULTURE. By Prof. S. Lemstrōm. 3s. 6d.

\section{SELECTED LIST OF STANDARD WORKS FOR STUDENTS.}

Abney-INSTRUCTION IN PHOTOGRAPHY. By Capt. Sir W. de W. Abney, F.R.S. Tenth edition. 6s. Abney-PHO'TOGRAPHY WITH EMULSIONS. By Capt. Sir

Allsop-INDUCTION COILS AND COIL MAKING. By F. C. Allsop. 3s, 6d.

Arrhenius-TEXT BOOK OF ELECTRO-CHEMISTRY. By Svante Arrhenius. Translated by J. McCrae, Ph.D. 9s.6d. net.

Barlow-BARLOW'S TABLES OF SQUARES, CUBES; SQUARE ROOTS, CUBE ROOTS. Reciprocals of all Integer Numbers up to 10,000. Post 8vo., cloth, 6s.

Bigelow-INTERNATIONAL SYSTEM OF ELECTRO-THERAPEUTICS. For Students, General Practitioners and Specialists, Edited by H, R. Bigelow. $34 \mathrm{~s}$.

Blount and Bloxam-CHEMISTRY FOR ENGINEERS AND MANUFAC'CURERS. By Bertram Blount, F.I.C., F.C.S, and A. G. Bloxam. In two vols. Vol. I. - Chemistry of Engineering, Building and Metallurgy. Ios. 6d. Vol. 11.-Chemistry ot Manufacturing Processes. I6s.

Castell-Evans-PHYSICO-CHEMICAL TABLES. By J. CastellEvans. Vol. I. 24s.

Classen and Löb-QUANTITATIVE CHEMICAL ANALYSIS BY ELECTROLYSIS. Translated from the German of Dr. A. Classen and Dr. W. Löb by W. H. Herrick and B. B. Boltwood, 12s. 6 d, net.

Clowes and Coleman-ELEMENTARY PRACTICAL CHEMISTRY AND QUALITATIVE ANALYSIS FOR ORGANISED SCIENCE SCHOOLS. By Prof. F. Clowes, D.Sc., and J. Bernard Coleman. .8vo, 3s. 6d.

"THE ELECTRICIAN" PRINTING \& PUBLISHING CO., LTD., I, 2 and 3, Salisbury Court, Fleet Street, London, E.C. 
Deschanel-NATURAL PHILOSPHY: An Elementary Treatise. By Prof. A. Privat Deschanel. Translated and added to by Prof. J. D. Everett, D.C.L., F.R.S. Twelfth Edition. Cloth, I8s. Also in four parts.-I. Mrchanics, HyDRostatics, \&c.; II. Hrat; III. (New Edition) Electricity and MagnutisM; IV. Sound AND Ligh T, 4s, 6đ̃. each.

Everett-ELECTRICITY. By J. D. Everett, F.R.S. An Expansion of Everett's "Deschanel," Patt III., on the lines of Modern Electrical Theory.

Everett-ILLUSTATIONS OF THE C.G.S. SYSTEM OF UNITS. With Tables of Pbysical Constants. By Prof. J.D Everett. 5s.

FitzGerald-THE SCIENTIFIC WRITINGS OF THE LATE PROF. G. F, FITZGERALD. $x 5$ s.

Fleming-MAGNETS AND ELECTRIC CURRENTS: An .Elementary Treatise for Electrical Artisans and Science Teachers. By Dr. J.;Fleming; M.A., F.R.S., \&c. Crown 8vo., cloth, 7s, 6d.

Glazebrook-ELECTRICITY AND MAGNETISM. By R. T. Glazebrook, M.A., F.R.S.7s.6d.

Gray-ELECTRICAL INFLUENCE MACHINES. By John Gray. 5s.

Gray and Matthews-TREATISE ON BESSEL FUNCTIONS AND THEIR APPLICATIONS TO PHYSICS. By Prof. A. Gray, M.A., F.R.S.E., and $G$. B. Matthews. M.A. I6s.

Heaviside-ELECTRICAL PAPERS. For advanced Students in Electricity. By Oliver Heaviside. 2 vols. 30s. net.

Hedley-THERAPEUTIC ELECTRICITY. By W. S. Hedley, M.D. 8s. 6d,

Herschell-POLYPHASED CURRENTS IN ELECTROTHERAPY. By G. Herschell, M, D, 2s, 6d.

Hertz-MISCELLANEOUS PAPERS. By the late Prof. Heinrich Hertz. Translated by D. E. Jones, B.Sc., and G. A. Schott, B.A., B.Sc. With an Introduction by Prof, Philip Lenard, ros. $6 \mathrm{~d}$, nett.

Jacoby-ELECTRO-THERAPY. By Geo. W. Jacoby, M.D. Two vols., each I2s. $6 \mathrm{~d}$, nett.

Jones-MEDICAL ELECTRICITY. By H. Lewis Jones, M.D. ros. $6 \mathrm{~d}$.

Kelvin-POPULAR LECTURES AND ADDRESSES ON VARIOUS SUBJECTS IN PHYSICAL SCIENCE. By Lord Kelvin. 3 vols. Vols. I, and III. ready, 7 s. 6 d. each.

Kohlrausch-INTRODUCTION TO PHYSICAL MEASUREMENTS. By Dr. F. Kohlrausch. Translated by T. H. Waller and H. R. Procter. Third English Edition. rss.

Kolle-X-RAYS, THEIR PRODUCTION AND APPLICATION. By F.S. Kolle, M.D. 5s.

Langdon-THE APPLICATION OF ELECTRICITY TO RAILWAY WORKING. By W. E. Langdon. ros. 6d.

Lardner-HANDBOOK OF ELECTRICITY, MAGNETISM, AND ACOUSTICS. By Dr. Lardner. Edited by Geo. Carey Foster, B.A. 5s.

Larmor- ETHER AND MATTER. By Dr. Joseph Larmor. tos.

Le Chatelier and Boudouard-HIGH TEMPERATURE MEASUREMENTS. By H. Le Chatelier and $O$. Boudouard. r2s. 6 d. nett.

Lewes-ACETYLENE. By Prof. Vivian B. Lewes, F.I.C. 32s. nett.

Lummer-PHOTOGRAPHIC OPTICs. By Dr. Otto Lummer; translated by Prof, S. P. Thompson, D.Sc., F.R.S. 6s. nett.

MacDonald-ELECTRIC WAVES. By H. M. MacDonald. ros. nett.

M'Millan-ELECTRO-METALLURGY, TREATISE ON. By Walter G. M'Millan, ros. $6 \mathrm{~d}$.

"THE ELECTRICIAN" PRINTING \& PUBLISHING CO., LTD., I, 2 and 3 , Salisbury Court, Fleet Street, London, E.C. 
Meldola-CHEMISTRY OF PHOTOGRAPHY. By Prof. R. Meldola. Crown 8vo, 6s.

Perry-CALCUluS FOR ENGINeERS. By Prof. John Perry, F.R.S. $7 \mathrm{~s}, 6 \mathrm{~d}$.

Poynting and Thomson-A TEXT-BOOK OF PHYSICS. By Prof. J. H. Poynting, D.Sc., F.R.S., and Prof. J. J. Thomson, M.A., F.R.S. SOUND (Seconnd Edition), 8s, 6d. PROPERTIES OF MATTER, Ios. 6d. HEAT, MAGNETISM AND ELECTRICITY, AND LIGH'

Preece and Stubbs-MANUAL OF THE TELEPHONE. By Sir W. Preece, K.C.B., and A. J. Stubbs. Over 500 pages and 334 illustrations. I5s.

Pryde-MATHEMATICAL TABLES. By James Pryde, F.E.I.S. 4s. 6d.

Ramsay-SYSTEM OF INORGANIC CHEMISTRY. By Prof. Sir W. Ramsay, F.R.S. 15s.

Righi and Dessau-LA TELEGRAFIA SANZA FILO. By Profs. A. Righi and B. Dessau. Ios.

Roscoe and Schorlemmer-CHEMISTRY : A TREATISE ON. By Sir H. E. Roscoe, F.R.S., and C. Schorlemmer, Vols. I. and II.: Inorganic Chemistry. Vol. I., The Non-Metallic Elements, 2rs. Vol. II., Metals, in two parts, 18s. each. Vol. III.: Organic Chemistry. Parts 1, 2, 4 and 6, 2Is. each. Parts 3 and 5, I8s. each.

Smith-MEASUREMENT CONVERSION TABLES; English and Metrical. By Prof. R. H. Smith. 8s. 6d.

Stark-DIE ELEKTRIZITÄT IN GASEN. By Dr. Johannes Stark. I2s.

Thompson-LIGHT, VISIBLE AND INVISIBLE. By Prof. S. P. Thompson, D.Sc., F.R.S. 6s. nett.

Thompson-THE ELECTRO-MAGNET AND ELECTROMAGNETIC MECHANISM. By Silvanus P. Thompson, D.Sc., F.R.S. and Edition, $45^{\circ}$ pages, $21_{3}$ illustrations. I5s.

Thomson-APPLICATIONS OF DYNAMICS TO PHYSICS AND CHEMISTRY. By Prof. J. J. Thomson. 7s. 6d.

Thomson-CONDUCTIVITY OF ELECTRICIIY THROUGH GASES. By Prof. J. J. Thomson, M.A., F.R.S. 16 s.

Thomson-RECENT RESEARCHES IN ELECTRICITY AND MAGNETISM. By Prof. J. J. Thomson, M.A., F.R.S. I8s. 6d.

Thomson-THE DISCHARGE OF ELECTRICITY THROUGH GASES. By Prof. J. J. Thomson, D.Sc., F.R.S. 4s. 6d. nett.

Thomson and Bloxam-BLOXAM'S INORGANIC AND ORGANIC CHEMISTRY, with Experiments. Re-written and Revised by Prof. J. M. Thomson, F.R.S., and Arthur G. Bloxam. Eighth Edition, I8s. Gd.

Thorpe-DICTIONARY OF APPLIED CHEMISTRY. By

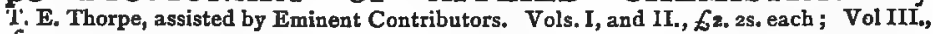
E3. 35 ,

Von Helmholtz-POPULAR LECTURES ON SCIENTIFIC SUBJECTS. By Prof. H. von Helmholtz. Two Volumes. 7s, 6d. each.

Walmsley-ELECTRICITY IN THE SERVICE OF MAN. A Popular and Practical Treatise on the Applications of Electricity in Modern Life. New Edition. Revised by R. Mullineux Walmsley, D.Sc, (Lond.), F.R.S.E. Medium 8vo., with upwards of 950 illustrations, 10s. 6d. Cheap Edition, 75. 6d. New and Revised Edition in the Press.

Walsh-RONTGEN RAYS IN MEDICAL WORK. By D. Walsh, M.D. Second Edition. ros. 6d, nett.

Wright-THE INDUCTION COIL IN PRACTICAL WORK. By Lewis Wright. 4s.

"THE ELECTRICIAN" PRINTING \& PUBLISHING CO., LTD., I, 2 and 3, Salisbury Court, Fleet Street, London, E.C.' 



